\title{
Split distribution, biogeography and morphological and genetic diversity of the Iberobathynellini Tribe in the family Parabathynellidae (Crustacea, Malacostraca, Bathynellacea)
}

\author{
Ana Isabel Camacho | ORCID: oooo-0oo3-0596-7678 \\ Museo Nacional de Ciencias Naturales (CSIC), Dpto. Biodiversidad y Biología Evolutiva, \\ C/ José Gutiérrez Abascal 2, 28oo6 Madrid, Spain \\ mcnac22@mncn.csic.es
}

Paloma Mas-Peinado | ORCID: oooo-0oo2-9290-5805

Museo Nacional de Ciencias Naturales (CSIC), Dpto. Biodiversidad y Biología Evolutiva,

C/ José Gutiérrez Abascal 2, 280o6 Madrid, Spain

Centro de Investigación en Biodiversidad y Cambio Global CIBC-UAM, Facultad de

Ciencias, Universidad Autónoma de Madrid, c/Darwin 2, 28049 Madrid, Spain

maspeina@gmail.com

E. Karen López-Estrada | ORCID: oooo-ooo1-5539-4826

Museo Nacional de Ciencias Naturales (CSIC), Dpto. Biodiversidad y Biología Evolutiva,

C/ José Gutiérrez Abascal 2, 28oo6 Madrid, Spain

lokaren21@gmail.com

Beatriz A. Dorda | ORCID: oooo-0002-2741-1841

Museo Nacional de Ciencias Naturales (CSIC), Dpto. Colecciones, Colección de Tejidos y ADN, C/ José Gutiérrez Abascal 2, 280o6 Madrid, Spain

balvarez@mncn.csic.es

Isabel Rey | ORCID: 0000-0002-2122-5124

Museo Nacional de Ciencias Naturales (CSIC), Dpto. Colecciones, Colección de Tejidos y ADN, C/ José Gutiérrez Abascal 2, 280o6 Madrid, Spain

monrf3g@mncn.csic.es

\begin{abstract}
The "Iberobathynella group", or Iberobathynellini tribe, is a complex of six genera consisting of 33 nominal species and several cryptic species with an amphiatlantic distribution (in Europe, North Africa and North 
America). A modern systematic revision of this group of subterranean crustaceans is presented here. A phylogenetic and biogeographic study using morphological and molecular data (mitocondrial cor and nuclear $18 \mathrm{~S}$ ) was carried out and allowed to a) re-evaluate the taxonomic status and validity of previously erected subtribes, genera and subgenera that show congruence in the data; b) assess whether the identified mitochondrial lineages represent cryptic species; c) provide a plausible phylogenetic hypothesis for the relationships within Iberobathynellini and with the other two genera of the family Parabathynellidae that inhabit North America and Europe (Montanabathynella and Parabathynella, respectively); d) propose a plausible temporal and historical framework (paleobiogeographic scenario) for the diversification and evolution of the Iberobathynellini tribe based on the current distribution of morphotypes and their estimated times of divergence. Our results show that in parabathynellids, molecular and morphological divergences are not always congruent. Subtribe and subgenus are invalid categories so they must be eliminated. Paraiberobathynella genus needs to be revisited. The molecular dating results support the early divergence of the Iberobathynellini Tribe (Upper Cretaceous, around $78 \mathrm{Mya}$ ) and the vicariance by plate tectonics as main factor to explain the amphi-Atlantic distribution shown by this ancient subterranean crustacean group. Since there are species morphologically very similar to I. magna and I. imuniensis, but genetically different, we can ensure the existence of at least three cryptic species. Texanobathynella is undoubtedly a valid genus distinct from Iberobathynella. Montanabathynella and Parabathynella are two well-differentiated genera closely related to the Iberobathynellini tribe.

\section{Keywords}

Parabathynellidae - Iberobathynellini tribe - stygofauna - taxonomic uncertainties - systematics molecular tools - 18S - COI - palaeobiogeography

\section{Introduction}

The Iberobathynellini tribe Camacho \& Serban, 1998 is one of the most diverse and best known groups within the family Parabathynellidae Noodt, 1965. It includes six genera distributed in Spain and Portugal within Europe and in North Africa and North America. Iberobathynella Schminke, 1973, the most speciose genus of the Tribe, with its 22 formally described species (and some cryptic ones), is the third largest genus in terms of number of species, after Allobathynella Morimoto \& Miura, 1957 (with 25 species) and the cosmopolitan genus Hexabathynella Schminke, 1972 (with 23 species) (Camacho, 2019) inside to the Parabathynellidae family. Iberobathynella is widely distributed throughout the Iberian Peninsula (Camacho, 2019). Of the 22 species of Iberobathynella, 21 belong to three subgenera (Camacho \& Serban, 1998): I. (Iberobathynella) and $I$. (Espanobathynella), with five species each, and $I$. (Asturibathynella), with 11 species. The remaining species, I. pedroi Camacho, 2003, does not fit into any of the three subgenera (Camacho, 2003b).

Texanobathynella Delamare Deboutteville, Coineau \& Serban, 1975 comprises the second most speciose genus of the tribe. It comprises three North American species from Texas ( $T$. bowmani Delamare Deboutteville, Coineau \& Serban, 1975; T. aaronswinki Camacho \& Hutchins, 2021 and T. coloradoensis Camacho \& Hutchins, 2021) and one from California (T. sachi Cho, 1996). This genus is the most 
widely distributed of the six, covering a range of about $9000 \mathrm{~km}$ that extends from Texas to California.

The third genus of the tribe is Paraiberobathynella Camacho \& Serban, 1998. It is the second most widely distributed genus of the six, and includes two subgenera and three species: Pi. (Paraiberobathynella) fagei (Delamare Deboutteville \& Angelier, 1950), whose distribution extends from the south of France to Andalusia in Spain and the Balearic Islands (Mallorca and Menorca-Pretus, 1989); Pi. (Paraiberobathynella) maghrebensis (Boutin \& Coineau, 1987) from North Africa (Morocco) and Pi. (Orihuelabathynella) notenboomi (Camacho, 1989), known only from its locality type in Alicante (Spain).

The fourth genus, Hexaiberobathynella Camacho and Serban, 1998, is found in the Iberian Peninsula. It consists in Hi. mateusi (Galhano, 1967), whose type locality is in Oporto (Portugal) but its distribution extends widely throughout the central Iberian Peninsula (Camacho, 1988; Camacho \& Coineau, 1989; Camacho et al., 1997; Camacho \& Serban, 1998; Camacho \& Serban, 2000; Camacho et al., 2000; Camacho et al., 2014; Camacho, 2019), and Hi. hortezuelensis Camacho \& Serban, 1998, whose distribution is restricted to its type locality in a single well in the province of Soria.

The remaining two genera of the Iberobathynellini tribe are Guadalopebathynella Camacho \& Serban, 1998, from the Iberian Peninsula, and Californibathynella (Schminke \& Noodt, 1988), from North America.

Schminke and Noodt (1988) considered Californibathynella californica (Schminke and Noodt, 1988), a species endemic to California, as a species of Iberobathynella, and also synonymized Texanobathynella, from Texas, with Iberobathynella. However, Schminke (2011), in his monograph of the family Parabathynellidae, later recognized Californibathynella and Texanobathynella as valid genera, as well as the subgenera Paraiberobathynella (Paraiberobathynella) and (Orihuelabathynella). However, he did not use other categories, such as the tribe, subtribe and subgenera of Iberobathynella that had been erected by Camacho \& Serban (1998).

Life underground supposes strong selective pressures and physical isolation. Barriers inhibiting the dispersal of different populations in disconnected habitats (i.e., aquifers, springs, hyporheic habitats or catchment boundaries) can lead to high genetic divergence yet morphological convergence (Finston et al., 2007). Convergent evolution of morphological characters is associated with adaptations to the subterranean environment (Jones et al., 1992; Kane et al., 1994), making the classical (morphological) taxonomy of stygobitic organisms very complex. In the case of Bathynellacea, the taxonomy is complicated, in addition to the extensive morphological simplification observed in the group, by the extreme progenetic development of its species (Schminke, 1981) and the lack of morphological distinguishability between species that could be caused by recent divergence, niche conservatism or morphological convergence (Zagmajster et al., 2018). Due to the increased use of molecular techniques in systematic studies, cryptic species have been detected in almost all taxonomic groups (Knowlton, 1993; Amato et al., 2007; Beheregaray \& Caccone, 2007; Le Gac et al., 2007; Heraty et al., 2007; Pfenninger \& Schwenk, 2007; Barroso et al., 2010, González-Miguéns et al., 2020), including Bathynellacea (Guzik et al., 2008; Camacho et al., 2011, 2012; Little \& Camacho, 2017; Camacho et al., 2018a, b, c). The presence of such species necessitates the use molecular approaches for species delimitation (González-Miguéns et al., 2020). 
The main goal of this study is to identify the morphospace of the Iberobathynellini tribe in order to analyse congruence between morphological variability versus morphological homogeneity and genetic divergence, as assessed using both rapidly (mitochondrial cytochrome oxidase subunit I, COI) and slowly (nuclear 18S) evolving genes. Exclusively representatives of the genera of the family that live in the area of the study have been analyzed, excluding other genera of the Parabathynellidae family from all over the world (Australia, India, Asia ...) that were already analized globally in previous papers (Camacho et al., 2018; Camacho et al., 2021a), since the study tries to find the precise relationships between the genera of the Parabathynellidae family that inhabit Iberian Peninsula and North America using as outgroup Hexabathynella, the only cosmopolitan Bathynellacea genus, because it is very different of rest of genera of Parabathynellidae and has only 6 pairs of legs, a character only shared with the Iberian genus Hexaiberobathynella. The specific objectives of this study are to i) define taxonomic units with congruent morphological and molecular data to evaluate the validity of genera and subgenera classifications; ii) assess whether the identified mitochondrial lineages represent cryptic species; iii) provide a plausible phylogenetic hypothesis for the relationships within Iberobathynellini and with the only other two genera of Parabathynellidae, not belonging to the Tribe Iberobathynellini, that inhabit North America and Europe (Montanabathynella Camacho, Stanford \& Newell, 2009 and Parabathynella Chappuis, 1926, respectively, two genera closely related to each other and very different of genera tribe as we already demonstrated (Camacho et al, 2021b)) and iv) propose a plausible paleobiogeographic scenario based on the current distribution and divergence time estimates of the Iberobathynella group.

\section{Material and methods}

\section{Study area}

The study area includes the USA in North America, Morocco in North Africa and the Iberian Peninsula and Balearic Islands in Europe. Species distributions are shown on the map in fig. 1.

\section{Molecular study}

Specimen collection for D NA analysis. A total of 208 specimens of Parabathynellidae were collected from Spain, Morocco and Texas from groundwater found in caves, springs, wells or hyporheic zones of streams by A.I. Camacho, B. Hutchins, B.F. Schwartz, A. Brancelj and D. Jaume (supplementary appendix $\mathrm{S} 1$ ).

Of these, 205 belong to the Iberobathynella group (16 nominal species and three cryptic species that likely represent new species) from different populations in 30 localities (table 1) and three to the other genera of Parabathynellidae present in North America or/and Europe (Montanabathynella, Parabathynella and the cosmopolitan genus Hexabathynella) (table 1 and supplementary appendix $\mathrm{S}_{1}$ ). We chose the genus Hexabathynella as outgroup for being cosmopolitan, because we had DNA sequences of Spanish species to compare and additionaly for being a genus whose species only have six pairs of legs and it is very different of ingroup species. Specimen voucher numbers are provided in table 2 and supplementary appendix $\mathrm{S}$.

Specimens used in the molecular analysis were stored either in $95 \%$ alcohol or in $0.5 \mathrm{ml}$ of digestion buffer (Gilbert et al., 2007) at $-2 \mathrm{O}^{\circ} \mathrm{C}$.

DNA extraction, amplification, and sequencing. The DNA extraction, amplification, and sequencing protocols used were as previously described (Camacho et al., 2018c; Camacho et al., 2021a). DNA was extracted 


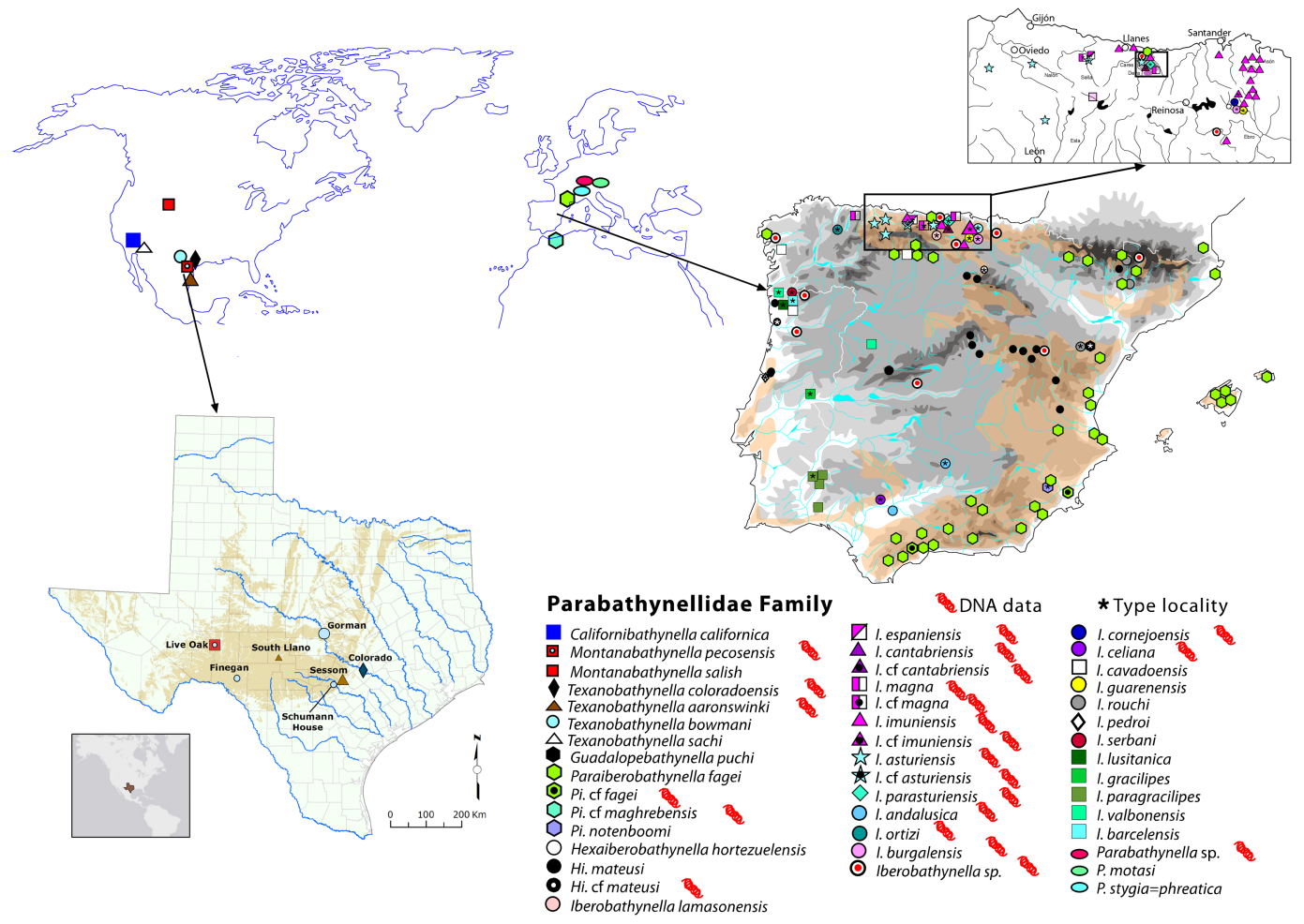

FIGURE 1 World distribution map of species and populations of the "Iberobathynellini tribe" and those of Montanabathynella and Parabathynella.

from whole specimens or from abdominal tissue, and samples were deposited in the Tissues and DNA Collection of the Museo Nacional de Ciencias Naturales, Madrid (MNCN). Briefly, the abdomen or whole specimen placed in $0.5 \mathrm{ml}$ digestion buffer (Gilbert et al. 2007) and incubated overnight at $55^{\circ} \mathrm{C}$ with gentle agitation. DNA was then extracted from the digestion buffer using a Qiaquick PCR Purification Kit (QIAGEN), following the protocol used by Alda et al. (2007). A 507 base-pair (bp) fragment of COI was amplified using the primers $\mathrm{C} 1-\mathrm{J}-1718$ and HCO2198 (Folmer et al., 1994; Simon et al., 1994). For nuclear $18 \mathrm{~S}$ rRNA, three fragments, totalling $1702 \mathrm{bp}$, were amplified using the primers $1 \mathrm{~F}$ and ${ }_{3} \mathrm{R},{ }_{3} \mathrm{~F}$ and ${ }_{5} \mathrm{R}$, and ${ }_{5} \mathrm{~F}$ and $9 \mathrm{R}$ (Giribert et al., 1996). The PCR was performed employing standard methods (Camacho et al., 2018c). PCR products were purified by treatment with ExoSAP-IT (USB Amersham, Buckinghamshire, UK) and sequenced in both directions using the BigDye Terminator v3.1 sequencing kit (Applied Biosystems Inc., Foster City, USA).

All sequences were compiled, assembled and edited using Geneious v. 10.2.4 (https:// www.geneious.com) (Kearse et al., 2012). Sequences were aligned automatically in MAFFT (Katoh \& Toh, 2008), as implemented in Geneious, and the final alignment was checked with Geneious and Mesquite v3.04 (Maddison \& Maddison, 2015) for gaps and translate it to see if stop codons were present. Sequence divergences (uncorrected p-distances) of $18 \mathrm{~S}$ among genera were estimated using PAUP*4.ob 10 (Swofford, 2002). 
TABLE 1 Number of specimens used from each locality in Cor molecular analyses.

Species

Locality

Specimen

number

Iberobathynella andalusica Camacho, 2007

I. asturiensis Serban \& Comas, 1978

I. burgalensis Camacho, 2005

I. cantabriensis Camacho \& Serban, 1998

I. celiana Camacho, 2003

I. cornejoensis Camacho, 2005

I. espaniensis Serban \& Comas, 1978

I. imuniensis Camacho, 1987

I. imuniensis

I. imuniensis

I. imuniensis

I. imuniensis

I. imuniensis

I. magna?

I. ortizi Camacho, 1989

I. parasturiensis Camacho \& Serban, 1998

I. parasturiensis

I. parasturiensis

I. sp.- I. sp. nov. 1 (cryptic I. magna)

I. sp. 1- I. sp. nov. 2 (cryptic I. imuniensis)

I. sp. 2- I. cantabriensis

I. sp. 2 - I. cantabriensis

\section{I. sp. 2 - I. cantabriensis}

I. sp. $3^{-}$I. sp. nov. 2 (cryptic I. imuniensis)

I. sp. $3^{-}$I. sp. nov. 2 (cryptic I. imuniensis)

I. sp. - I. sp. nov. 2 (cryptic I. imuniensis)

I. sp. 4- I. cantabriensis

I. sp. 4- I. cantabriensis

I. sp. $5^{-I}$. sp. nov. 3 (cryptic I. imuniensis)

I. sp. 6- I. sp. nov. 3 (cryptic I. imuniensis)

I. sp.- I. sp. nov. 3 (cryptic I. imuniensis)

Paraiberobathynella cf. fagei

Paraiberobathynella cf.fagei

Pi. maghrebensis (Boutin \& Coineau, 1987)

Texanobathynella cf bowmani

T. aaronswinki Camacho \& Hutchins, 2021

T. aaronswinki

* Varas River, Córdoba

1

* Infierno Cave, Asturias

1

* Ojo Guareña Cave (og53), Burgos

CO276 Lobos Cave, Cantabria

Viar Stream, Castiblanco, Sevilla

* Redonda Cave, Burgos

* Infierno Cave, Asturias

* Torca Morteros Cave, Burgos

Bernias Cave, Burgos

Calleja-Cueto Cave, Cantabria

Becerral Cave, Cantabria

Lunada Cave, Burgos

Torca V142 Cave, Burgos

6

CO262 Pelacristo Cave, Asturias

* Rei Cintolo Cave, Lugo

* CO209, Treslajorá Cave, Cantabria

co 34 , Nava Cave, Cantabria

Infierno Cave, Asturias

C0314, Pilar Cave, Asturias

c0314, Pilar Cave, Asturias

CO209, Treslajorá Cave, Cantabria

CO220, Carnero Spring Cave,

Cantabria

C0314, Pilar Cave, Asturias

c0314, Pilar Cave, Asturias

coo69, Pozo Agua Cave, Asturias

coo69, Pozo Agua Cave, Asturias

c0314, Pilar Cave, Asturias

coo89, Sorios Cave, Asturias

Fonda Cave, Vizcaya

Astui Cave, Vizcaya

Mina Elvira, Vizcaya

Higuera Cave, Murcia $\quad 25$

Pileta Cave, Málaga 11

Well, Nador, Morocco 8

Live Oak, Crockett County, Texas $\quad 1$

Sessom Creek, Hays County, Texas 1

*South Llano River, Kimble County, 1 
TABLE 1 Number of specimens used from each locality in COI molecular analyses. (cont.)

Species

Locality

Specimen

number

T. coloradoensis Camacho \& Hutchins, 2021

* Colorado River, Bastrop County,

4

Texas

Total

205

Outgroups

Montanabathynella pecosensis

Parabathynella sp. (Parabathynella cf

Live Oak, Crockett County, Texas, USA 1

Poltarica spring, Slovenia

motasi)

Hexabathynella sevillaensis Camacho, 2003

* Santiago el Grande Cave, Sevilla

* Type locality

\section{Phylogenetic and molecular clock analyses}

Phylogenetic analyses using Maximum Likelihood (ML) and Bayesian Inference (BI) approaches were used. We ran analyses with two datasets: (i) COI and ii) COI and 18S. The ML analyses were conducted in IQ-TREE 2.1.1 (Minh et al., 202O). We estimated the best partition scheme with the option MFP+MERGE in ModelFinder (Kalyaanamoorthy et al., 2017), with the following parameters: low perturbation strength (-pers 0.2 ), number of unsuccessful iterations to stop (-nstop) set to 500 and, to assess node support, 2000 ultrafast bootstrap replicates. The BI analyses were run in MrBayes 3.2.6 (Ronquist et al., 2012). We ran analyses implementing the partition scheme recovered by ModelFinder with three partitions for both the combined COI and 18S analyses (p1: 18S-coi pos2 $=1-1702,1703^{-}$ 2207 \3; p2: coi post $=1705^{-2209} \backslash 3$ and p3: coi pos3 $=1704-2208 \backslash 3)$ and the COI analyses (p1: coi pos1 $=3-507 \backslash 3 ;$ p2: coi pos2 $=1-505 \backslash 3$ and p3: coi pos3 $=2-506 \backslash 3)$. The substitution model space was explored with the reversible-jump model (option lset nst $=$ mixed rates = invgamma; Huelsenbeck et al., 2004). Two independent analyses were run with one cold and three heated chains, each chain ran for 100 million generations, with the first $25 \%$ discarded as burnin. From the resulting trees, a 50\% majority rule consensus tree was obtained.

For the divergence time analysis, we used relaxed molecular clocks to reconstruct the divergence time between lineages, and inferred credibility intervals in BEAST 1.8.4 (Drummond et al., 2012). Given the absence of a fossil record for the group, we calibrated the molecular clock based on the time to the most recent common ancestor (TMRCA) of Parabathynellidae [175.7 Ma (95\% HPD: 113.4-241.9 Ma); Lognormal Mean, 175.5; STdev, 0.2] that was included in a recent study of seventy specimens of Bathynellacea based on the substitution rates for the nuclear gene 18S (Camacho et al., 2021a). We used an uncorrelated lognormal relaxed molecular clock for each gene analysed to estimate its rate of molecular evolution. As priors, we used broad lognormal distributions with mean general substitution rates retrieved from Papadopoulou et al., (2010). We ran the analyses for 100 million generations, sampling every 10,00o generations. We specified a birth-death process as a speciation tree prior (Kendal, 1948; Stadler, 2009). Convergence 
TABLE 2 Specimens of Parabathynellidae Noodt, 1965 used in the phylogenetic analysis (COI $+18 S)$.

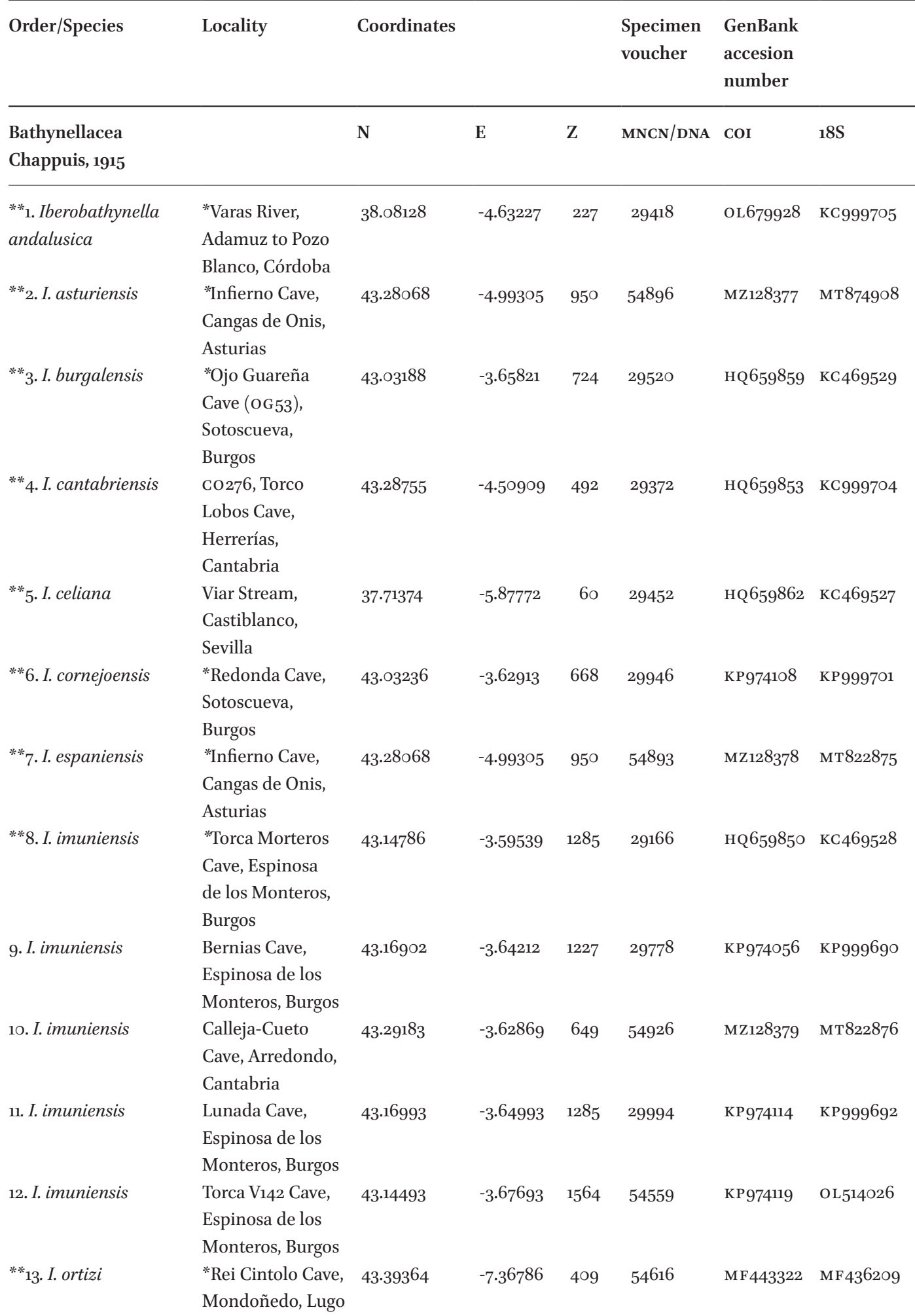


TABLE 2 Specimens of Parabathynellidae Noodt, 1965 used in the phylogenetic analysis (COI+18S). (cont.)

\begin{tabular}{lll}
\hline Order/Species $\quad$ Locality & Coordinates & $\begin{array}{l}\text { Specimen } \\
\text { voucher } \begin{array}{l}\text { GenBank } \\
\text { accesion } \\
\text { number }\end{array}\end{array}$
\end{tabular}

\begin{tabular}{|c|c|c|c|c|c|c|c|}
\hline $\begin{array}{l}\text { Bathynellacea } \\
\text { Chappuis, } 1915\end{array}$ & & $\mathbf{N}$ & $\mathrm{E}$ & $\mathrm{Z}$ & MNCN/DNA & COI & $18 \mathrm{~S}$ \\
\hline${ }^{* *} 14$. I. parasturiensis & $\begin{array}{l}\text { *CO209, Treslajorá } \\
\text { Cave, Peñarrubia, } \\
\text { Cantabria }\end{array}$ & 43.26725 & -4.59085 & 1132 & 29561 & KP9740O5 & КР999698 \\
\hline 15. I. parasturiensis & $\begin{array}{l}\text { co34, Nava } \\
\text { Cave, Lamasón, } \\
\text { Cantabria }\end{array}$ & 43.25928 & -4.50022 & 492 & 29612 & КС974O21 & KC999697 \\
\hline 16. I. parasturiensis & $\begin{array}{l}\text { Infierno Cave, } \\
\text { Cangas de Onis, } \\
\text { Asturias }\end{array}$ & $43.28 \circ 68$ & $-4.993 \circ 5$ & $95^{\circ}$ & 54897 & OL679948 & MT 822878 \\
\hline $\begin{array}{l}\text { 17. I. sp.- I. sp. nov. } 1 \\
\text { (cryptic I. magna) }\end{array}$ & $\begin{array}{l}\text { co314, Pilar Cave, } \\
\text { Peñamellera Baja, } \\
\text { Asturias }\end{array}$ & $43.295^{8} 3$ & -4.53996 & 538 & 29708 & KP974069 & KР999707 \\
\hline $\begin{array}{l}\text { 18. I. sp. 1- I. sp. } \\
\text { nov. } 2 \text { (cryptic } \\
\text { I. imuniensis) }\end{array}$ & $\begin{array}{l}\text { co314, Pilar Cave, } \\
\text { Peñamellera Baja, } \\
\text { Asturias }\end{array}$ & $43.295^{8} 3$ & -4.53996 & 538 & 29709 & КР974O71 & OL514O25 \\
\hline $\begin{array}{l}\text { 19. I. sp. } 2 \text { - I. } \\
\text { cantabriensis }\end{array}$ & $\begin{array}{l}\text { CO209, Treslajorá } \\
\text { Cave, Peñarrubia, } \\
\text { Cantabria }\end{array}$ & 43.26725 & -4.59085 & 1132 & 29573 & KC974102 & KC999725 \\
\hline $\begin{array}{l}\text { 2O. I. sp. } 2-\text { I. } \\
\text { cantabriensis }\end{array}$ & $\begin{array}{l}\text { CO220, Carnero } \\
\text { Spring Cave, } \\
\text { Lamasón, } \\
\text { Cantabria }\end{array}$ & 43.2868 o & -4.47784 & 156 & 29734 & KP974107 & OL514O27 \\
\hline $\begin{array}{l}\text { 21. I. sp. } 2-I . \\
\text { cantabriensis }\end{array}$ & $\begin{array}{l}\text { co314, Pilar Cave, } \\
\text { Peñamellera Baja, } \\
\text { Asturias }\end{array}$ & $43.295^{8} 3$ & -4.53996 & 538 & 29755 & OL67993o & OL514O2O \\
\hline $\begin{array}{l}\text { 22. I. sp. 3-I. sp. nov. } 2 \\
\text { (cryptic I. imuniensis) }\end{array}$ & $\begin{array}{l}\text { co314, Pilar Cave, } \\
\text { Peñamellera Baja, } \\
\text { Asturias }\end{array}$ & 43.29583 & -4.53996 & 538 & 29473 & HQ659866 & KC999728 \\
\hline $\begin{array}{l}\text { 23. I. sp. } 3-\text { I. sp. } \\
\text { nov. } 2 \text { (cryptic } \\
\text { I. imuniensis) }\end{array}$ & $\begin{array}{l}\text { coo69, Pozo } \\
\text { del Agua Cave, } \\
\text { Peñamellera Baja, } \\
\text { Asturias }\end{array}$ & 43.28383 & -4.52318 & 374 & 29705 & КС974O79 & KC999713 \\
\hline $\begin{array}{l}\text { 24. I. sp. } 4^{-} \\
\text {I. cantabriensis }\end{array}$ & $\begin{array}{l}\text { co314, Pilar Cave, } \\
\text { Peñamellera Baja, } \\
\text { Asturias }\end{array}$ & $43.295^{8} 3$ & -4.53996 & 538 & 54544 & OL679935 & OL514O21 \\
\hline $\begin{array}{l}\text { 25. I. sp. 6- I. } \\
\text { sp. nov. } 3 \text { (cryptic } \\
\text { I. imuniensis) }\end{array}$ & $\begin{array}{l}\text { Astui Cave, } \\
\text { Cestona, Vizcaya }\end{array}$ & 43.21756 & -2.18939 & 131 & 29978 & KP974110 & КР999710 \\
\hline
\end{tabular}


TABLE 2 Specimens of Parabathynellidae Noodt, 1965 used in the phylogenetic analysis (COI $+18 \mathrm{~S}) .($ cont.)

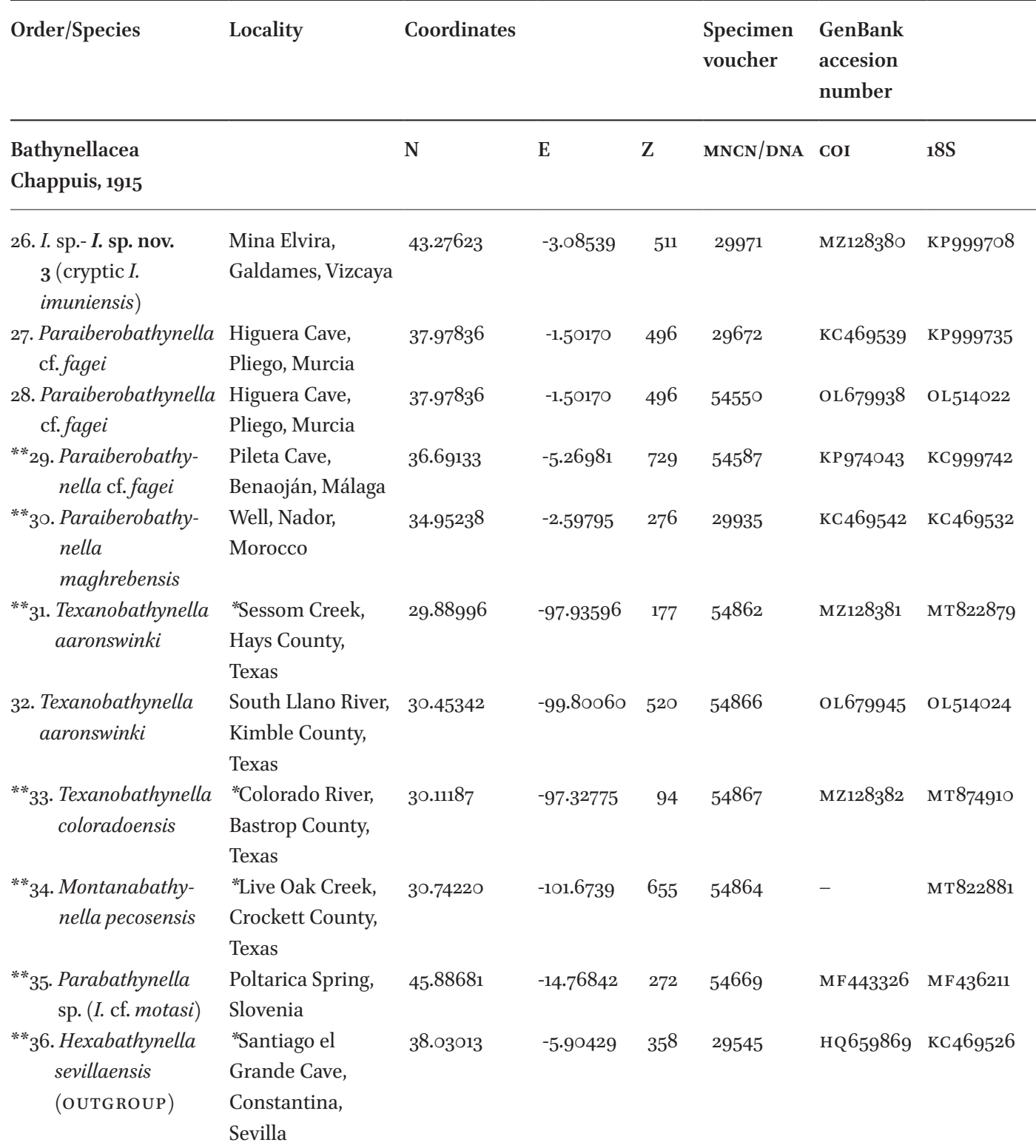

* Type locality; ** Specimens used in the combined analysis (morphological and molecular data)

and performance of each MCMC run were evaluated using Tracer 1.7.1, and the effective sample size (ESS) for each parameter was estimated. The results were summarized and annotated in a maximum clade credibility tree (MCC) generated in TreeAnnotator 1.8.4. (Drummond et al., 2012) with the first $25 \%$ of trees discarded as burnin. All analyses were performed in the cIPRES Science Gateway cluster (Miller et al., 2010) using BEAGLE (Miller et al., 2010; Ayres et al., 2012).

A haplotype network for COI was reconstructed in POPART (Leigh \& Bryant, 2015), which can convert a BI nexus file into a 
haplotype genealogy (http://datadryad.org/ resource/doi:10.5061/dryad.4n4j1).

\section{Morphological analysis}

For the morphological analysis, we studied specimens of Parabathynellidae that were previously collected, prepared and mounted by A.I. Camacho for more than 30 years and that were deposited in the Arthropod Collection (ARTP) of the MNCN in Madrid, Spain (Perina \& Camacho, 2016; Camacho et al., 2017). We achieved the following specific objectives:

1. We reviewed the taxonomic literature on the Iberobathynellini tribe and provided an updated systematic account and comparison with the genera Parabathynella and Montanabathynella (the only other genera of the Parabathynellidae family present in the study area).

2. We analysed the main morphological features that define the Iberobathynellini tribe as currently understood (Camacho \& Serban, 1998, 200o; Camacho, 2003a, b, 2005). Differences and similarities among subtribes, genera and subgenera are listed in table 3 (as were defined in the taxonomic reorganization of Camacho \& Serban, 1998).

3. We compared the morphology of the eight European and North American genera (six of the Iberobathynellini tribe, Parabathynella and Montanabathynella) of Parabathynellidae to understand the extent of variability among its 39 species Hexabathynella sevillaensis Camacho, 2005 (the only cosmopolitan genus), was used as outgroup) (table 4). Drawings are included to facilitate the comparison.

4. We defined the morphospace of the Iberobathynellini tribe based on the character states of each species for 28 selected characters (table 5), and the phylogenetic relationships based on a matrix of morphological features (table 6) to assess the validity of taxonomic subcategories (subtribe and subgenus).

Species of Parabathynellidae show observable morphological variability. Characters used to distinguish genera can be observed after a full dissection and preparation of the body parts (Perina \& Camacho, 2016). Most of the structures require examination under a compound microscope and/or a 100x oil immersion objective.

Variability among the genera, and differences and similarities among the subgenera (table 3) and species (table 4), of the Iberobathynellini tribe are illustrated through drawings of the antenna, mouthparts (labrum, mandibles, maxillule and maxilla), thoracopod I, thoracopod viII of males and females, uropods and furcal rami of several representative species of the six genera (and five subgenera) under study and the two species of Montanabathynella and Parabathynella that have been included for comparison (figs. 9-17).

\section{Abbreviations used}

Morphology

AI

antennule

AII

antenna

Endp

endopod

Exp

exopod

Md

mandible

Mx.I

maxillule

Mx.II

maxilla

Sgt

Symp

segment

Th I-VIII

sympod

Urp thoracopods I-VIII

uropod 


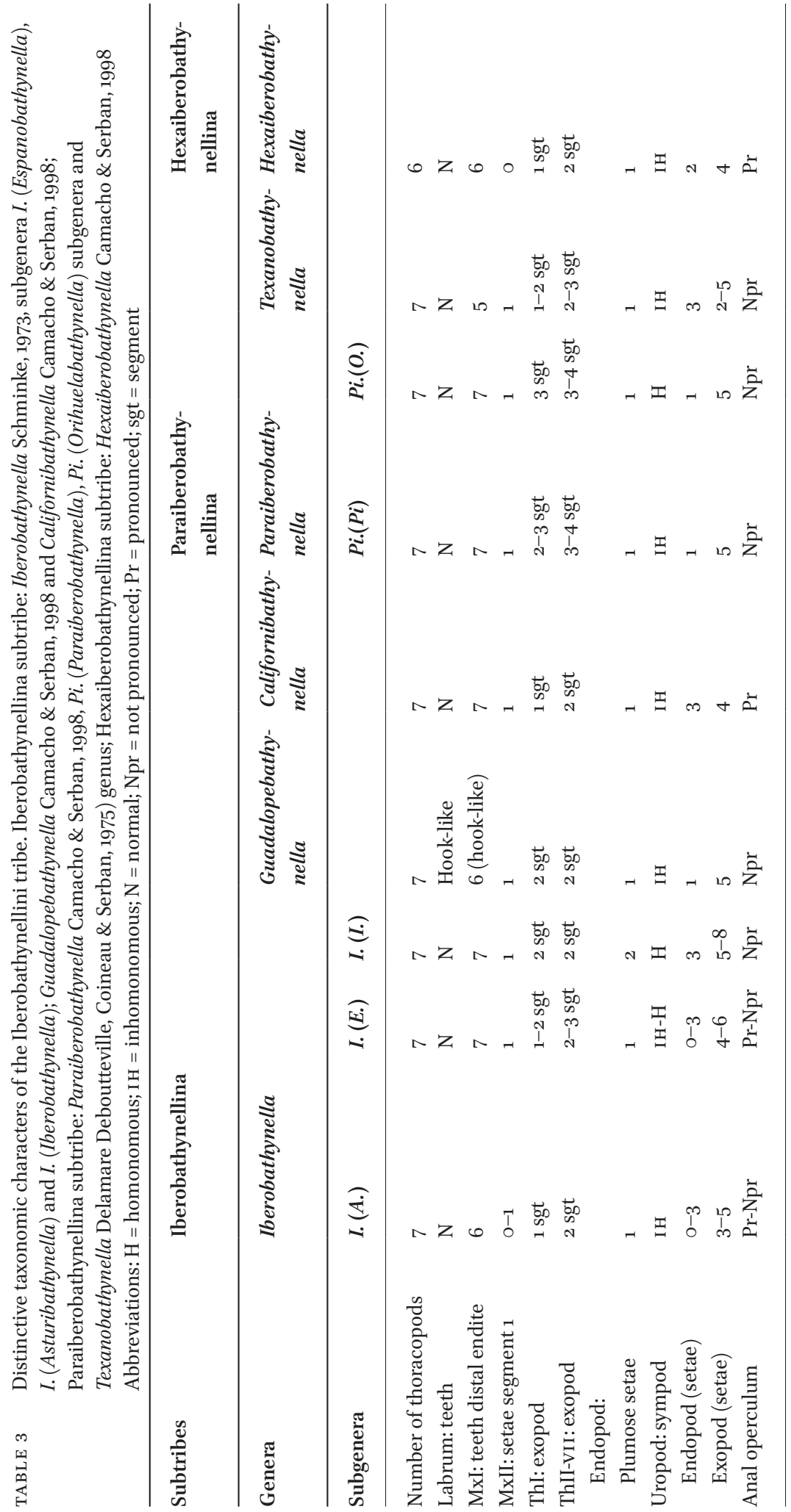


Acronyms

MNCN

Museo Nacional de Ciencias

Naturales de Madrid (Spain)

CSIC

Consejo Superior de Investigaciones Científicas (Spain)

ARTP/MNCN Arthropod Collection of the MNCN

MNCN/ADN Tissues and DNA Collection of the MNCN.

There are currently 33 nominal species in three subtribes: Iberobathynellina with three genera and subgenera and 24 species; Paraiberobathynellina with two genera and subgenera and seven species and Hexaiberobathynellina with one genus and two species.

Tribe Iberobathynellini *Molecular data of specimens from the type locality and ${ }^{* *}$ molecular data of specimens from non-type localities.

Subtribe Iberobathynellina Camacho \& Serban, 1998

Genus Iberobathynella Schminke, 1973 Subgenus Iberobathynella (Asturibathynella) Camacho \& Serban, 1998

${ }^{*}$ I. (A.) asturiensis Serban \& Comas, 1978. Spain.

I. (A.) cavadoensis (Noodt \& Galhano, 1969). Portugal and Spain.

**I. (A.) celiana Camacho, 2003. Spain. *\& **I. (A.) cornejoensis Camacho, 2005. Spain.

I. (A.) guarenensis Camacho, 2003. Spain.

${ }^{*} \&{ }^{* *} I .($ A. $)$ imuniensis Camacho, 1987 . Spain.

I. (A.) lamasonensis Camacho, 2005. Spain.

*I. (A.) ortizi Camacho, 1989. Spain.

${ }^{*} \&{ }^{* *} I$. (A.) parasturiensis Camacho \& Serban, 1998. Spain.

I. (A.) rouchi Camacho \& Serban, 1998. Spain.

I. (A.) serbani Camacho, 2003. Spain.
Subgenus

Iberobathynella

(Espanobathynella) Camacho \& Serban, 1998

*I. (E.) andalusica Camacho, 2007. Spain.

*I. (E.) burgalensis Camacho, 2005. Spain.

**I. (E.) cantabriensis Camacho \& Serban, 1998. Spain.

*I. (E.) espaniensis Serban \& Comas, 1978. Spain.

*\&**I. (E.) magna Camacho \& Serban, 1998. Spain.

Subgenus

Iberobathynella

(Iberobathynella) Schminke, 1973

I. (I.) barcelensis (Galhano, 1970). Portugal.

I. (I.) gracilipes (Braga, 1960). Portugal. I. (I.) lusitanica (Braga, 1949). Portugal.

I. (I.) paragracilipes Camacho \& Serban, 1998. Spain.

I. (I.) valbonensis (Noodt \& Galhano, 1969). Portugal and Spain.

I. pedroi Camacho, 2003. Spain.

Genus Guadalopebathynella Camacho \& Serban, 1998.

G. puchi Camacho \& Serban, 1998. Spain. Genus Californibathynella Camacho \& Serban, 1998.

C. californica (Schminke \& Noodt, 1998). USA.

Subtribe Paraiberobathynellina Camacho \& Serban, 1998

Genus Paraiberobathynella Camacho \& Serban, 1998

Subgenus Paraiberobathynella (Paraiberobathynella) Camacho \& Serban, 1998.

**Pi. (Pi.) fagei (Delamare Deboutteville \& Angelier, 1950). France, Spain.

**Pi. cf (Pi.) maghrebensis (Boutin \& Coineau, 1987). Morocco.

Subgenus Paraiberobathynella (Orihuelabathynella) Camacho \& Serban, 1998

Pi. (O.) notenboomi (Camacho, 1989).

Spain, 


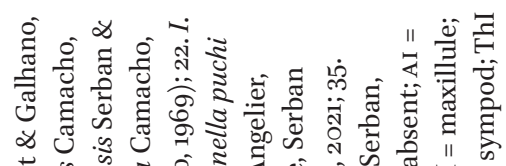

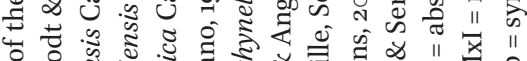
ฐँ ๘

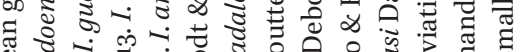
๘

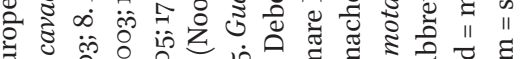

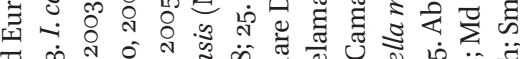

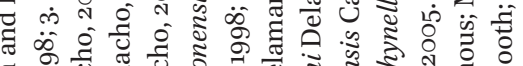
范

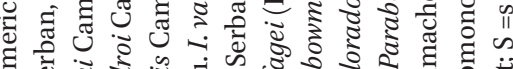
दूर

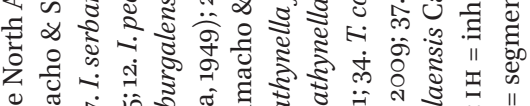
ฐ

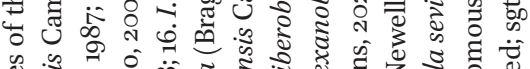

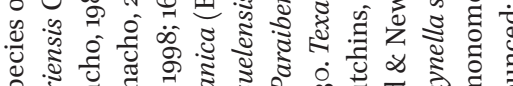

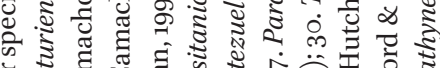

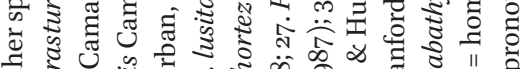

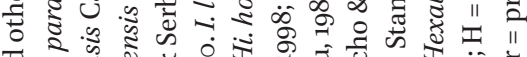

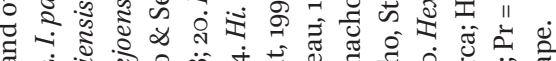

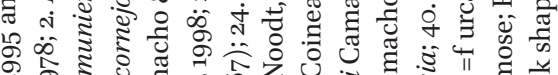
S वี 离泀

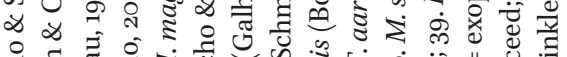

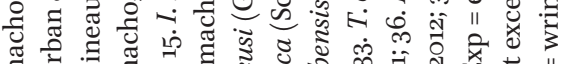

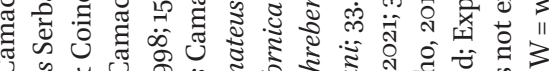

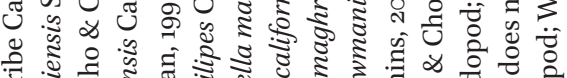

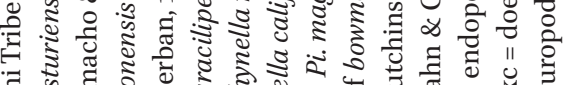

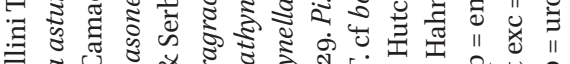
क्ष

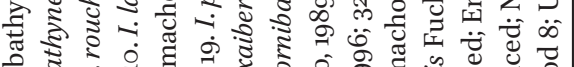

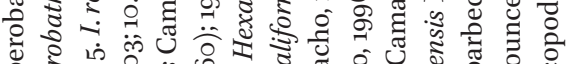

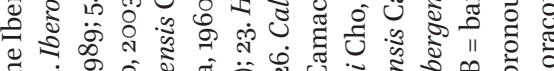

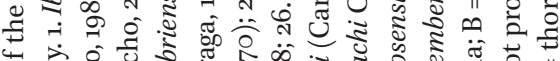

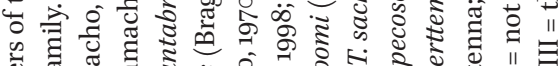

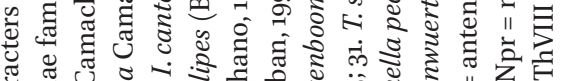

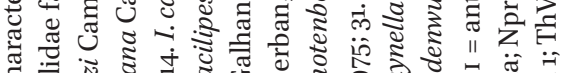

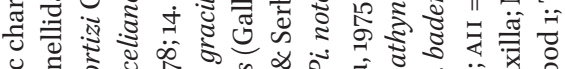

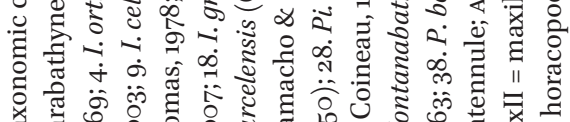

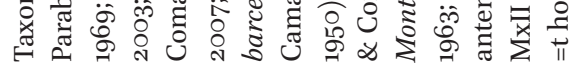

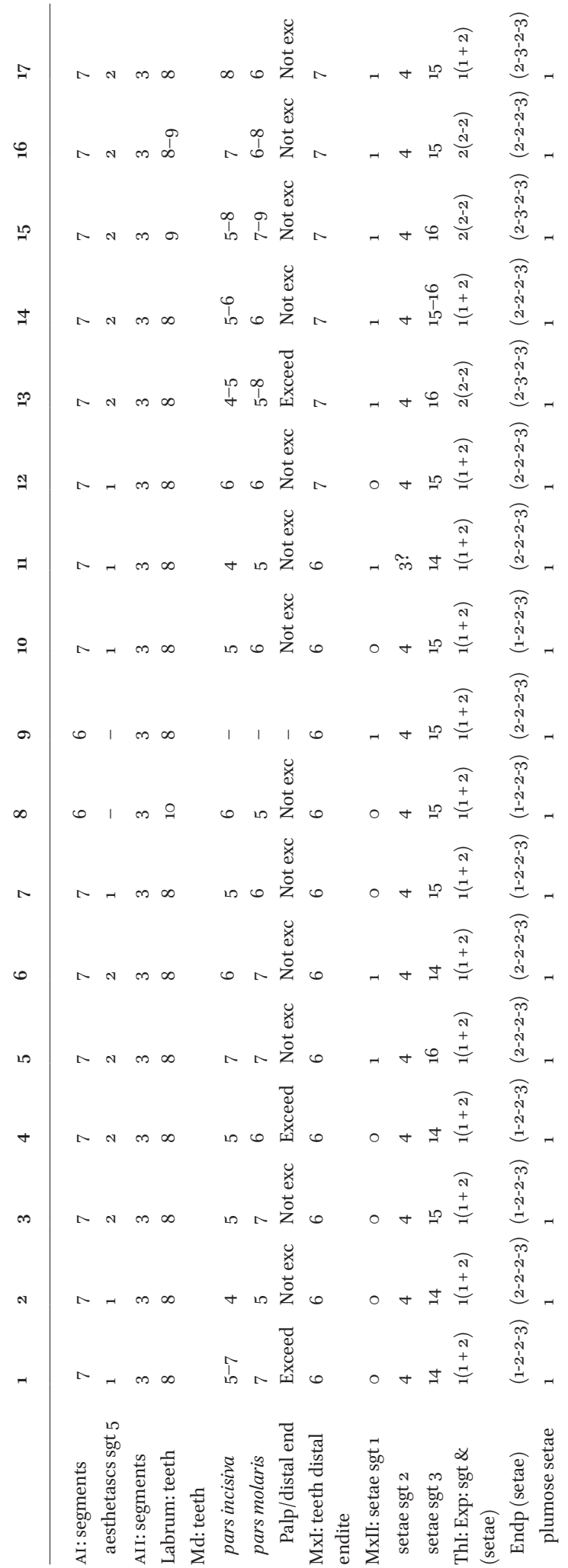




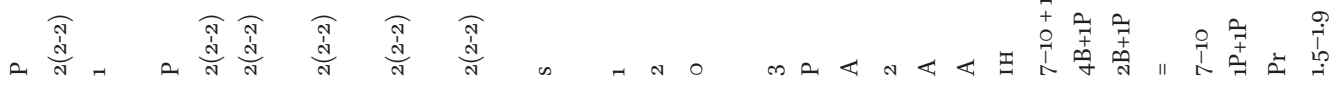

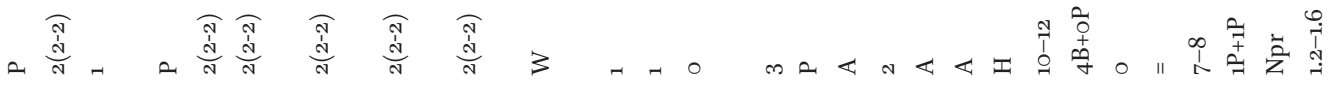

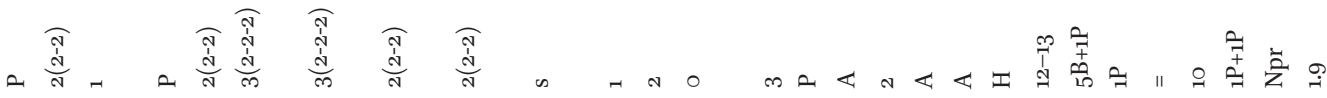

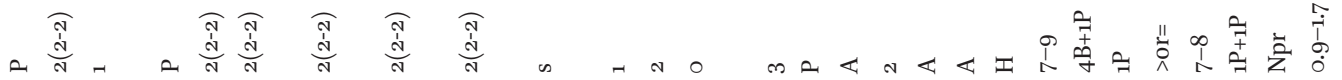

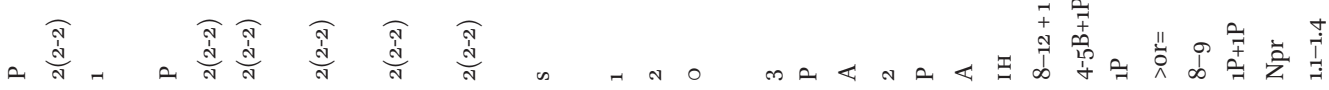

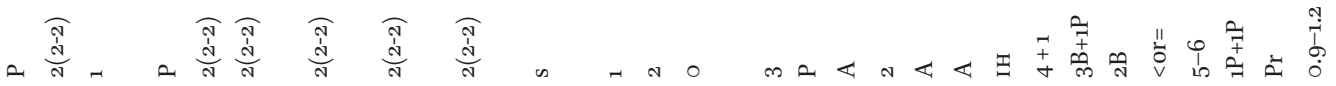

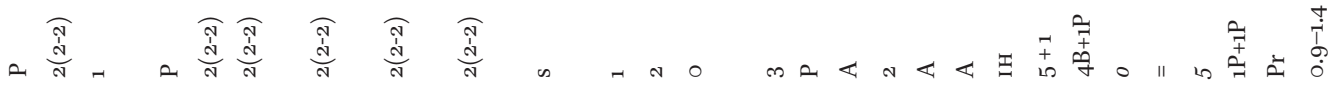

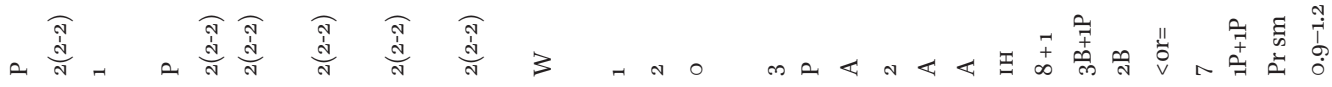

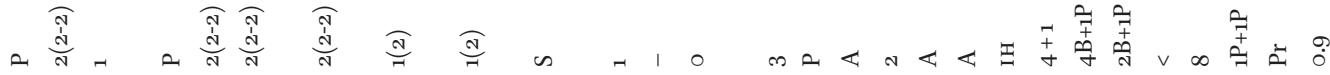

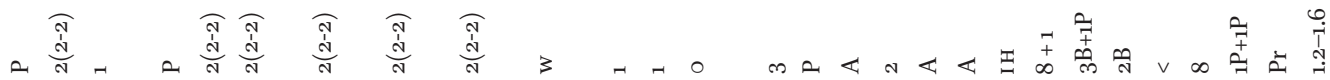

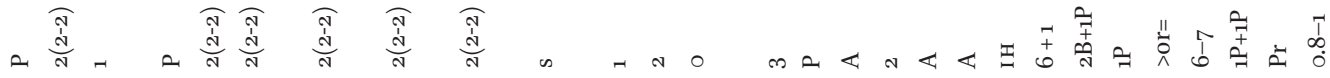

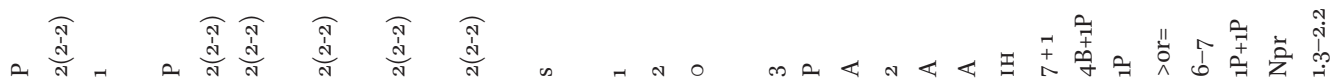

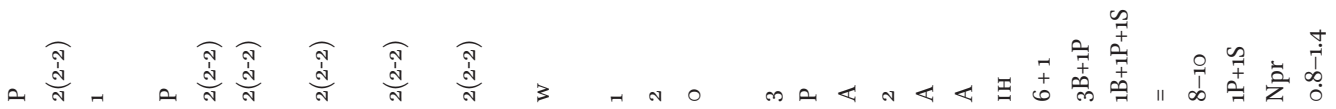

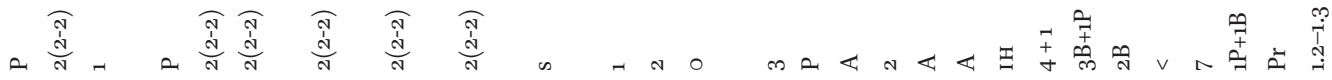

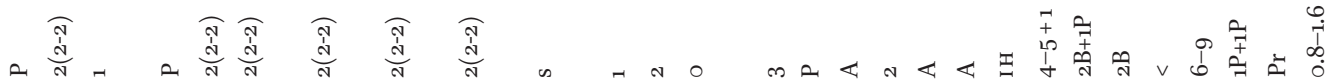

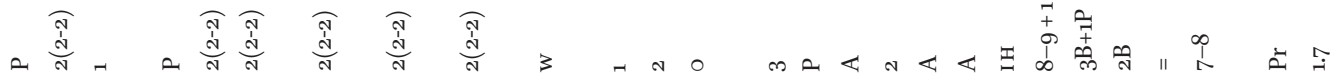

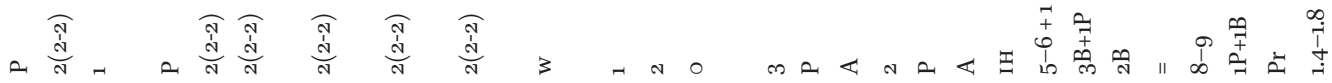

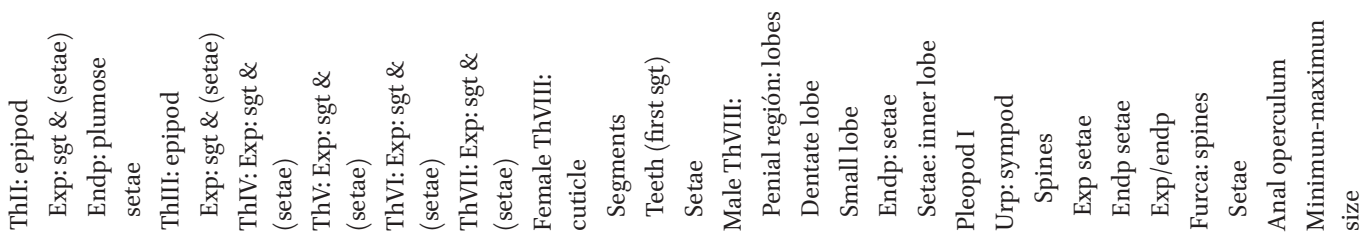




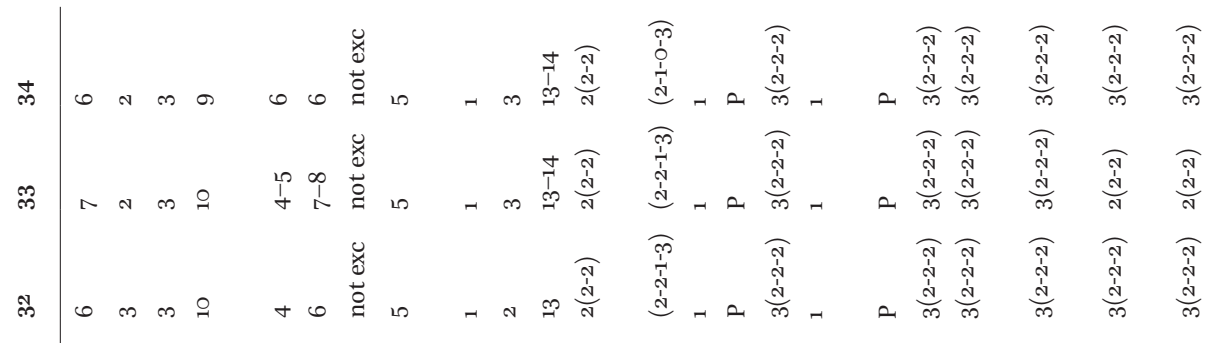

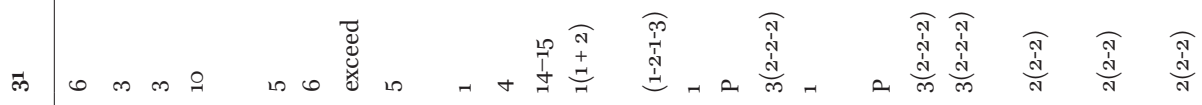

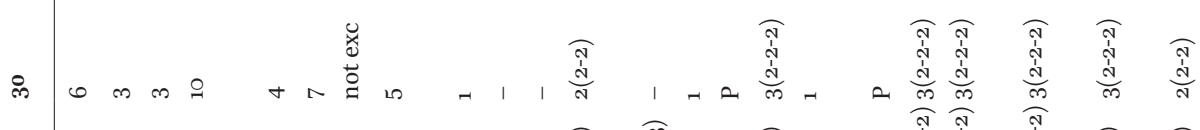

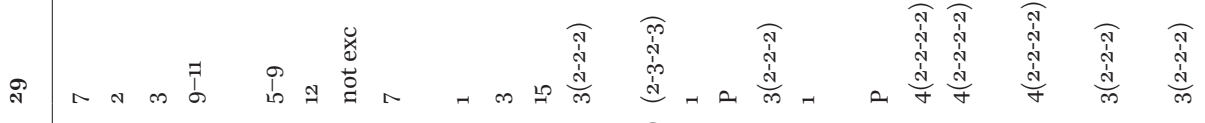

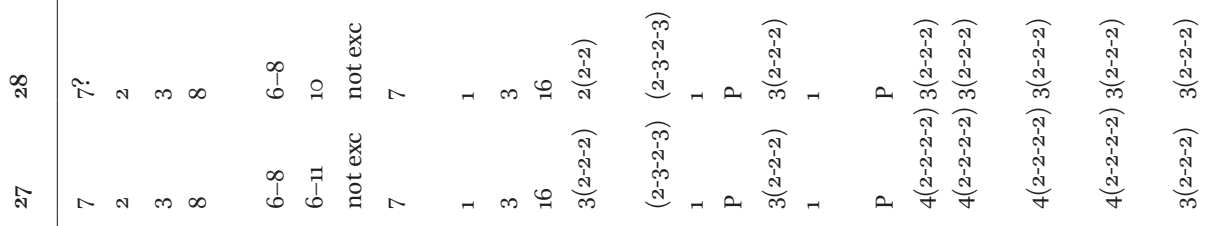

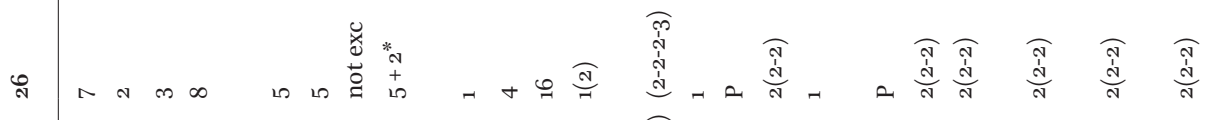

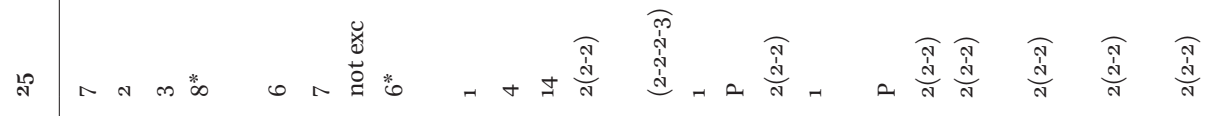

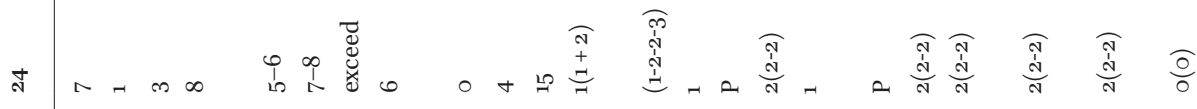

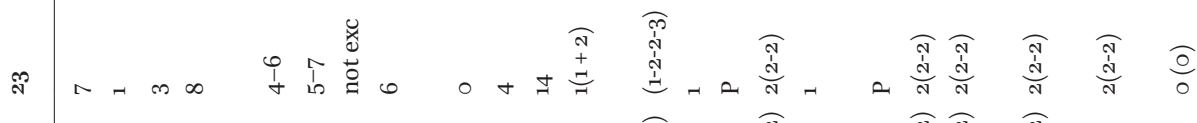

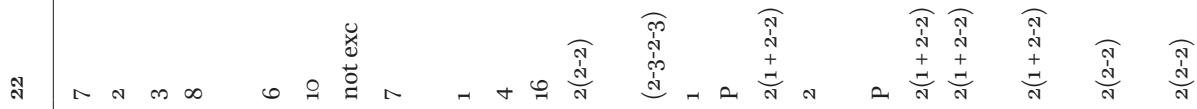

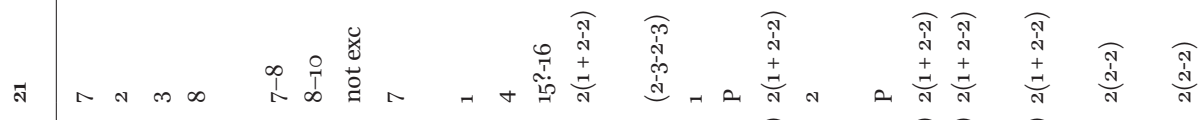

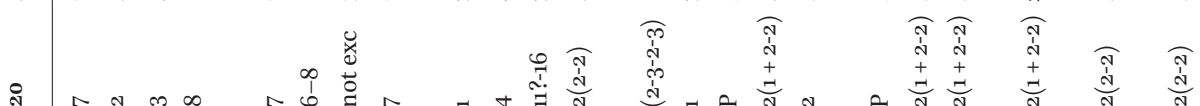

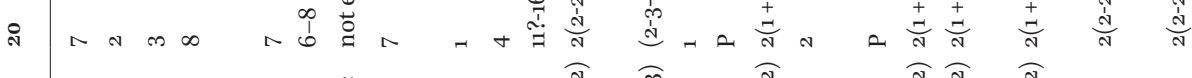

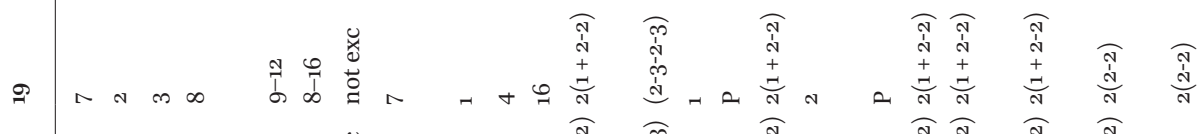

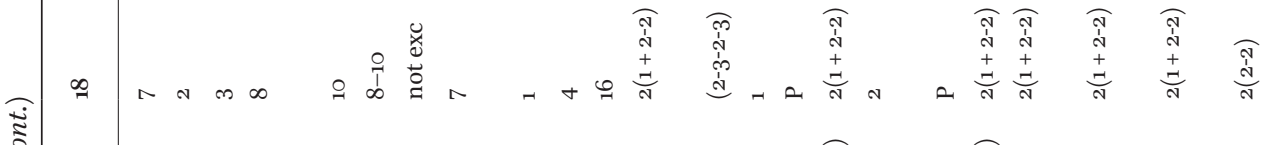

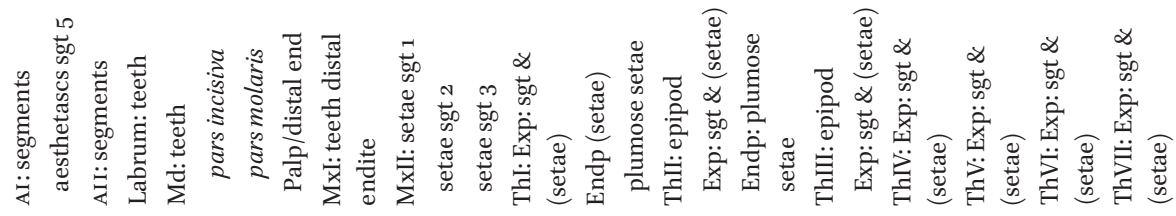




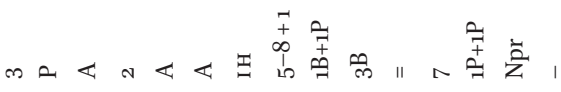

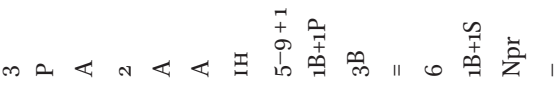

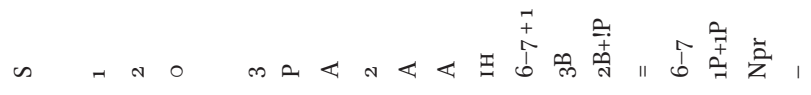

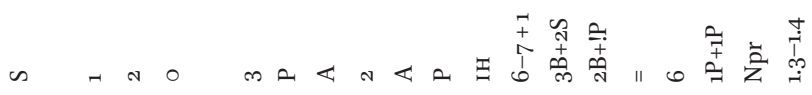

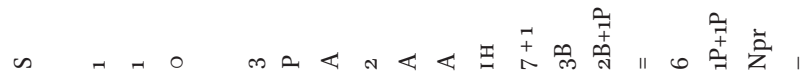

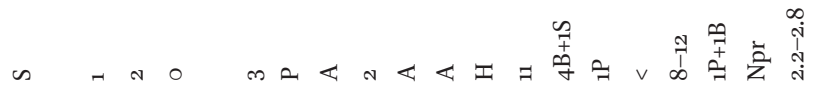

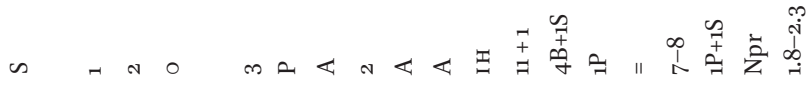

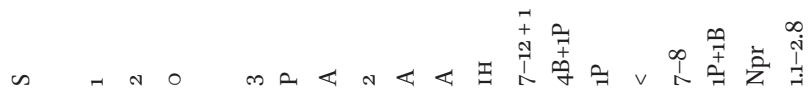

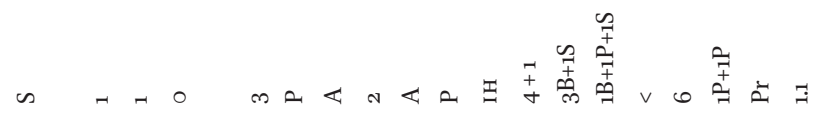

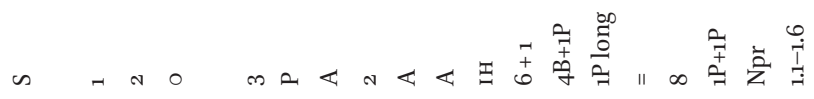

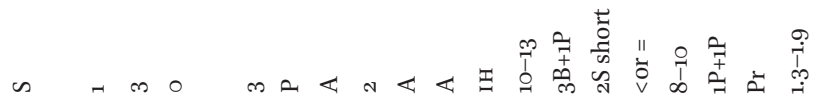

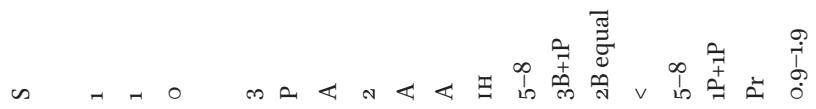

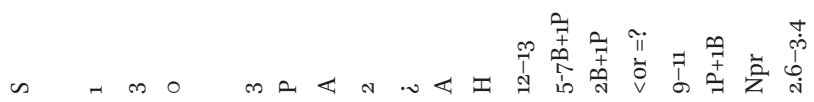

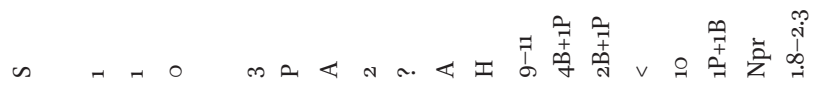

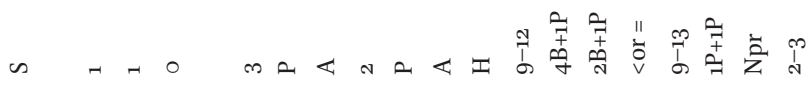

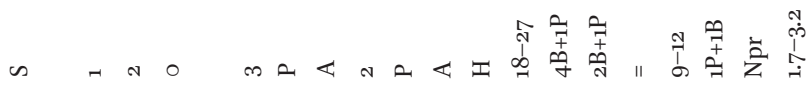

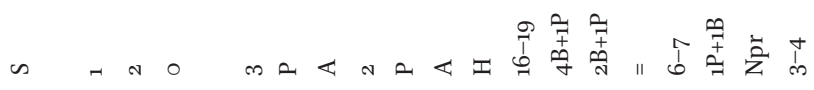

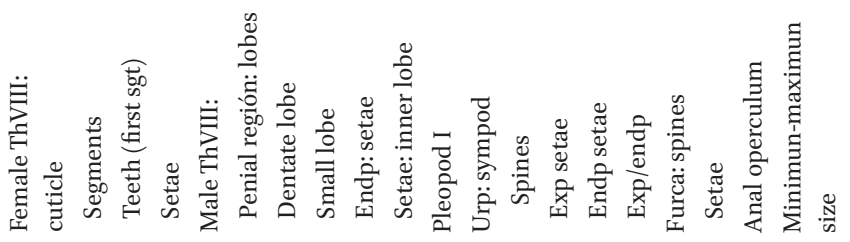




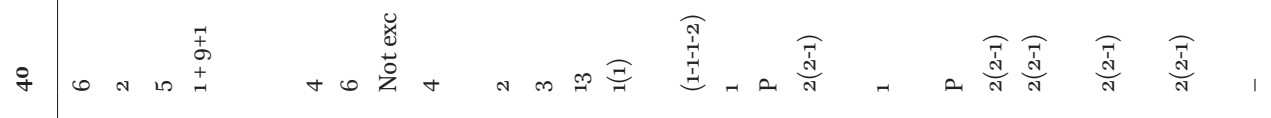

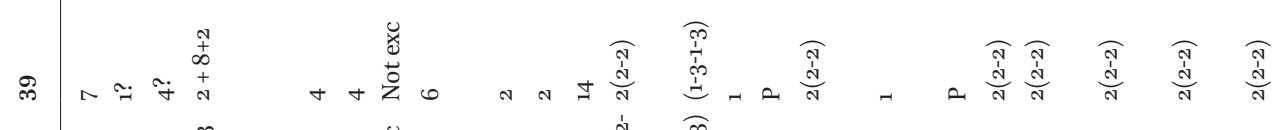

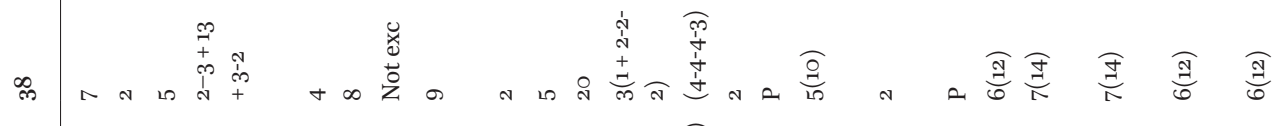

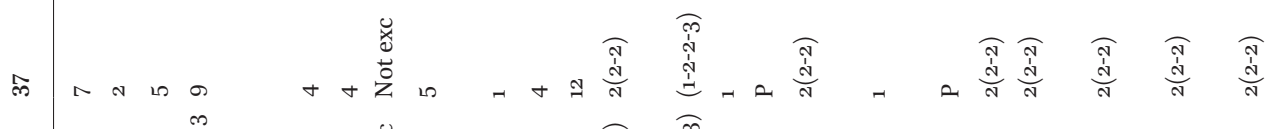

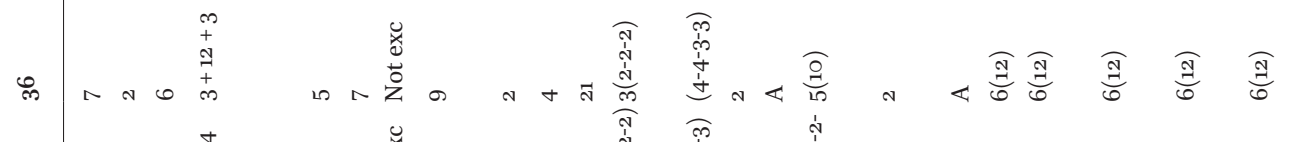

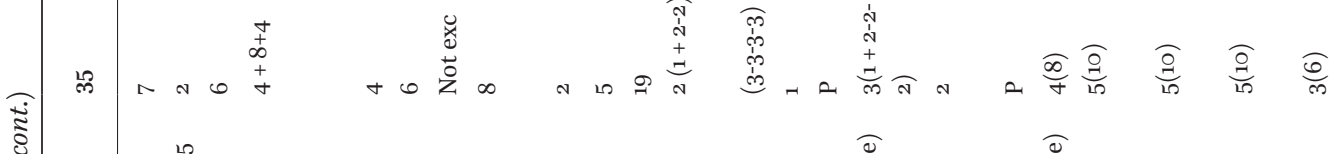

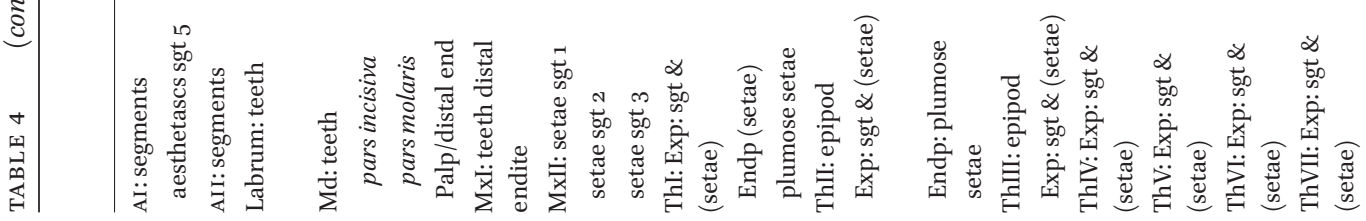




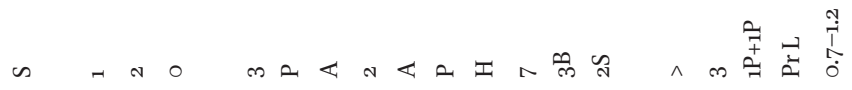

n $\quad$ ○ $m$ m $m$ a

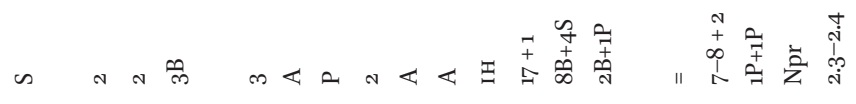

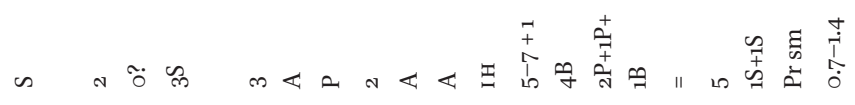

⿰ 小 $\stackrel{+}{+}$ के

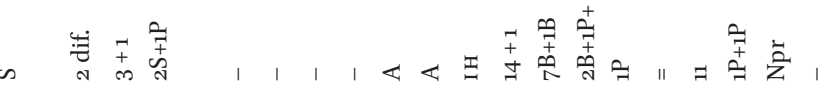

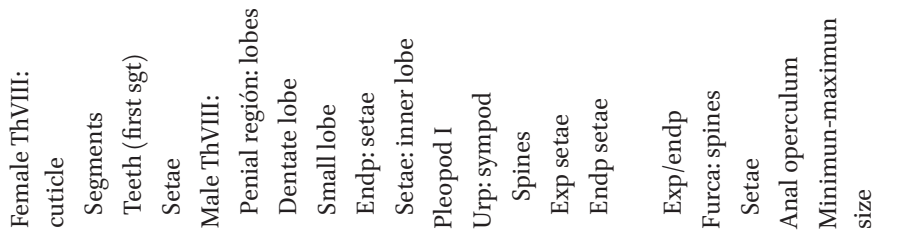


Genus Texanobathynella Delamare Deboutteville, Coineau \& Serban, 1975

T. bowmani Delamare Deboutteville, Coineau \& Serban, 1975. USA.

T. sachi Cho, 1996. USA.

*T. aaronswinki Camacho \& Hutchins, 2021. USA.

${ }^{*}$ T. coloradoensis Camacho \& Hutchins, 2021. USA.

Subtribe Hexaiberobathynellina Camacho \& Serban, 1998

Genus Hexaiberobathynella Camacho \& Serban, 1998

${ }^{* *} \mathrm{Hi}$. cf mateusi (Galhano, 1967). Portugal.

*Hi. hortezuelensis Camacho \& Serban, 1998. Spain

\section{Morphological phylogenetic inference and character coding}

Our morphological matrix included 28 informative unordered and coded characters (code is provided in supplementary table $S_{1}$ ) for all the 33 nominal species included within the tribe Iberobathynellini (100\% of taxon sampling). The matrix (table 5) scored a wide variety of external characters, many of which have been previously used in phylogenetic inferences and also considered useful for delimiting species (Camacho \& Serban, 2000; Camacho et al., 200o; Guil \& Camacho, 2001). Missing characters are coded with a (?), and not applicable ones with (----). Fifteen characters were scored as discrete binary, and thirteen as multistate morphological characters (supplementary table $\mathrm{S}_{1}$ ). Following the results of Camacho et al. (2018a) and Camacho et al. (2021a) in order to analyse a more complete set of taxa, we also included representative species of the genera of Parabathynellidae present in Europe or North America, Montanabathynella pecosensis Camacho \&
Hutchins, 2021; Parabathynella motasi Dancau \& Serban, 1963. Hexabathynella sevillaensis was used as outgroup.The morphological matrix was analysed using the Mk model with variable coding and gamma-distributed rate heterogeneity (Lewis, 2001). The analysis was run in MrBayes v.3.2.6 (Ronquist et al., 2012), and consisted of two simultaneous chains of 100,000,000 generations each. A tree was sampled every 10,000 generations, resulting in 10,000 sampled trees. Convergence and mixing among chains were evaluated by checking the average standard deviation of split frequencies (<0.01) and the Ess values for every parameter $(>200)$. A majority consensus tree for each analysis was reconstructed after discarding the first $25 \%$ of the sampled trees as burn-in. To calculate the posterior probability of each analysis, we constructed a 50\% majority rule consensus tree from the remaining trees, and the percentage of times a clade occurred among the sampled trees was interpreted as its posterior probability.

We also explored the flexibility of the software RevBayes (Höhna et al., 2016) to relax and alleviate some of the assumptions of the Mk model (e.g., character state symmetry) and others sources of bias (e.g,. ascertainment bias). For this, we applied the alternative priors suggested in the RevBayes tutorial (https://revbayes.github.io/tutorials/morph_ tree/V2.html) to the morphological matrix. This analysis was run with a chain of length of 40 ooo generations, and a maximum a posteriori tree was constructed after discarding the first $25 \%$ of sampled trees.

\section{Definitions of the morphological character in} the phylogenetic analysis

1. Number of AI segments: 6 or 7 .

2. Teeth of labrum: normal (plain or concave) or hook like.

3. Number of teeth in distal endite of MxI: $4,5,6,7$ or 8 . 


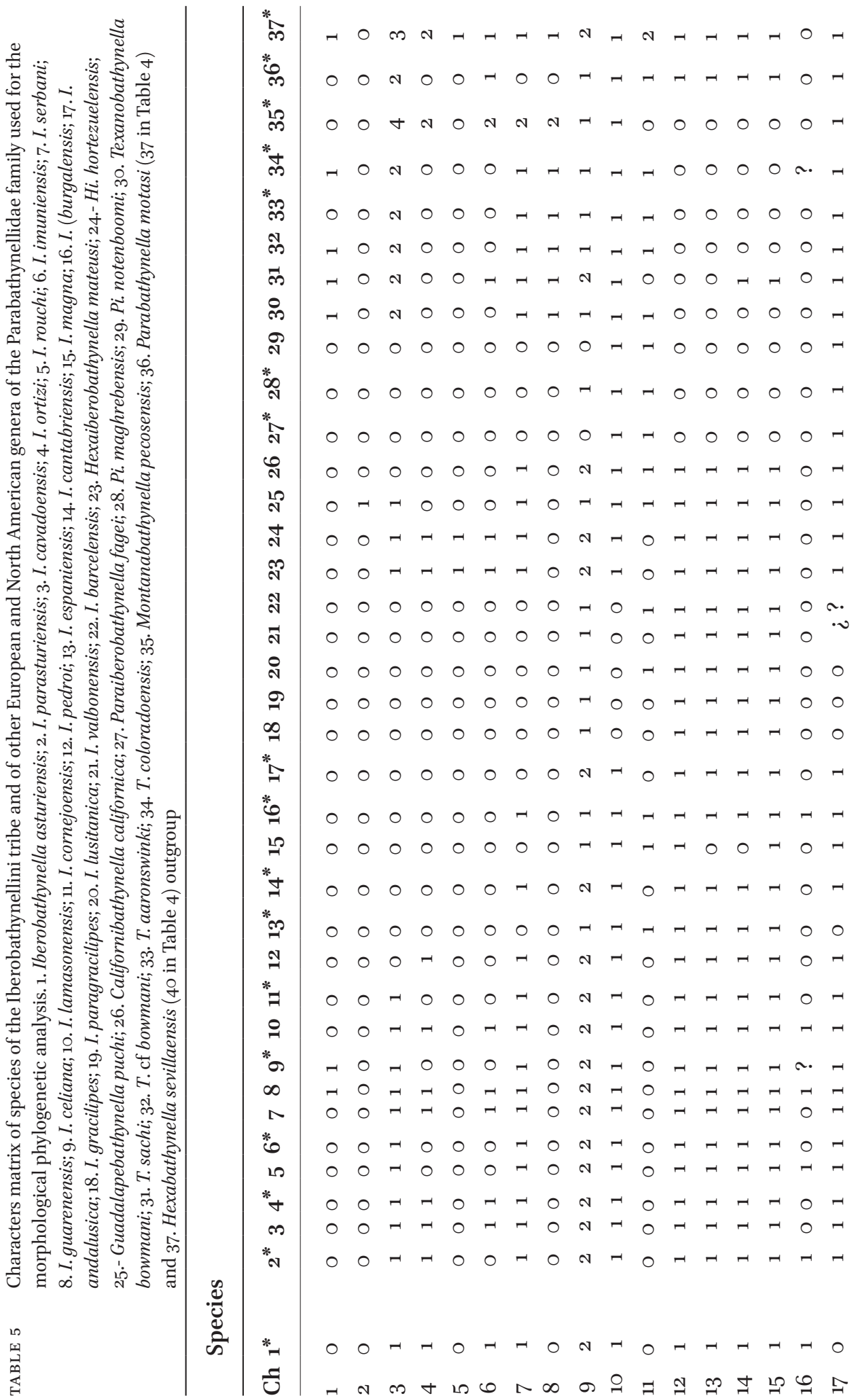




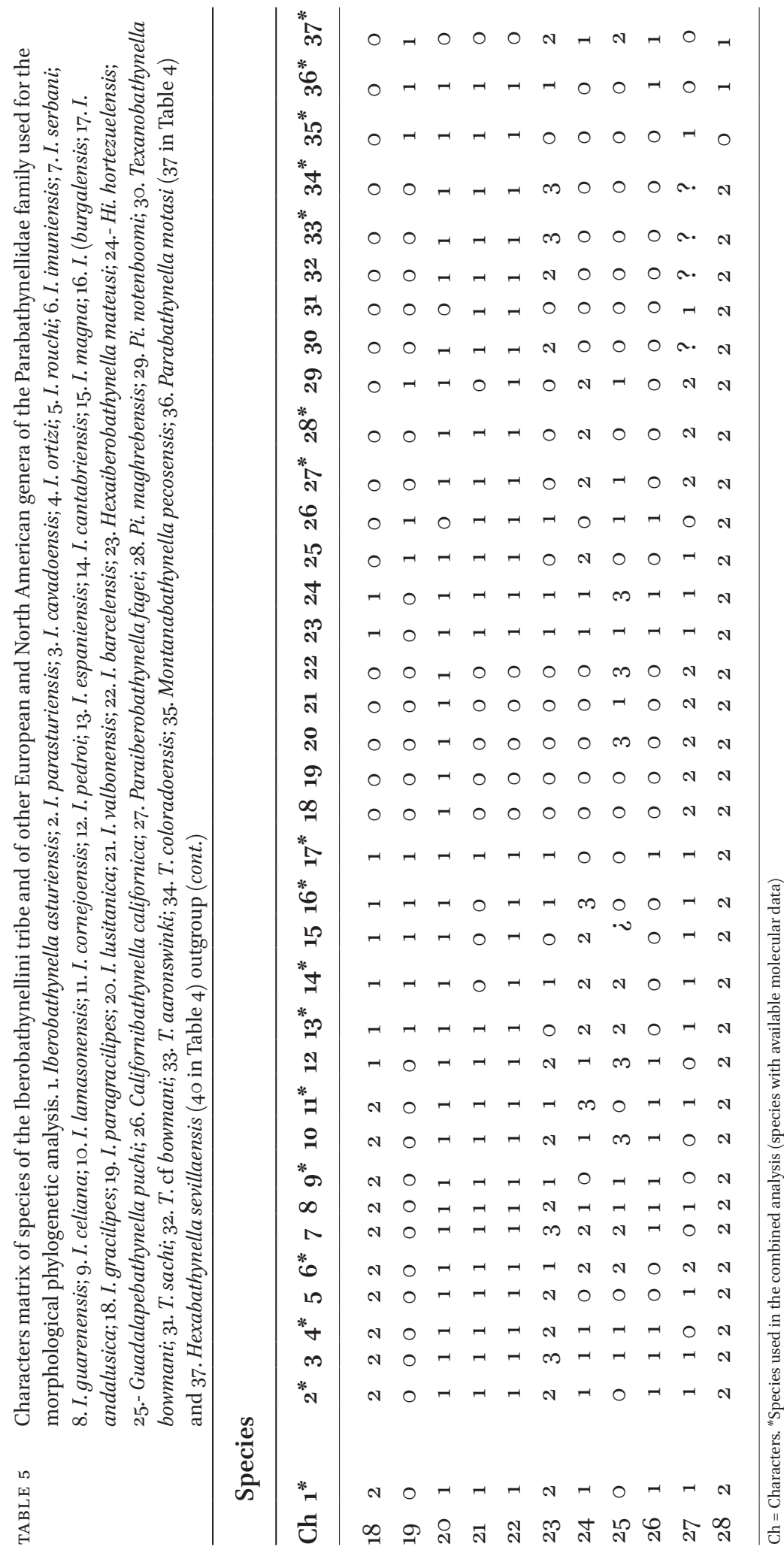


TABLE 6 A. Genetic divergence range (\%) for COI within and between the genera and subgenera of the Iberobathynellini tribe and between these and Parabathynella. B. Genetic divergence range (\%) for cor between different populations of Iberobathynella imuniensis

\begin{tabular}{llllll} 
A. & $\mathbf{1 .}$ & $\mathbf{2}$ & $\mathbf{3}$ & $\mathbf{4}$ & $\mathbf{5}$ \\
\hline 1. I. (Asturibathynella) & $11.8-20.5$ & & & \\
2. I. (Espanobathynella) & $14.8-19.7$ & $9.3-20.8$ & & \\
3. Paraiberobathynella & $13.0-23.3$ & $13.0-23.1$ & $6.6-9.0$ & & \\
4. Texanobathynella & $16.3^{-22.5}$ & $16.0-22.8$ & $16.4-22.5$ & $12.3-17.2$ & \\
5. Parabathynella & $18.5^{-21.4}$ & $16.7-21.8$ & $15.4-19.6$ & $21.1-21.9$ & 0.00 \\
B. I. imuniensis & $*$ Morteros & Bernias & Lunada & V142 & Becerral \\
* Morteros & 0.2 & & & & \\
Bernias & $0.8-1.0$ & 0.0 & & & \\
Lunada & $6.8-7.2$ & $6.8-7.0$ & 0.2 & & \\
V142 & $6.4-6.6$ & 6.4 & $0.8-1.0$ & 0.0 & \\
Becerral & $1.0-1.2$ & 0.2 & $7.0-7.2$ & 6.6 & \\
\end{tabular}

* Type locality

4. Number of setae on first segment of MxII: 0,1 or 2.

5. Thoracopods VII: absent or present.

6. Number of setae on first segment of endopod of ThI: 1,2 or 3 .

7. Number of smooth setae on second segment of endopod of ThI: 1,2 or 3 .

8. Number of setae on the third segment of endopod of ThI: 1,2 or 3 .

9. Number of segments of exopod of ThI: 1 , 2 or 3 .

10. Number of dorsal setae on first segment of endopod of ThII to VII: o or 1.

11. Number of setae on first segment of exopod of ThI: 1,2 or 3 .

12. Number of segments of exopod of ThII and III: 2 or 3 to 4 .

13. Number of segments of exopod of ThIV: 2 or 3 to 5 .

14. Number of segments of exopod of ThV:2 or 3 to 5 .

15. Number of segments of exopod of ThVI: 2 or 3 to 5 .
16. Cuticle of female ThVIII: smooth or wrinkled.

17. Type of inner lobe on male ThVIII: with dense setae or with sparse setae or no setae.

18. Orientation of main axis of outer lobe of male ThVIII: vertical, inclined or curved.

19. Shape of lateral side of outer lobe of male ThVIII: triangular or rectangular.

2o. Pleopods: present or absent.

21. Sympod of the uropod: homonomous or inhomonomous.

22. Ctenidia on exopod of uropods: present or absent.

23. Number of barbed setae on exopod of the uropod: 2, 3, 4 or 5 or more.

24. Number of setae on the endopod of the uropod: o, 1, 2 or 3 or more.

25. Exopod length/endopod length of the uropod: $=,<,<$ or $=$, or $>$ or $=$.

26. Anal operculum: protruded or not protruded. 
27. Maximum body size: small $(<1.3 \mathrm{~mm})$, medium $\left(1.3^{-1.9} \mathrm{~mm}\right)$ or large $(>1.9 \mathrm{~mm})$.

28. Number of AII segments: 3,5 or 6 .

\section{Combined analysis}

A total-evidence analysis was performed by combining the morphological and molecular data. We reduced the terminals of the morphological matrix (table 5 , species with *) to those samples for which COI and $18 \mathrm{~S}$ sequences are available (table 2). The final matrix included 17 terminals (14 species belonging to the Iberobathynella group, plus Montanabathynella pecosensis and Parabathynella cf motasi and, as outgroup, Hexabathynella sevillaensis) and a total of 2320 characters separated in three partitions. The main reason to choose Hexabathynella as outgroup is because it is morphologically quite distinct and, according to more complete molecular analysis (Camacho et al., 2021), it results quite different from the ingroup. Besides, Hexabathynella is a genus present throughout the world, (four species in North America and 10 in Europe, four in Iberian Peninsula), and has only six pairs of legs, such as Hexaiberobathynella (unfortunately we do not have complete COI and $18 \mathrm{~S}$ sequences fron Hexaiberobathynella to include in the analysis), all the other known genera in the world have seven pairs of legs. The phylogenetic reconstruction was performed in MrBayes as described above. The best substitution model of each partition was estimated by setting the command lset nst to mixed.

\section{Ancestral state reconstructions}

To explore the evolution of a subset of the selected characters, we reconstructed their ancestral states under a BI approach. Five characters of interest were selected: 1 ) the number of segments on the exopod of ThI (character 9); 2) the number of segments on the exopod of ThII-III (character 12); 3) the sculpture of the cuticle in females (character
$16)$; 4) the number of AII segments (character 28) and 5) the number of segments on ThVIII in females (one segment in all tribe species and Hexabathynella, and two in Montanabathynella and Parabathynella). We used the ultrametric tree derived from the BEAST analyses for the reconstructions. A character matrix was assembled for each character based on the data matrix provided in table 4. Analyses were performed in RevBayes (Höhna et al., 2016) following the script provided in the tutorials (https://revbayes.github. io/tutorials/morph/morph_more.html), the Mk model with unequal rates was used for this reconstruction. Analyses were run with a chain of length of 40 ooo generations. Results were summarized and plotted using the $\mathrm{R}$ package RevGadgets (https://github.com/ revbayes/RevGadgets).

\section{Results}

\section{Molecular results}

Phylogenetic analysis. The ML and BI phylogenetic analyses of the two molecular datasets (COI and concatenated coI and 18S) recovered similar topologies. In the concatenated analysis, three main lineages were recovered (fig. 2). The first one (linage I), comprising the species Parabathynella cf motasi and Montanabathynella pecosensis, was highly supported in the ML analysis (ultrafast bootstrap $(\mathrm{uBS})=95)$. The second (linage II) includes the three species of Texanobathynella (T. coloradoensis, T. cf bowmani and T. aaronswinki), representing a North American lineage (posterior probabilities $(\mathrm{PP})=1, \mathrm{uBS}=$ 100). The third one (linage III), though only supported by the BI analysis ( $\mathrm{PP}=98)$, represents an Iberian-North African lineage within the Iberobathynellini tribe that is comprised of six main clades. The first clade (III.1) ( $\mathrm{PP}=$ $1, \mathrm{uBS}=99$ ) includes the Andalusian species 


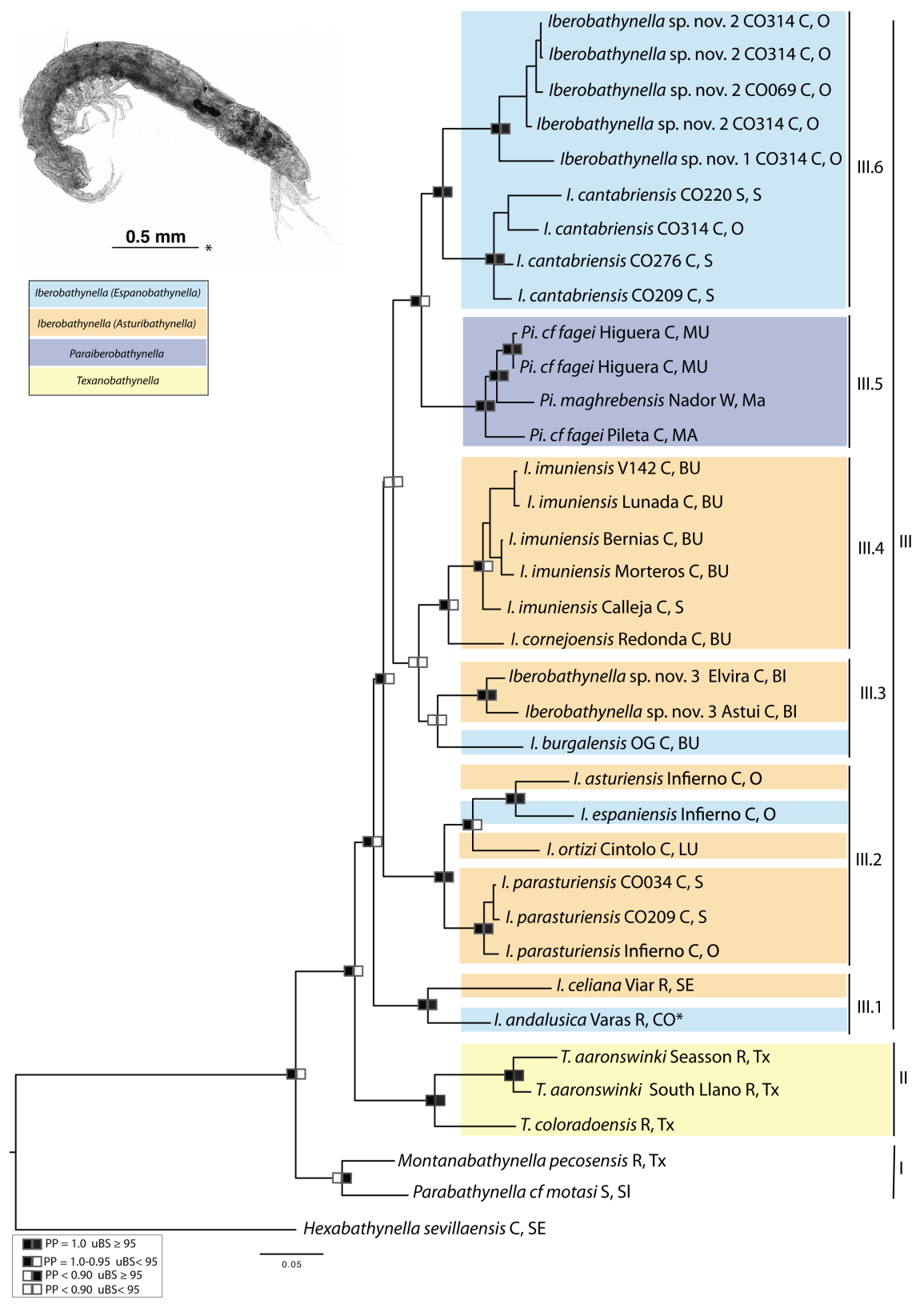

FIGURE 2 Bayesian phylogenetic tree based on the concatenated dataset [COI and $18 \mathrm{~S}$ (2209 bp)] of Parabathynellidae species. Support for each node is provided by the posterior probabilities (PP) and ultrafast bootstrap support values ( $\mathrm{uBS}$ ) with black and grey boxes. Habitat: $\mathrm{C}=$ cave; $\mathrm{R}=$ river; $\mathrm{S}=$ spring; $\mathrm{W}=$ well. Spain provinces: $\mathrm{BI}=$ Vizcaya; $\mathrm{BU}=$ Burgos; $\mathrm{CO}=$ Córdoba; $\mathrm{LU}=\mathrm{Lugo} ; \mathrm{MA}=$ Málaga; Ma: Morocco; $\mathrm{MU}=$ Murcia; $\mathrm{O}=$ Asturias $; \mathrm{S}=$ Cantabria; $\mathrm{SE}=$ Sevilla. $\mathrm{Tx}=$ Texas. $\mathrm{SI}=$ Slovenia.

I. celiana Viar River (Sevilla) and I. andalusica Varas River (Córdoba). The second clade (III.2) $(\mathrm{PP}=1$, uBS $=99)$ groups the northwestern Iberian species I. parasturiensis
(Cantabria-Asturias), I. ortizi Cintolo Cave (Lugo) and I. espaniensis and I. asturiensis, both from Infierno Cave (Asturias). The third clade (III.3) $(\mathrm{PP}=1, \mathrm{uBS}=98)$ is comprised of 
two specimens of a new species from Vizcaya, Iberobathynella sp. nov. 3, I. burgalensis oG, though this phylogenetic relationship was not supported. The fourth clade (III.4) (PP = 0.99, $\mathrm{uBS}=81$ ) contains two species: I. cornejoensis Redonda Cave (Burgos) and I. imuniensis (cave populations from Burgos and Cantabria). The fifth clade (III.5) (PP = 1, uBS = 100) includes the species of Paraiberobathynella from the southern Iberian Peninsula and Morocco: Pi. cf fagei Pileta Cave (Málaga), Pi. maghrebensis Nador well (Morocco) and Pi. cf fagei Higuera Cave (Murcia). The sixth clade (III.6) ( $\mathrm{PP}=$ o.97, uBS = 91) groups $I$. cantabriensis from cave populations in Asturias and Cantabria with two new species of Iberobathynella, Iberobathynella sp. nov. 1 from Cave c0314 (Asturias) and Iberobathynella sp. nov. 2 from Cave co314 and coo69 (Asturias).

Bayesian analyses of the mtDNA data set (COI) revealed two main lineages within the Iberobathynellini tribe (fig. 3). The first lineage (I), not supported, consists of seven clades containing the species distributed throughout the Iberian Peninsula, and the second (II) of the species from North America. The North American lineage $(\mathrm{PP}=1 ; \mathrm{uBS}=96)$ that includes the three species of Texanobathynella was recovered as the basal clade of the Iberobathynellini tribe. The phylogenetic relationships within the Iberobathynellini tribe were not well-supported based on this data set, however, seven clades were recovered. The relationships of two of the species (I. burgalensis and I. magna) were not supported. The first clade $(2.1)(\mathrm{PP}=1 ; \mathrm{uBS}=96)$ includes four species from the northwestern Iberian Peninsula: I. ortizi (dark blue) from Lugo (Rei Cintolo Cave); I. asturiensis (green) and I. espaniensis (garnet) from Asturias (Infierno Cave) and I. parasturiensis (light blue) from Cantabria-Asturias. According to the haplotype network, I. parasturiensis has the most divergent alleles within this clade. This species is found in sympatry with I. asturiensis and I. espaniensis in Infierno Cave. The second clade (2.2) $(\mathrm{PP}=1, \mathrm{uBS}=100)$ includes two specimens of the new species Iberobathynella sp. nov. 3 from the caves Astui (purple) and Fonda (orange) (in Vizcaya). The third clade (2.3) $(\mathrm{PP}=1, \mathrm{uBS}=95)$ groups I. cornejoensis (dark blue) from Redonda Cave (Burgos) with the more widely distributed I. imuniensis from Cantabria (Calleja-Cueto Cave) (purple) and Burgos [V142 and Lunada caves (yellow) and Torca de los Morteros and Bernias caves (red)]. The fourth clade (2.4) ( PP = 1, uBS = 97), whose phylogenetic position represents a major difference between the two datasets (mitochondrial vs concatenated), includes $I$. andalusica from Córdoba (Varas River) (blue) and $I$. celiana from Sevilla (Viar Stream, Castiblanco) (green). The fifth clade (2.5) includes the new species Iberobathynella sp. nov. 1 from Cave CO314 (red) and Iberobathynella sp. nov. 2 from caves C0314/COo69 (orange and purple), which live in sympatry in Cave CO314 (Pilar Cave, Asturias). The sixth clade (2.6) $(\mathrm{PP}=1$, $\mathrm{uBS}=100$ ) only includes the species I. cantabriensis from Asturias (Cave C0314; yellow, green and blue) and Cantabria [Cave CO276 (Lobos Cave); purple and c022O (Carnero Spring Cave); blue]. In the seventh clade (2.7) $(\mathrm{PP}=1, \mathrm{uBS}=100), P i$ cf fagei from Málaga (Pileta Cave; red) resolved as the sister species of Pi. maghrebensis from Morocco (Nador; green) and $\mathrm{Pi}$. cf fagei from Murcia (Higuera Cave; light blue) in the southeastern Iberian Peninsula.

Genetic divergence. As the nuclear $18 \mathrm{~S}$ gene is highly conserved in the species of the Iberobathynellini tribe, genetic divergence (uncorrected $\mathrm{p}$ distances calculated using PAUP $^{*}$ 4.ob 10) (Swofford, 2002)) between genera, subgenera and species and between these and Parabathynella, the other European genus, was only assessed using COI (table 6 and supplementary table S2). Saturation is 


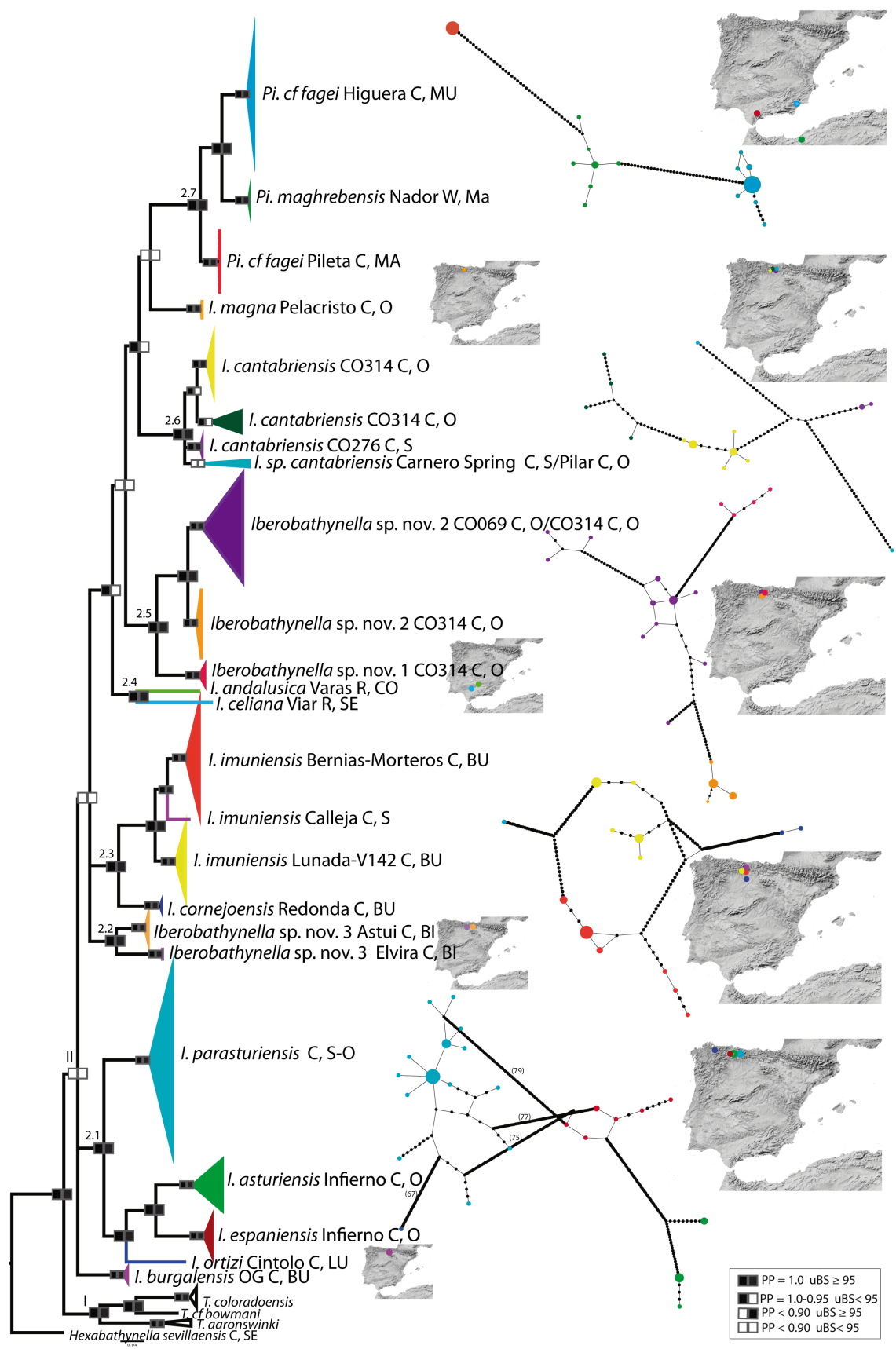

FIGURE 3 Bayesian phylogenetic tree based on COI sequences (507 bp) of Parabathynellidae species. Support for each node is provided by the posterior probabilities (PP) and ultrafast bootstrap support values (uBS) with black and grey boxes. 
generally observed between genera; however, the results are informative for discussing divergences among species. Base pair changes are observed in the following regions: $163-170$; 270-82; 780-794; 1234-1282; 1352-1373; 14011432; $1467-1475$ and $1578-1586$.

The estimated cor divergence between species of Iberobathynella is highly variable, ranging from $11.8 \%$ to $20.8 \%$. With respect to divergence between populations, nearly the same level of divergence is observed between nearby populations of some of the same species as between those of different genera. For instance, a divergence of $10.0 \%$ is observed between two specimens morphologically identified as $I$. (E.) cantabriensis from two nearby populations, Carnero Spring (CO22O) and Lobos Cave (CO276), both in Cantabria. This is similar to the divergence observed between two specimens morphologically identified as belonging to different genera (which present strong morphological differences) from two geographically distant populations, i.e., I. (Asturibathynella) parasturiensis (from Infierno Cave in northern Spain) and Paraiberobathynella (Pi.) maghrebensis (from northern Morocco), which diverge by $13.0 \%$.

Divergence time analysis. The time divergence analysis (fig. 4) reveals a Cretaceous TMRCA of the Parabathynellidae clade, and the divergence of Palearctic from Nearctic species of Iberobathynellini tribe around 76.8 Mya (95\% HPD: 57.2-98.6 Mya). The timing of these early divergences agrees with previous results (Camacho et al., 2018b, 2021a; Perina et al., 2019). The TMRCA of the Iberobathynella and Paraiberobathynella genera dates to the beginning of the Paleogene around 63.7 Mya (95\% HPD: 48.2-81.9 Mya), with the main splits within this group occurring during the Middle Eocene [I. celiana - I. andalusica, 40.8 Мya (95\% HPD: 26.9-56.6 Mya); I. imuniensis/I. cornejoensis - I. sp. nov.3/I. burgalensis, 39.8 Mya (95\% HPD: 28.9-52.8 Mya); Paraiberobathynella species $-I$. cantabriensis - I. sp. nov. 1/ sp. nov. 2, 47.6 Mya (95\% HPD: 35-62 Mya) and I. parasturiensis/I. ortizi - I. asturiensis/I. espaniensis, 41.8 Mya (95\% HPD: 29.3-55.1 Mya)].

\section{Morphological phylogenetic analysis.} The two consensus trees obtained with MrBayes and RevBayes derived from the morphological dataset present the same topology (fig. 5), and show, despite the high support ( $\mathrm{PP}>0.95$, as suggested by Alfaro et al., 2003), that Iberobathynellini tribe (PP $=1$ ) are not monophyletic. The trees show that phylogenetic relationships amongst the taxa are not fully resolved. Species belonging to Hexaiberobathynella group together in a well-supported clade ( $\mathrm{PP}=0.96)$, suggesting the monophyly of this genus. Intriguingly, none of the currently recognized subgenera of Iberobathynella are recovered as a monophyletic group, except for the nominal subgenus Iberobathynella (Iberobathynella), whose five species form a supported clade ( $\mathrm{PP}=$ 99). Species of the genera Paraiberobathynella and Texanobathynella form a clade, which also includes Montanabathynella pecosensis, although support for these relationships is low.

\section{Combined results}

The phylogenetic hypothesis derived from the combined analysis of the morphological and molecular datasets (fig. 6), which only included the morphologically defined species, yielded almost the same topology as the tree obtained from the concatenated molecular analyses (compare fig. 6 with fig. 2), with the exception of the phylogenetic position of I. burgalensis. In this analysis, I. burgalensis resolves as the sister taxon of I. cantabriensis; however, this relationship is unsupported.

\section{Ancestral state reconstruction}

Bayesian reconstructions of the ancestral states of some characters are illustrated in figs. 7 and 8. All ancestral state reconstruction Downloaded from Brill. com@4/26/2023 03:32:19PM 


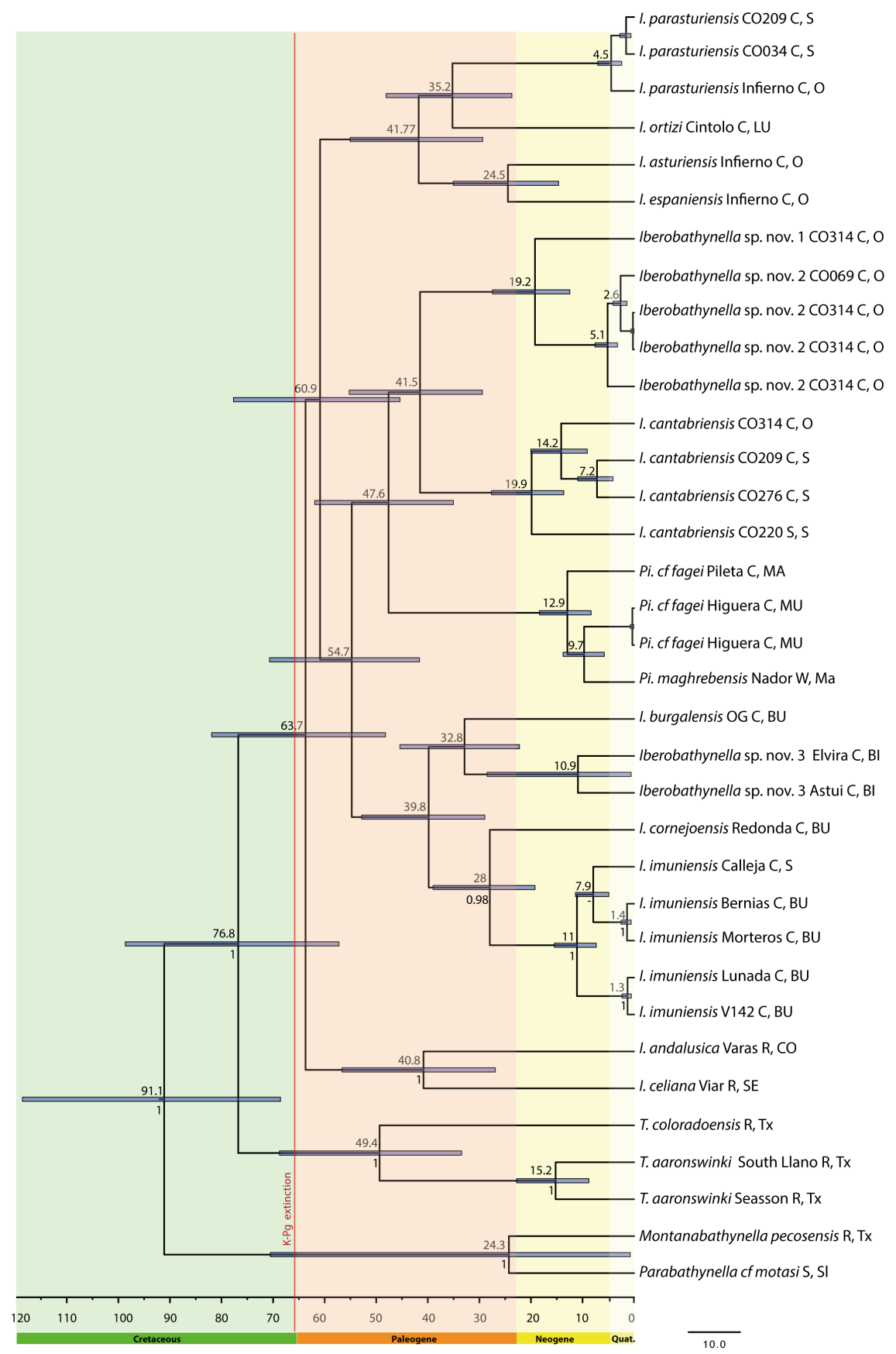

FIGURE 4 Temporal estimates derived from a relaxed molecular clock analysis. Divergence times are depicted in the coalescence-based MCc tree. Units of X-axis address Mya and blue bars at nodes indicate the $95 \%$ highest posterior density intervals (HPD). 


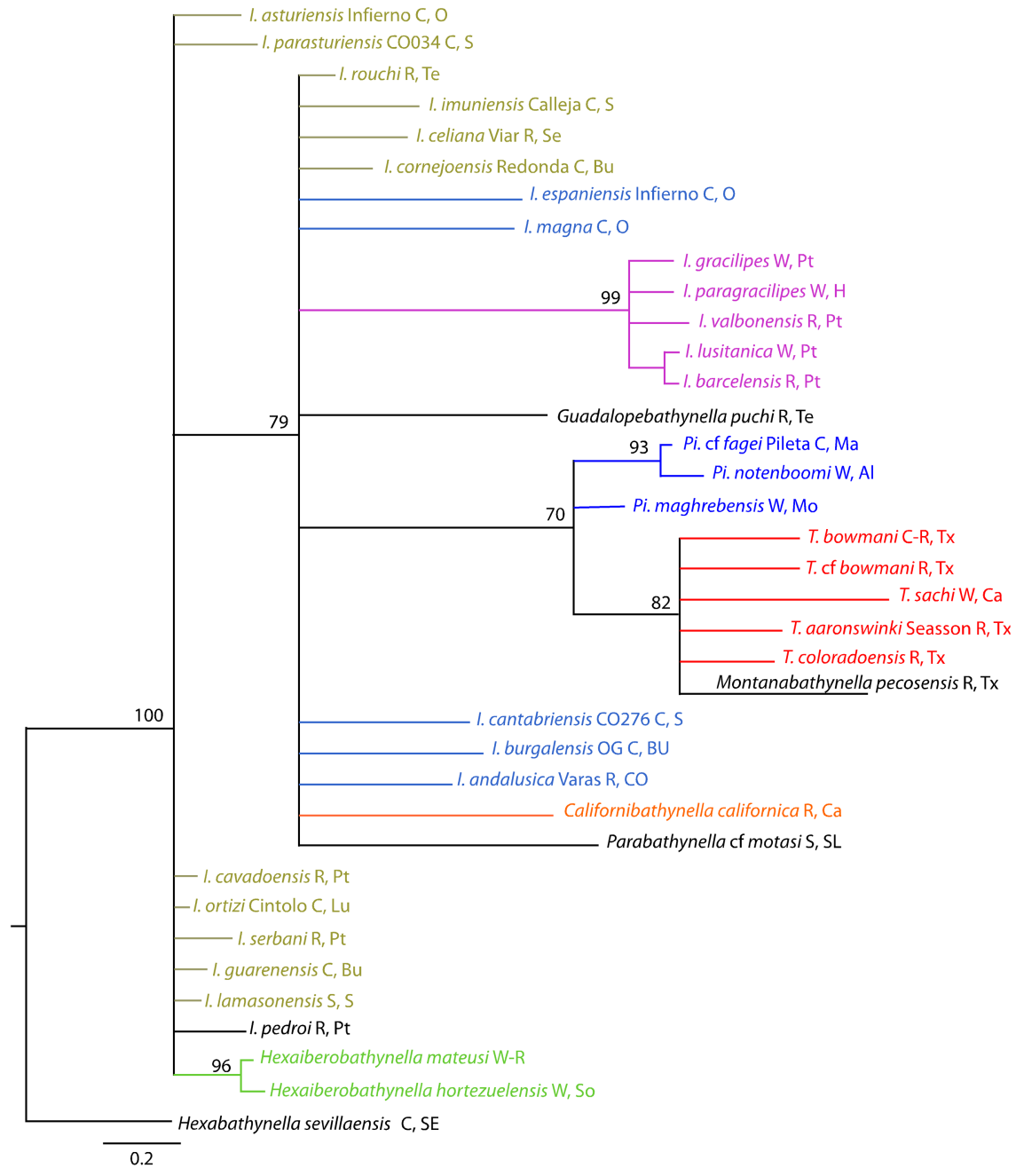

Iberobathynella (Iberobathynella) Schminke, 1973

Iberobathynella (Espanobathynella) Camacho \& Serban, 1998

Iberobathynella (Asturibathynella) Camacho \& Serban, 1998

Paraiberobathynella Camacho \& Serban, 1998

Hexaiberobathynella Camacho \& Serban, 1998

Texanobathynella Delamare Deboutteville, Coineau \& Serban, 1975

FIGURE 5 Bayesian phylogenetic tree based on the morphological dataset. Support for each node is provided by the posterior probabilities ( $\mathrm{PP})$.

analyses reached convergence, with traceplots showing adequate mixing and Ess values larger than 200 for all parameters. The results for each character are as follows:

1. Number of aii segments (Ch. 28) (fig. $7 \mathrm{~A})$ : The reconstruction indicates three segments as the ancestral condition of
Iberobathynellini, albeit with low statistical support $(\mathrm{PP}=0.5)$, and only one transition event, leading to five (Parabathynella cf motasi) or six (Montanabathynella pecosensis) segments.

2. Number of segments of the exopod of ThII-iii (Ch. 12) (fig. 7B): A ThII-III 


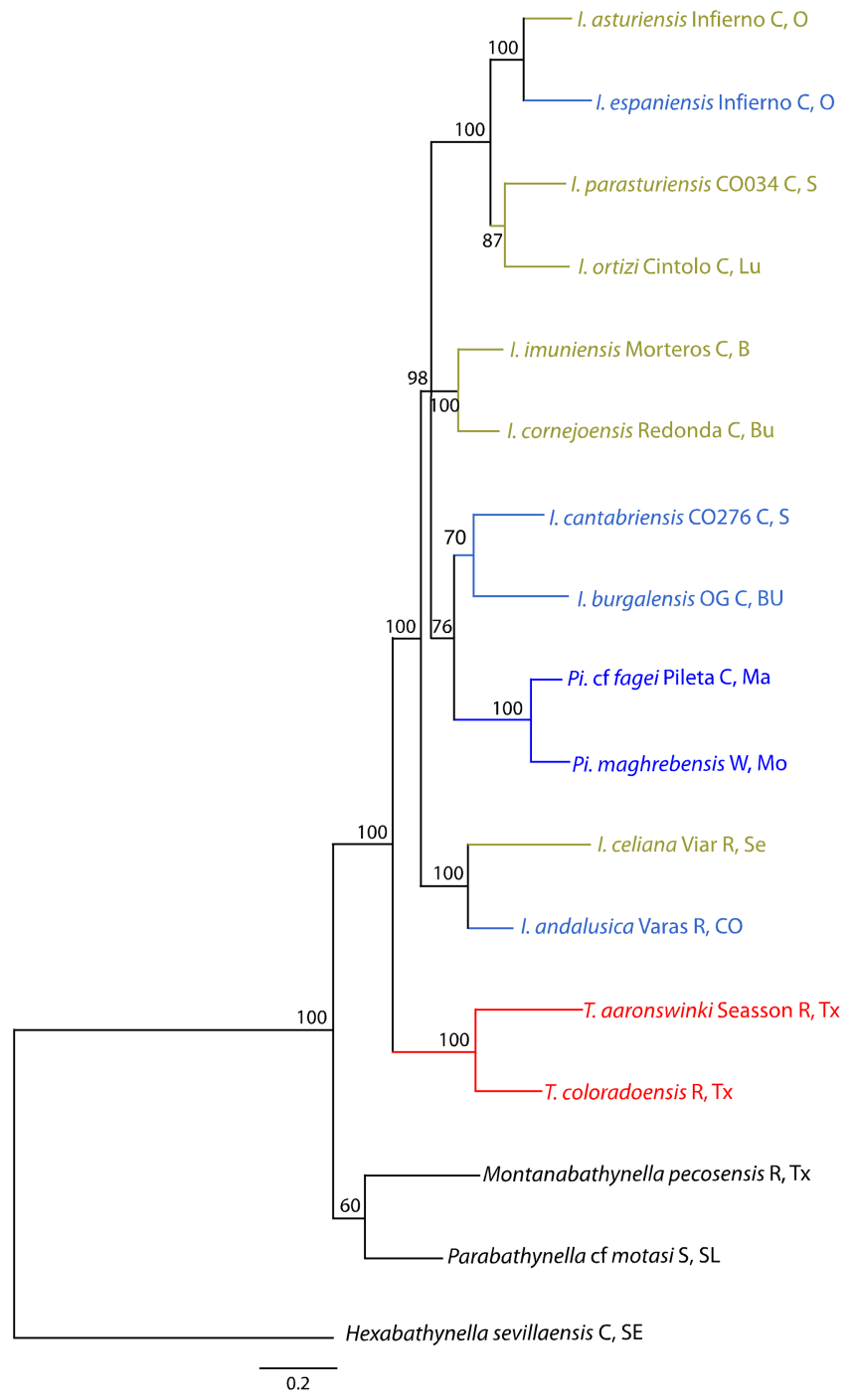

Iberobathynella (Espanobathynella) Camacho \& Serban, 1998

Iberobathynella (Asturibathynella) Camacho \& Serban, 1998

Paraiberobathynella Camacho \& Serban, 1998

Texanobathynella Delamare Deboutteville, Coineau \& Serban, 1975

FIGURE 6 Phylogenetic tree from the combined analyses (morphological and molecular dataset). Support for each node is provided by the posterior probabilities (PP).

exopod with three to four segments was reconstructed as the ancestral state of Iberobathynellini $(\mathrm{PP}=0.5)$. Our results suggest that the presence of only two segments evolved independently at least three times during the tribe's evolutionary history.

3. Number of segments of the exopod of ThI (Ch. 9) (fig. $7 \mathrm{C}$ ): A ThI exopod with a single segment was reconstructed as the 

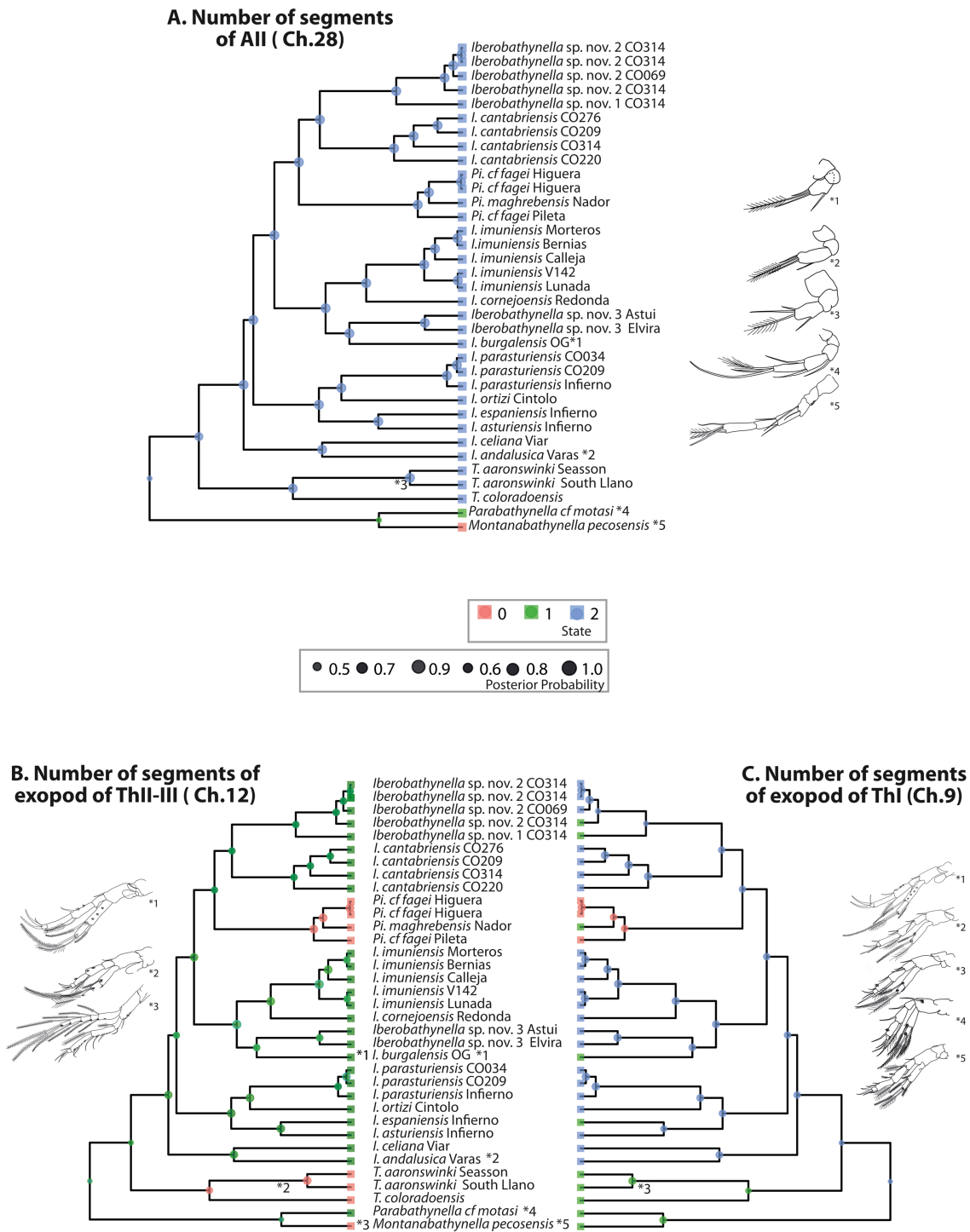

FIGURE 7 Ancestral State Reconstruction of: (A) Number of segments of AII (Ch.28); (B) Number of segments of exopod of ThII-III (Ch. 12) and (C) Number of segments of exopod of ThI (Ch. 9). Support for each node is provided by the size of circles indicating the posterior probabilities (PP). Coloured box depicted the state of the character.

ancestral state, however with low statistical support $(\mathrm{PP}=0.5)$. In this reconstruction, the presence of two segments evolved independently at least seven times. The presence of three segments evolved once in the lineage leading to the Paraiberobathynella clade. In this clade, only Pi. maghrebensis presents two segments, representing one of the seven transitions to a two-segmented exopod of ThI.

4. Sculpture of the cuticle in females (Ch. 16) (fig. 8A): A smooth cuticle in females of the Iberobathynellini lineage was reconstructed as the ancestral state $(\mathrm{PP}=0.8)$, with the wrinkled state evolving independently three times, and no reversal events. 

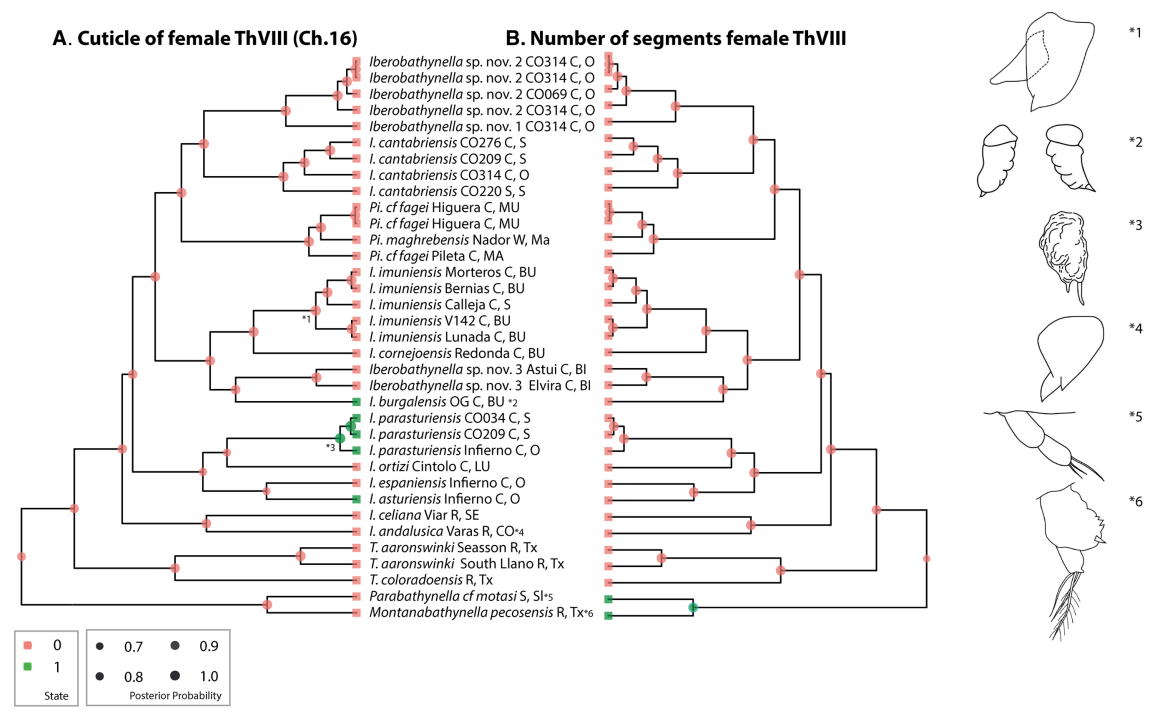

FIGURE 8 Ancestral State Reconstruction of (A) Cuticle of female Th viII (Ch.16) and (B) Number of segments female ThVIII. Support for each node is provided by the size of circles indicating the posterior probabilities (PP). Coloured box depicted the state of the character.

5. Number of ThVIII segments in females (fig. 8B): A ThVIII with a single segment appears to be the ancestral condition of the tribe $(\mathrm{PP}=0.70)$. A two-segmented ThVIII evolved in the most recent common ancestor of Parabathynella cf motasi and Montanabathynella pecosensis.

\section{Morphological results}

Systematic account. In this section, a morphological diagnosis of the Iberobathynellini tribe Camacho \& Serban, 1998 is provided, and some general considerations regarding previously established lower categories are discussed. Moreover, the relationships of genera within the tribe based on morphological characters are contrasted with the molecular data.

The distribution of the studied species is shown in fig. 1, and the list of the species and populations studied, including information on their habitat and locality, is provided in supplementary appendix S2. Updated diagnoses of rankings higher than species within the Iberobathynellini tribe are detailed in supplementary appendix S3. These updated morphological diagnoses highlight characters distinctive to the tribe or its genera (table 3 ) and provide a better understanding of the hierarchy of the taxa within the tribe.

\section{Tribe Iberobathynellini Camacho \& Serban, 1998}

Diagnosis (after Camacho et al., 2000): AI seven-segmented, very rarely six-segmented. AII three-segmented (fig. 9A-J), small and with four setae on the last segment. Common or special structure (hook-like teeth) (fig. 9S) on labrum, usually with eight main teeth. Strongly inclined connection of the mandible with the cephalon. Usually seven pairs of thoracopods, thoracopod I with a one-, two- or three-segmented exopod (fig. 13A-K) and the rest of the thoracopods with a two, three or four-segmented exopod; coxa of thoracopods with distinct conical projection at inner distal corner; thoracopod I without epipod. Male thoracopod VIII of type "Iberobathynella" (fig. $15 \mathrm{~A}-\mathrm{K})$ : large outer lobe, partially fused with basipod; small exopod on latero-external 
side of basipod, covered by outer lobe; endopod always present with distal end oriented towards the latero-external side. Pleopods usually absent.

In the Iberobathynellini tribe, the outer lobe of the male thoracopod VIII is well developed in both length and width, and is highly distinctive as a massive element of the lateral face always close to the endopod, in some case covering the distal part of the basipod, a very marked feature in I. rouchi; the main axis of the lobe can be vertical to inclined on the postero-distal or antero-distal side; its fusion with the basipod (Serban, 1977) is at the level of the basal parts of the posterior edge of the lobe and the anterior face of the basipod; the exopod is greatly reduced. In Iberobathynellini, the outer lobe (O.lb) is small; in Parabathynella (fig. $15 \mathrm{M}$ ), it is narrow and slightly longer than the exopod and the outer lobe is not fused with the basipod. The exopod is located on the lateral face of the basipod and is covered by the distal part of the outer lobe, however, its small size makes it the most difficult structure to observe in species of the Iberobathynellini tribe.

The division of the tribe into three subtribes (Camacho \& Serban, 1998) is based on the diversification of the thoracopods at the exopod level in Iberobathynellina and Paraiberobathynellina, on the different number of thoracopods in Hexaiberobathynellina (table 3), and to organize the taxonomy of the morphogroup and to understand the relationships between the genera.

Type genus: Iberobathynella Schminke, 1973

Subtribe: Iberobathynellina Camacho \& Serban, 1998

Paraiberobathynellina Camacho \& Serban, 1998

Hexaiberobathynellina Camacho \& Serban, 1998

The main morphological differences identified among the three subtribes and six genera (and subgenera) in 1998 are shown in table 3. Morphospace was organized by fitting all known species into the three subtribes and established subgenera.

The number of thoracopods clearly separated the subtribes Iberobathynellina and Paraiberobathynellina from Hexaiberobathynellina, which have seven and six, respectively. More than two segments on the exopod of thoracopods II to VII are only found in the genera of the subtribe Paraiberobathynellina (Paraiberobathynella and Texanobathynella) and in $I$. (E.) magna (in thoracopods IV and $\mathrm{v})$. The number of teeth in the distal endite of MxI also distinguishes the genera: five in Texanobathynella, six in Hexaiberobathynella and Guadalopebathynella, seven in Californibathynella and Paraiberobathynella, and in the subgenera of Iberobathynella, seven in Iberobathynella and Espanobathynella and six in Asturibathynella. Guadalopebathynella shares many character states with the subgenus Asturibathynella, but its curved (hooklike) teeth in both the labrum and distal endite of MxI clearly distinguish G. puchi from $I$. (A.) imuniensis, with which it is most similar. Other characters are not exclusive to a single subgenus or genus; however, the set of characters allowed the identification of the nine morphotypes corresponding to the six genera and five subgenera (see table 3). But as new species were found, the characters overlapped between subtribes and subgenera and some species such as I. pedroi Camacho, 2003 no longer fit into any of the 3 subgenera of Iberobathynella (table 4).

Comparative morphological analysis of the Iberobathynellini and non-Iberobathynellini genera from the study area

Table 4 lists the set of character states exhibited by the 33 morphotypes of the Iberobathynellini tribe, and the five species 
of Montanabathynella and Parabathynella, included in the present study. This list highlights the level of variability in the main morphological characters often used to discriminate taxa in taxonomic studies of this group of crustaceans. Below, we briefly review the main characters and discuss the distribution of variability among the nine taxa (genera and subgenera). Of the species of Iberobathynella, 21 can be placed into one of the three morphologically established subgenera. However, the species I. pedroi displays character states present in the subgenera Asturibathynella and Espanobathynella and is therefore compared separately.

Species belonging to the Iberobathynellini tribe vary considerably in size, with some barely reaching or exceeding one millimetre: for instance, I. celiana measures $0.9 \mathrm{~mm}$; I. serbani, $1.0 \mathrm{~mm}$; I. lamasonensis and $I$. pedroi, $1.2 \mathrm{~mm}$ and Californibathynella californica, $1.1 \mathrm{~mm}$. Some species of the subgenera Asturibathynella and Espanobathynella can reach $2.2 \mathrm{~mm}$ and $1.9 \mathrm{~mm}$, respectively. Paraiberobathynella fagei and Pi. notenboomi can reach $2.8 \mathrm{~mm}$, while the species $I$. gracilipes and I. paragracilipes, both from the subgenus Iberobathynella, are some of the largest, with some specimens measuring up to $4.0 \mathrm{~mm}$ or $3.2 \mathrm{~mm}$, respectively. Large species are also found in Montanabathynella, such as M. salish Camacho, Newell \& Stanford, 2009, which can measure up to $3.0 \mathrm{~mm}$. Finally, some species of Parabathynella can measure $2.5 \mathrm{~mm}$.

The variability in the selected morphological structures are described below and illustrated in figs. 9 to 17.

Antennule: Seven-segmented AI characterizes most species of the tribe ( 28 species). Two species of Iberobathynella (I. celiana and I. guarenensis) and four of Texanobathynella present a six-segmented AI. The five species comprising the genera Montanabathynella and Parabathynella also have a seven-segmented AI. The number of setae and aesthetascs on the segments varies among the genera and species.

Antenna (fig. 9): All species of the tribe have three segments (fig. 9A-J) and only setae (four) on the last segment; segment length may vary slightly between species. Montanabathynella (fig. $9 \mathrm{~K}$ ) has six segments while Parabathynella has five (fig. $9 \mathrm{~L}$ ).

Labrum (fig. 9M-X): The labrum presents as relatively flat (fig. $9 \mathrm{M}, \mathrm{N}, \mathrm{R}, \mathrm{T}, \mathrm{U}$ ), concave (fig. 9O, P, Q, V) or convex (fig. 9S). Most species have eight main teeth on the labrum except I. guarenensis (10 teeth); I. magna (9 teeth); Pi. notenboomi (11 teeth) (fig. $9 \mathrm{U}$ ) and those of Texanobathynella (9 or 10 teeth) (fig. $9 \mathrm{~V}$ ). The labrum in Guadalopebathynella is convex (fig. $9 \mathrm{~S}$ ), and has eight hook-like shaped teeth. Compared with the other species, the number of main teeth varies more in Montanabathynella (8 to 12 teeth; fig. $9 \mathrm{~W}$ ) and Parabathynella (8 to 13 teeth; fig. $9 \mathrm{X}$ ).

Mandible (fig. 10): The number of teeth in the pars incisive varies between four and 12 in Iberobathynella: six to 12 in the subgenus Iberobathynella (fig. $10 \mathrm{~F}$ ), four to seven in Asturibathynella (fig. 10A, B) and four to eight in Espanobathynella (fig. 10D, E); I. pedroi has six teeth (fig. 10C). Fewer teeth characterize the other genera: Hexaiberobathynella has four to six (fig. $10 \mathrm{H}$ ), Californibathynella has five (fig. 10J), Paraiberobathynella has six to nine, despite having very large specimens (fig. $10 G$ ), and Texanobathynella has four to six (fig. 10K). Montanabathynella (fig. $10 \mathrm{~L}$ ) and Parabathynella (fig. 10M) have only four teeth except M. salish, which has five. In the pars molaris, the number of teeth is highly variable among species of the tribe, ranging between five and 16; teeth features also varies: they can be with or without denticles, have the two most proximal teeth always joined and have fine setules. Species with the most teeth 


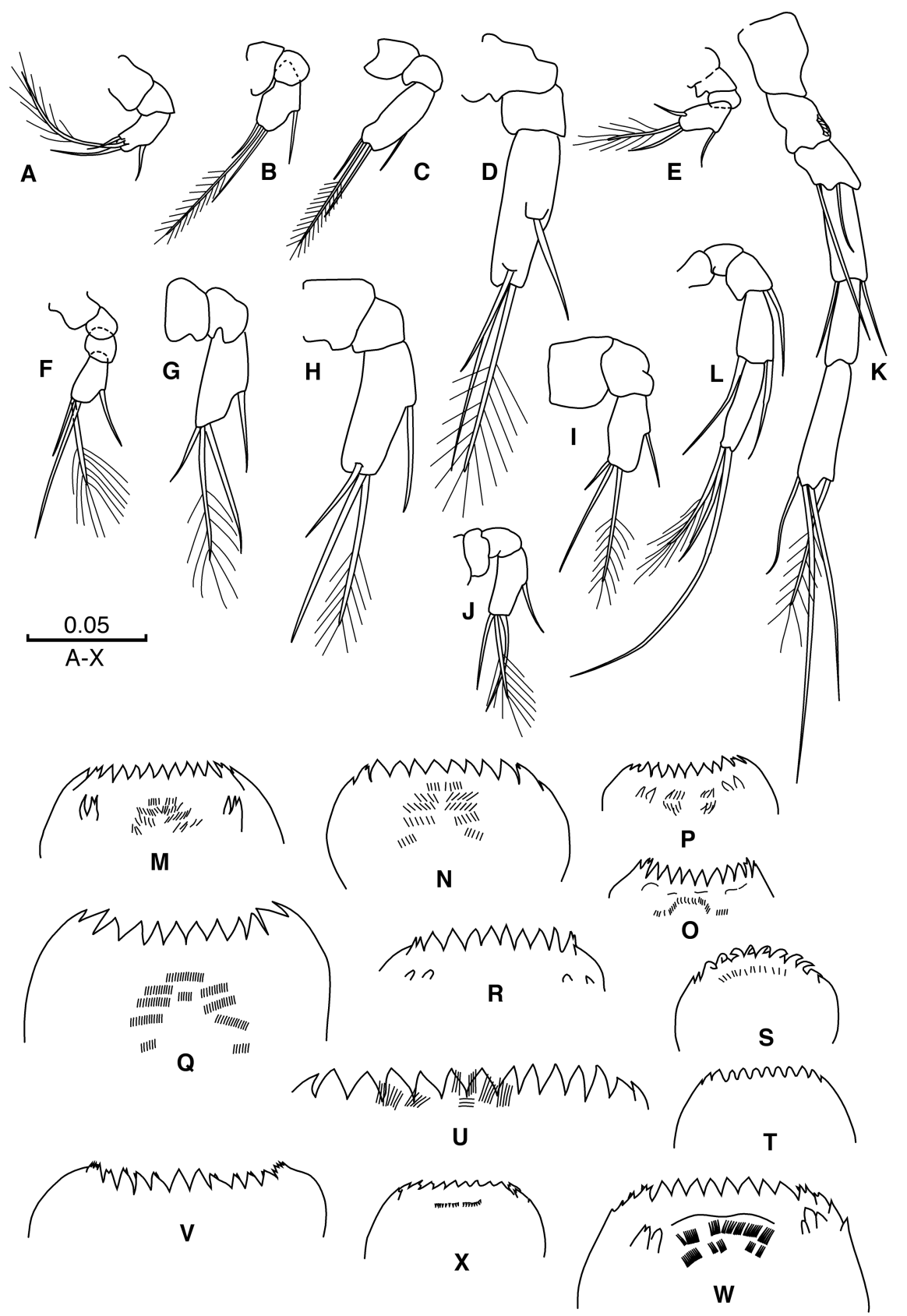

FIGURE 9 Antenna (AII) A-L: A. Iberobathynella lamasonensis; B. I. burgalensis; C. I. andalusica; D. I. paragracilipes; E. Guadalopebathynella puchi; F. Californibathynella californica; G. Hexaiberobathynella hortezuelensis; H. Paraiberobathynella notenboomi; I. Texanobathynella aaronswinki; J. I. pedroi; K. Montanabathynella pecosensis; L. Parabathynella motasi. Labrum M-X: M. I. burgalensis; N. I. andalusica; O. I. cornejoensis; P. I. pedroi; Q. I. paragracilipes; R. Hexaiberobathynella hortezuelensis; S. Guadalopebathynella puchi; T. Californibathynella californica; U. Paraiberobathynella notenboomi; V. Texanobathynella aaronswinki; W. Montanabathynella pecosensis; X. Parabathynella motasi. 


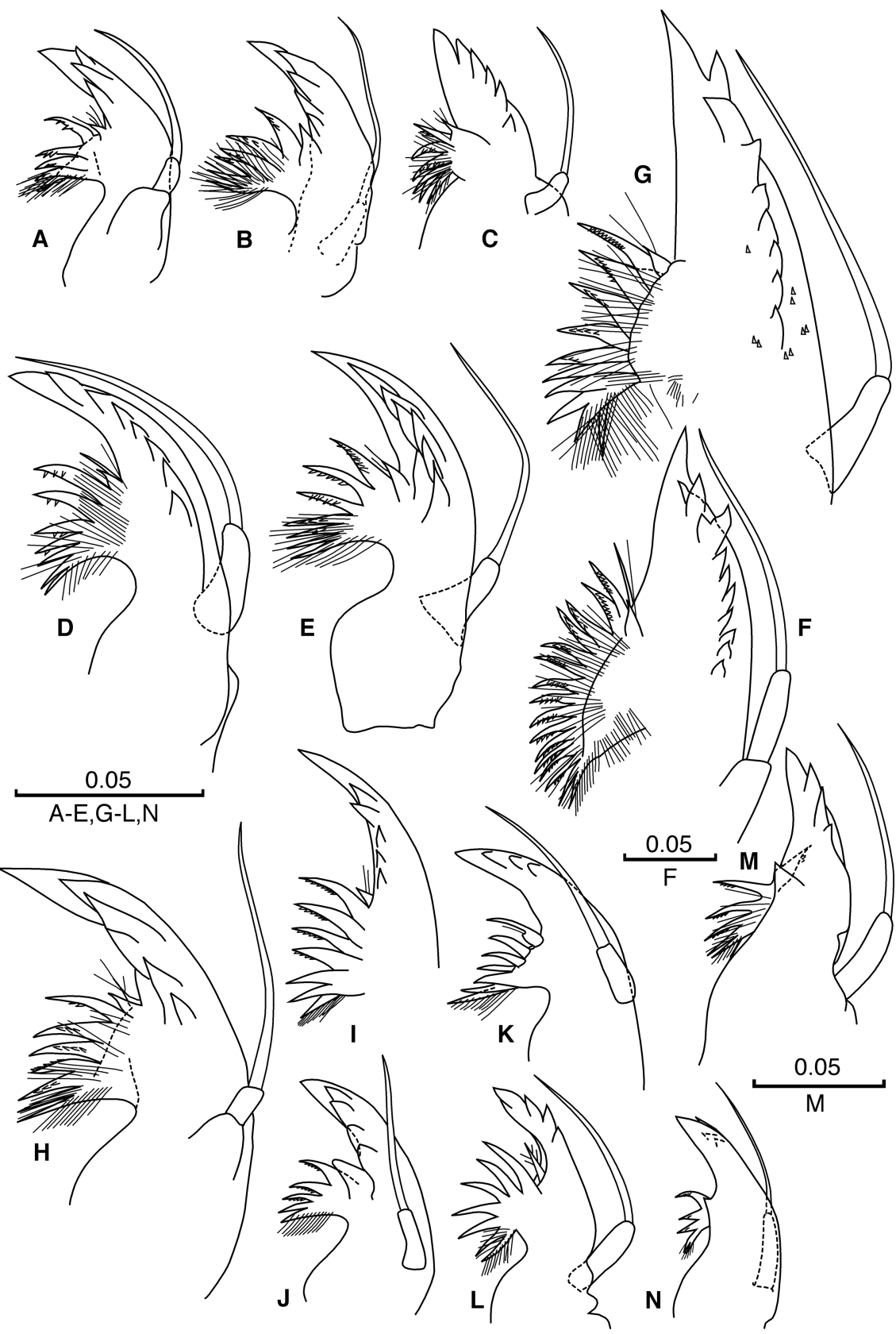

FIGURE 10 Mandible (Md): A. Iberobathynella cornejoensis; B. I. lamasonensis; E. I. pedroi; D. I. andalusica; E. I. burgalensis; F. I. paragracilipes; G. Paraiberobathynella notenboomi; H. Hexaiberobathynella hortezuelensis; I. Guadalopebathynella puchi; J. Californibathynella californica; K. Texanobathynella bowmani; L. Texanobathynella aaronswinki; M. Montanabathynella pecosensis; N. Parabathynella motasi. 


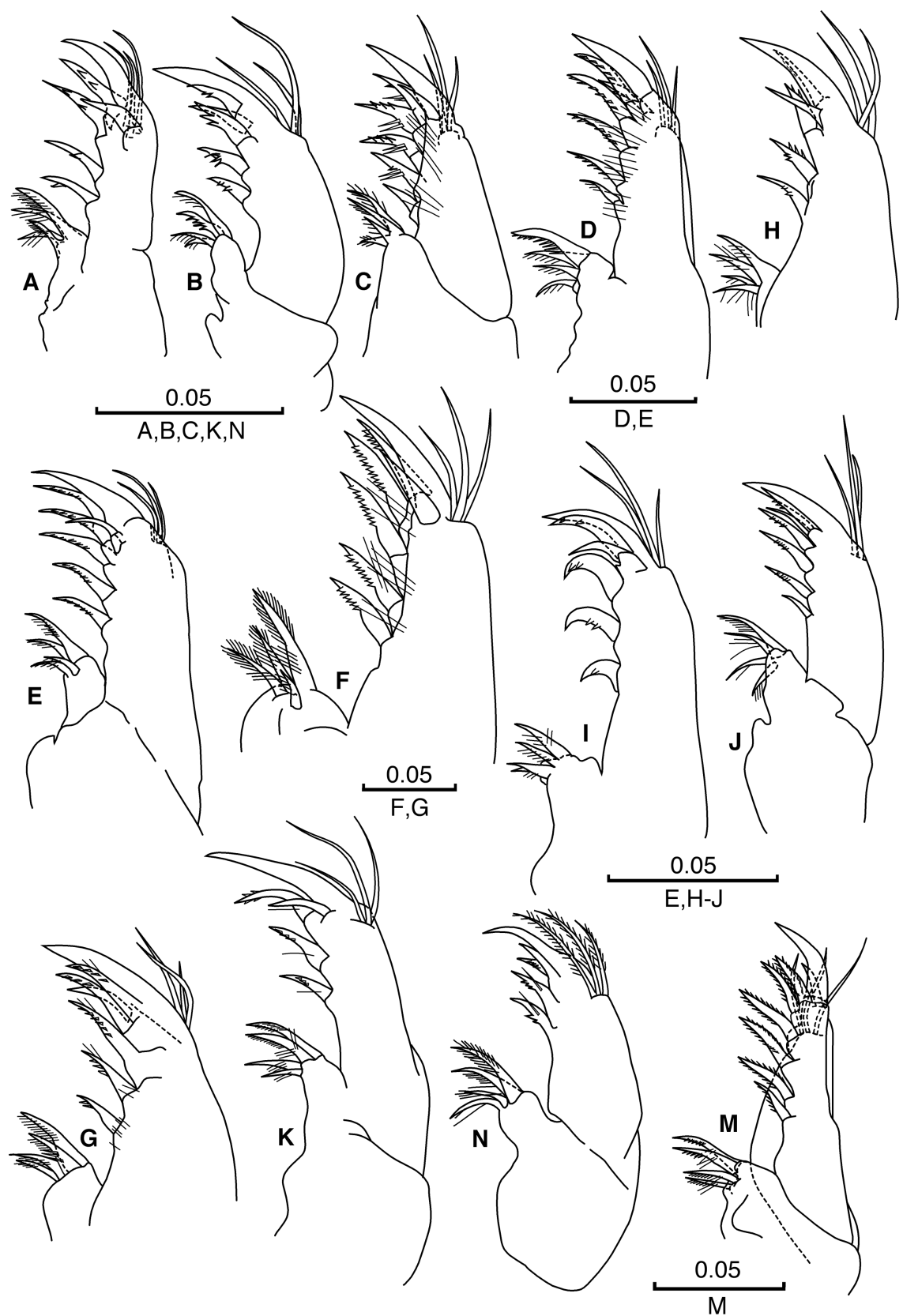

FIGURE 11 Maxillule (MxI): A. Iberobathynella lamasonensis; B. I. cornejoensis; C. I. pedroi; D I. andalusica; E. I. burgalensis; F. I. paragracilipes; G. Paraiberobathynella notenboomi; H. Hexaiberobathynella mateusi; I. Guadalopebathynella puchi; J. Californibathynella californica; K. Texanobathynella aaronswinki; L. Parabathynella motasi; M. Montanabathynella pecosensis.

belong to the subgenera Iberobathynella (6 to 16 teeth) (fig. $10 \mathrm{~F}$ ) and Paraiberobathynella (6 to 12 teeth) (fig. 10G); Montanabathynella has six or seven teeth (fig. $10 \mathrm{M}$ ), and P. motasi has only four (fig. $10 \mathrm{~N}$ ), whereas P. badenwuerttembergensis has eight. All species have a small tooth on the ventral edge between both parts that is variable in size, more or less triangular 


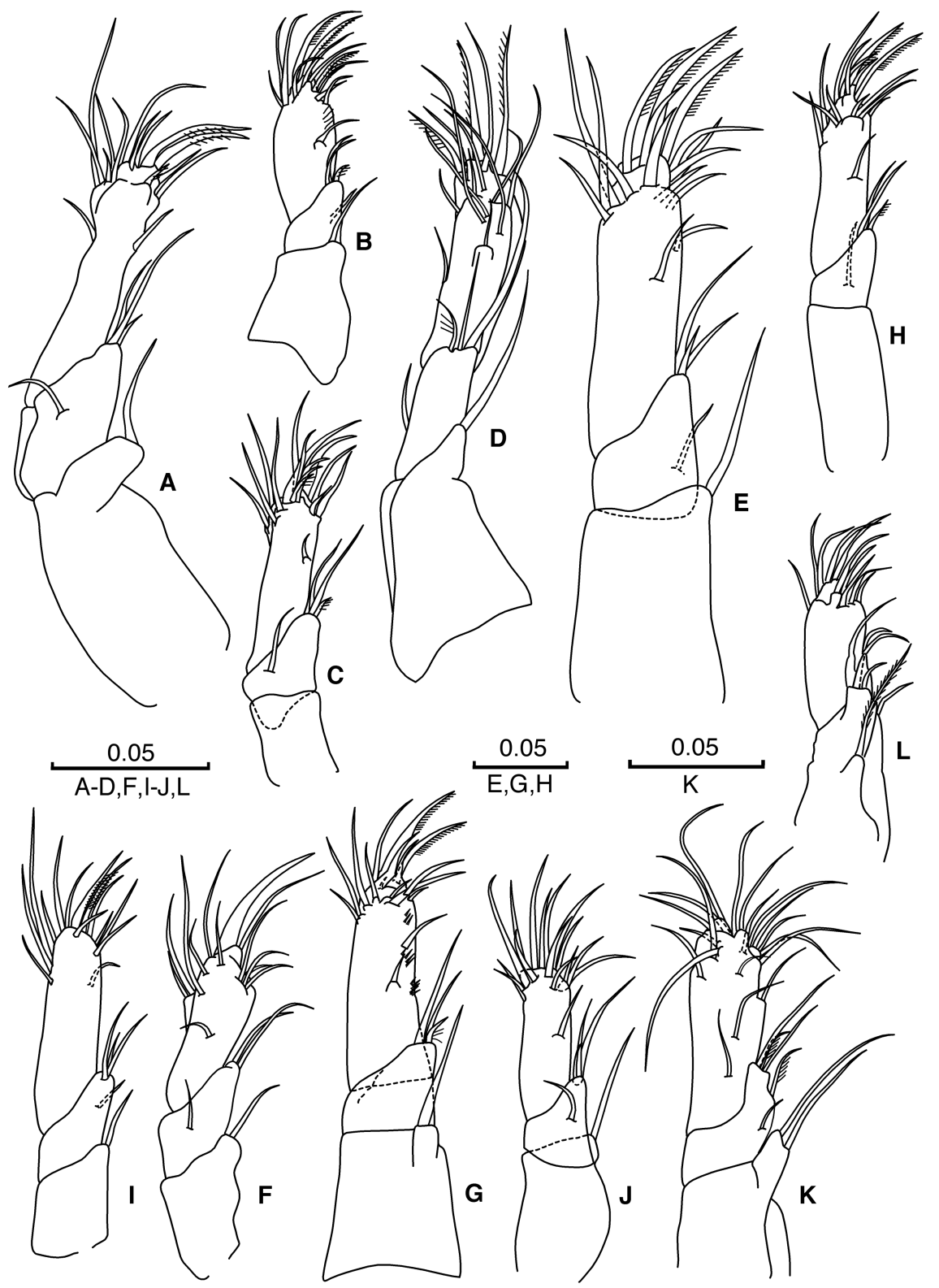

FIGURE 12 Maxilla (MxII): A. Iberobathynella burgalensis; B. I. cornejoensis; C. I. lamasonensis; D. I. andalusica; E. I. paragracilipes; F. Hexaiberobathynella hortezuelensis; G. Paraiberobathynella notenboomi; $\mathrm{H}$. Guadalopebathynella puchi; I. Californibathynella californica; J. Texanobathynella aaronswinki; K. Montanabathynella pecosensis; L. Parabathynella motasi.

and, in some cases, with small setae at the base (fig. 10D, F, H). The mandibular palp consists of one segment that is variable in size, with a single seta that either reaches the distal edge of the mandible (fig. 10D, F, J, K), surpasses it (in five species only), as in P. motasi (fig. $10 \mathrm{~N}$ ), or does not even reach it (fig. 10G).
Maxillulle (fig. 11): In the proximal endite, all species have four claws (spine-like) of different sizes. The number of teeth in the distal endite varies between six and seven in Iberobathynella but is constant in all species of each subgenus: six teeth in Asturibathynella (fig. 11A, B) and seven in Espanobathynella 


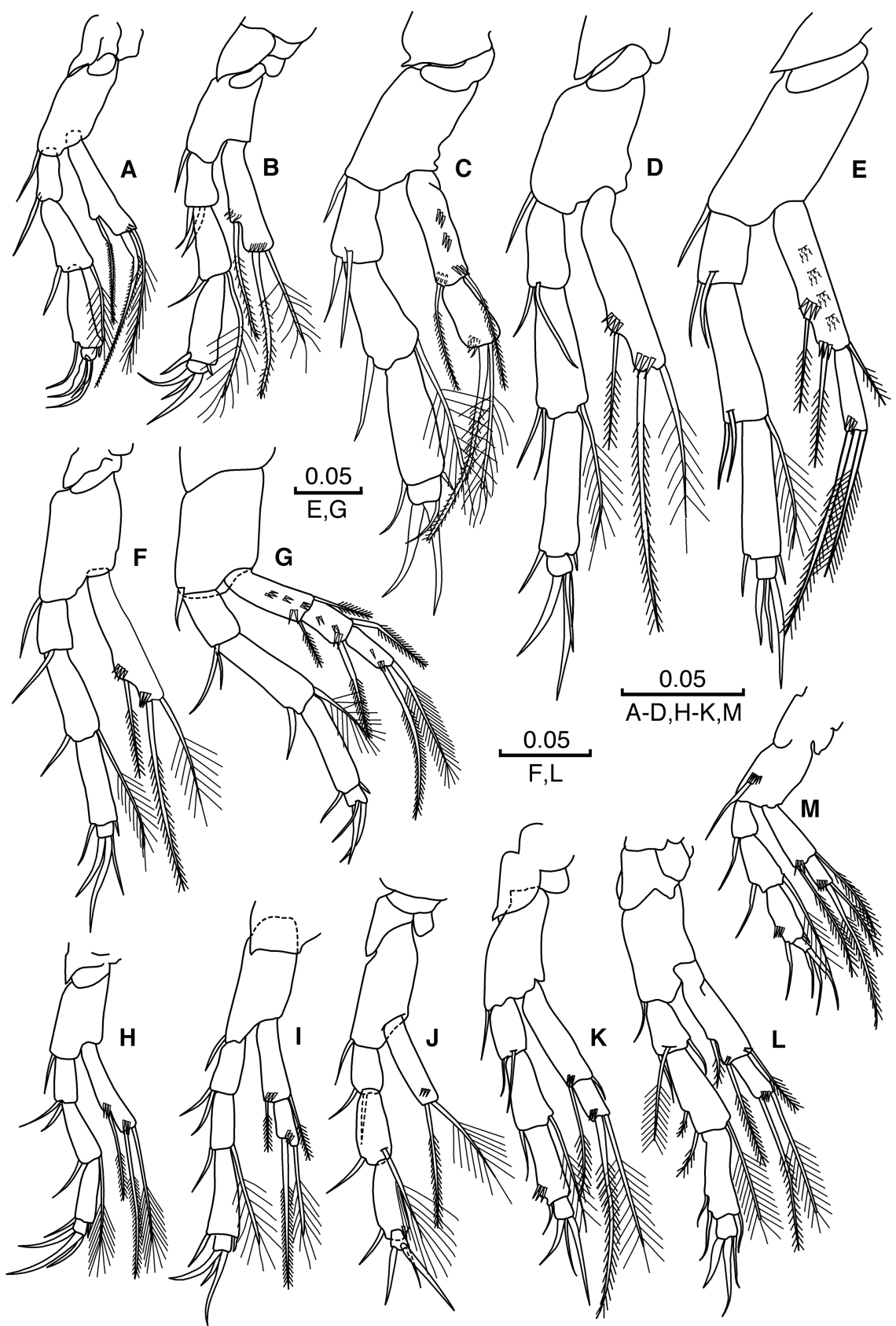

FIGURE 13 Thoracopod I: A. Iberobathynella lamasonensis; B. I. cornejoensis; C. Iberobathynella burgalensis; D. I. andalusica; E. I. paragracilipes; F. Hexaiberobathynella hortezuelensis; G. Paraiberobathynella notenboomi; H. I. pedroi; I. Guadalopebathynella puchi; J. Californibathynella californica; K. Texanobathynella aaronswinki; L. Montanabathynella pecosensis; M. Parabathynella motasi. 

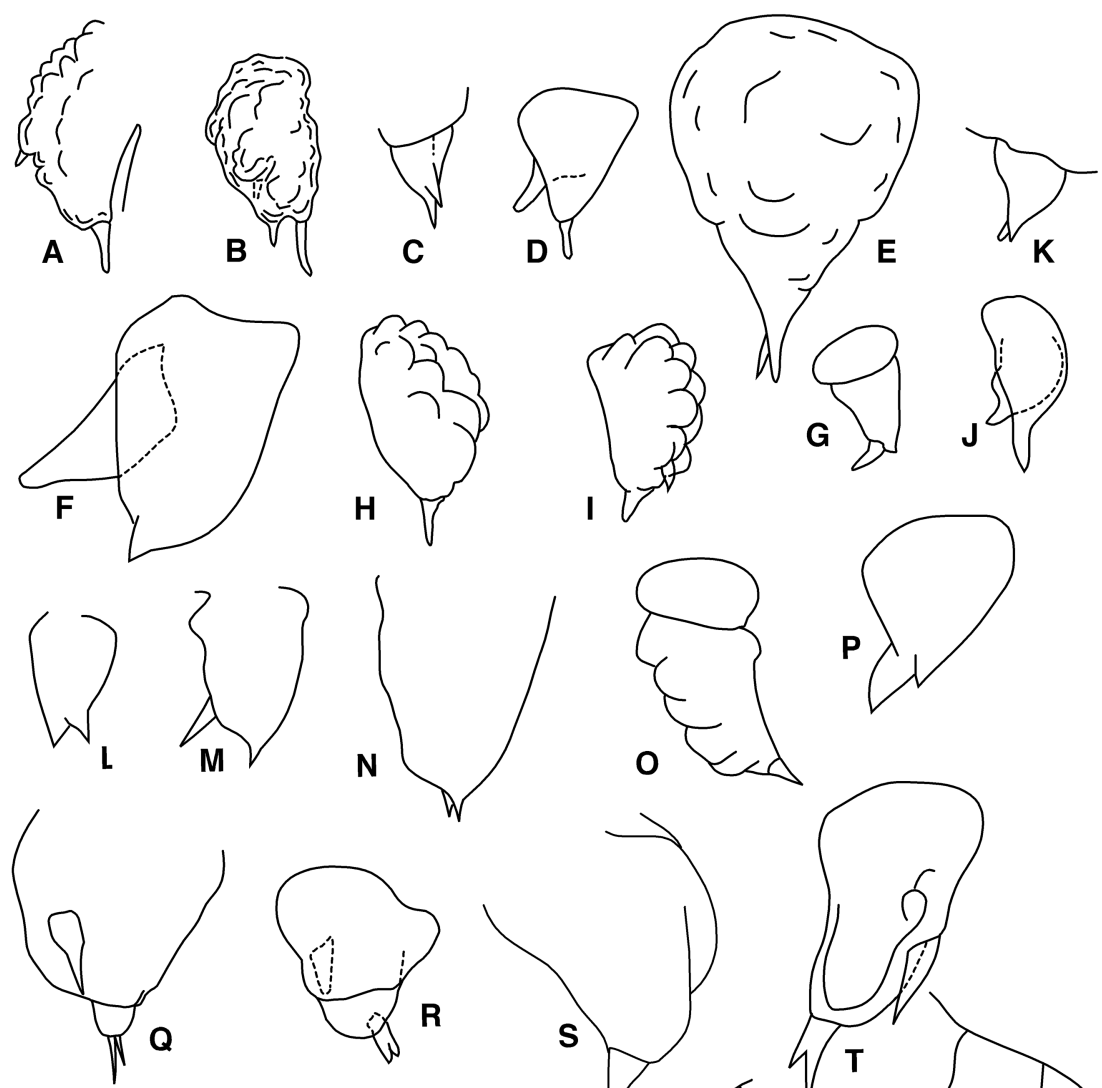

$\mathbf{S}$
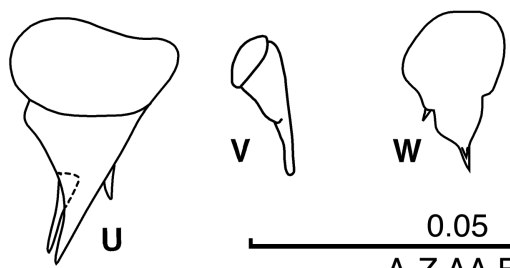

\subsection{5}

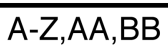<smiles>[X]C1CCCC1[X]</smiles>

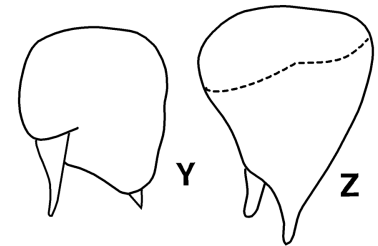

AA
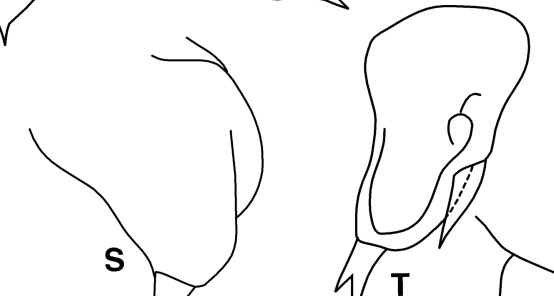

$$
\text { . }
$$



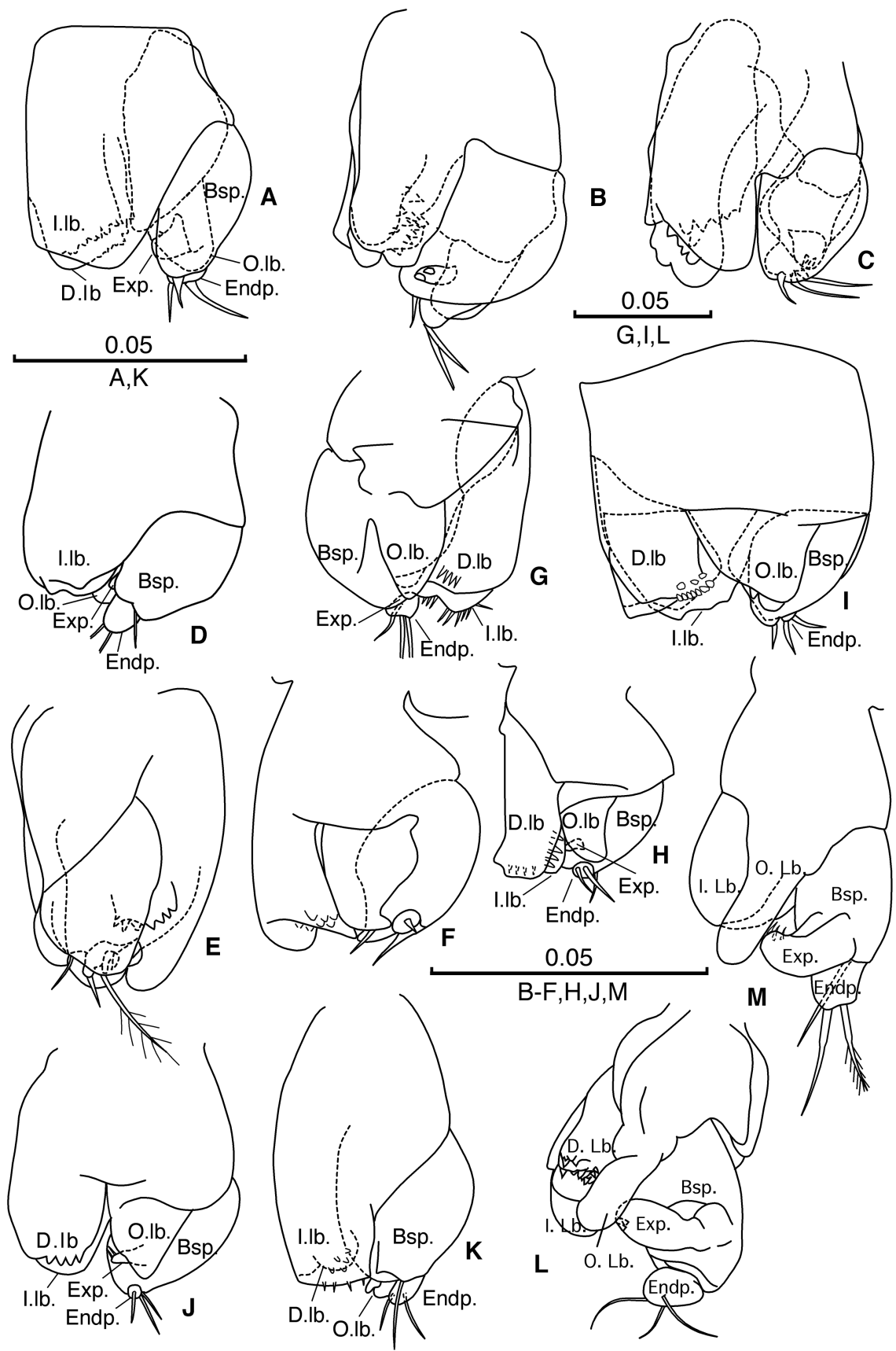

FIGURE 15 Male Th VIII: A. Iberobathynella burgalensis; B. I. lamasonensis; C. I. cornejoensis; D. I. andalusica; E. I. pedroi; F. Californibathynella californica; G. I. paragracilipes; H. Hexaiberobathynella hortezuelensis; I. Paraiberobathynella notenboomi; J. Guadalopebathynella puchi; K. Texanobathynella bowmani. L. Montanabathynella pecosensis; M. Parabathynella motasi. Abbreviations: Bsp, basipod; D.lb, dentate lobe; Endp, endopod; Exp, exopod; I.lb, inner lobe; O.lb, outer lobe. 


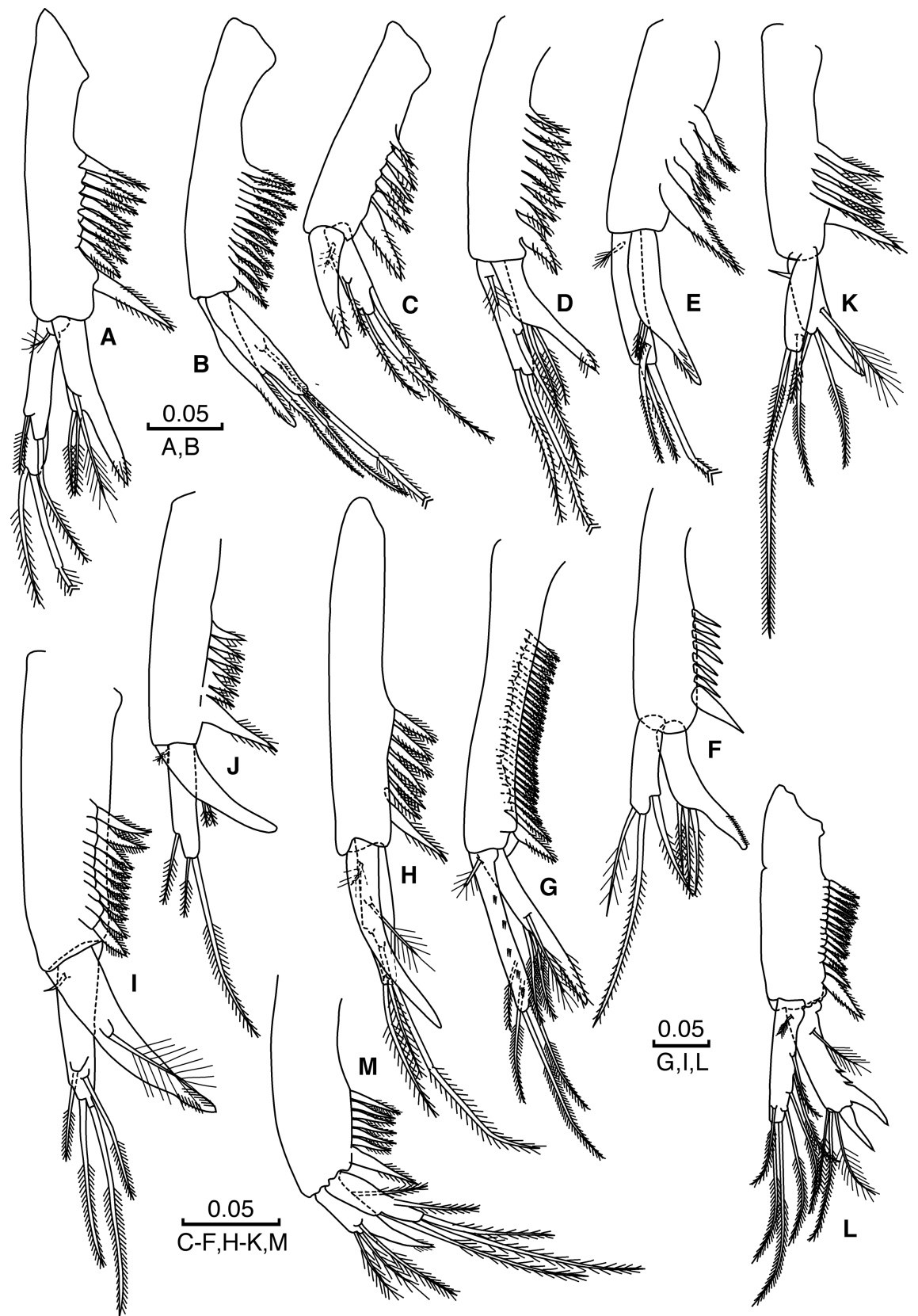

FIGURE 16 Uropod: A. Iberobathynella andalusica; B. I. burgalensis; C. I. cornejoensis; D. I. lamasonensis; E. I. pedroi; F. Texanobathynella bowmani; G. I. paragracilipes; H. Guadalopebathynella puchi; I. Paraiberobathynella notenboomi; J. Hexaiberobathynella mateusi; K. Californibathynella californica; L. Montanabathynella pecosensis; M. Parabathynella motasi.

(fig. $11 \mathrm{D}, \mathrm{E}$ ) and Iberobathynella (fig. $11 \mathrm{~F})$, and also in I. pedroi (fig. ${ }_{11 C}$ ). Paraiberobathynella and Californibathynella each have seven teeth (fig. $11 \mathrm{G}, \mathrm{J}$ ); Hexaiberobathynella and
Guadalopebathynella have six (fig. $11 \mathrm{H}$, I); Texanobathynella has five (fig. $11 \mathrm{~K}$ ); Montanabathynella has eight to nine (fig. 11M) and Parabathynella has five (as in P. motasi, 


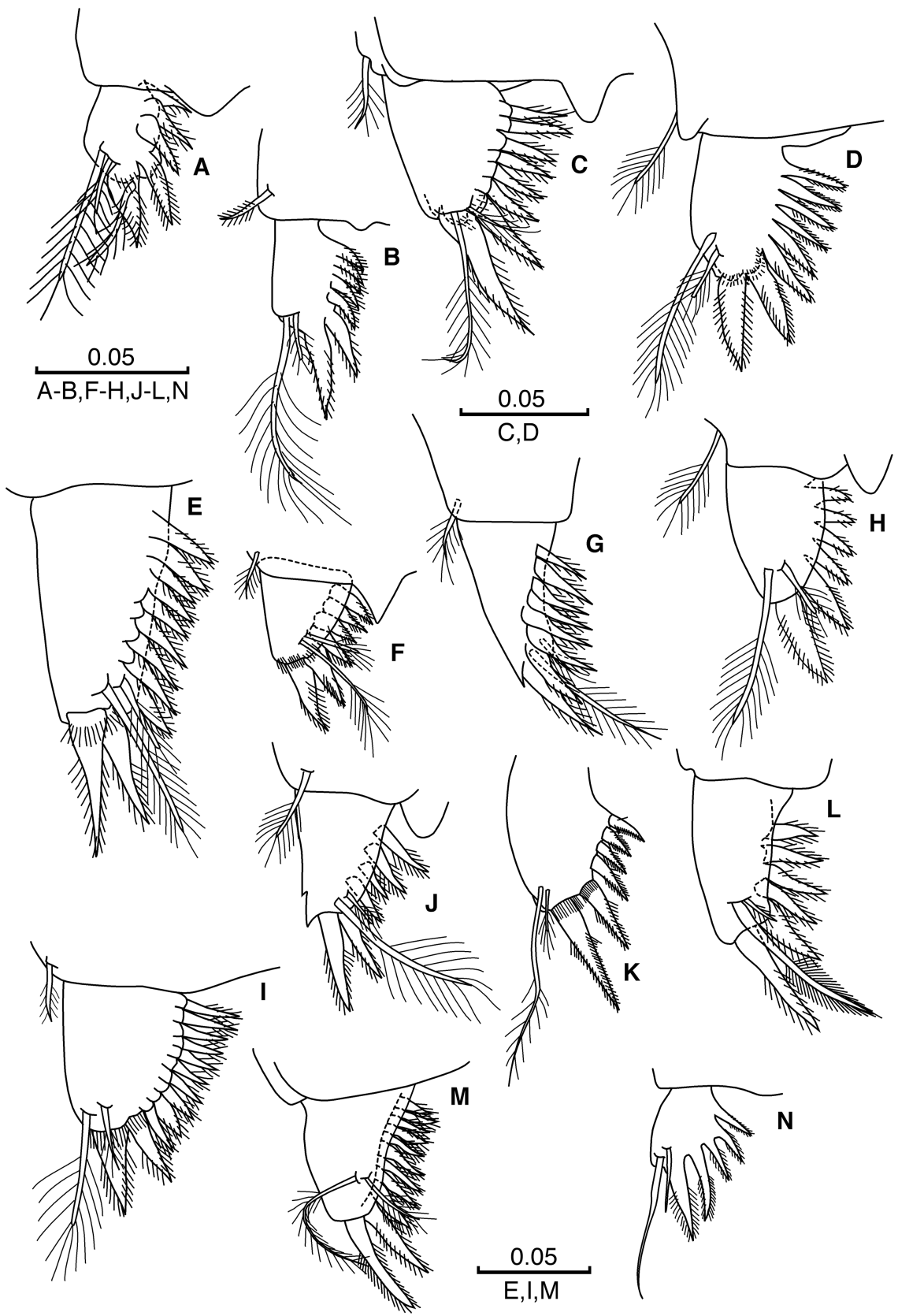

FIGURE 17 Furcal rami: A. Iberobathynella cornejoensis; B. I. lamasonensis; C. I. andalusica; D. I. burgalensis;

E. I. paragracilipes; F. I. pedroi; G. Guadalopebathynella puchi; H. Hexaiberobathynella mateusi;

I. Paraiberobathynella notenboomi; J. Californibathynella californica; K. Texanobathynella bowmani;

L. T. aaronswinki; M. Montanabathynella pecosensis; N. Parabathynella motasi.

fig. $11 \mathrm{~L})$ to six or nine. The three subterminal smooth setae on the outer distal margin, common in the family Parabathynellidae, are of different lengths, which differ among the species of the tribe.
Maxilla (fig. 12): The three segments comprising maxilla differ in size in the different species, however, the third segment is always the longest, and the second, the shortest. In the proximal segment, most species of the 
tribe present a single seta (fig. 12A, B, D, E, F-I, $\mathrm{J})$; the two species of Hexaiberobathynella lack setae (fig. $12 \mathrm{H}$ ), as do the species I. asturiensis, I. parasturiensis, I. cavadoensis, I. ortizi, I. lamasonensis (fig. ${ }_{12} \mathrm{C}$ ), I. serbani and I. guarenensis, all of the subgenus Asturibathynella, and $I$. pedroi. The two species of Montanabathynella have two setae (fig. 12K), as do the species of Parabathynella except P. motasi (fig. $12 \mathrm{~L}$ ), which has one. In the second segment, species of Iberobathynella have four setae (fig. $12 \mathrm{~A}-\mathrm{D})$, as do those of Guadalopebathynella (fig. ${ }_{12} \mathrm{H}$ ), Hexaiberobathynella (fig. ${ }_{12} \mathrm{~F}$ ) and Californibathynella (fig. 12I), whereas Paraiberobathynella has three (fig. $12 \mathrm{G}$ ); Texanobathynella has two, three or four (fig. 12J); Montanabathynella has four or five (fig. $12 \mathrm{~K}$ ) and Parabathynella has two, four or five (fig. $12 \mathrm{~L}$ ). The number of setae in the third segment of MxII (or third and fourth together) varies very little, between 14 and 16 , among genera and species of the tribe (fig. 12A-J) (some specimens of different species of Texanobathynella present 13 setae). Montanabathynella presents between 19 and 21 setae (fig. $12 \mathrm{~K}$ ), and P. motasi (fig. $12 \mathrm{~L}$ ) and P. stygia Chappuis, 1926 have 12 and 14, respectively, but $P$. badenwuerttembergensis Fuchs, Hahn \& Cho, 2012 has 20.

Thoracopod I (fig. 13): All species of the tribe lack an epipod on this leg (fig. 13A-K), as do the species in the genera Montanabathynella (fig. 13l) and Parabathynella (fig. 13M). The basipod has a smooth seta in the distal outer margin. The exopod may have one segment (in 18 species) (fig. 13A, B, D, F, H, J), two segments (fig. ${ }_{13} \mathrm{C}, \mathrm{E}, \mathrm{H}, \mathrm{I}, \mathrm{K}$ ), (in 14 species) or, in the case of two species of the Paraiberobathynella (fig. $\left.{ }_{13} \mathrm{G}\right)$ three segments. Irrespective of segment number, the exopod is always shorter than the endopod. Normally, setation consists of three setae in the first or single segment (except in Californibathynella, which only has two distal setae in its single segment) (fig. 13J) and two terminal setae (of which, one is always plumose) in the second and, when present, third segments (fig. $13 \mathrm{G}$ ); clusters of ctenidia present at the base of setae and on the posterior side (fig. ${ }_{13} \mathrm{C}, \mathrm{E}, \mathrm{G}$ ). Endopod consists of four segments of different sizes: the first is about half the length of the second and third, which are similar in length, and the fourth is very small; on the fourth segment, species of the Iberobathynellini tribe and those in the genera Montanabathynella and Parabathynella all present two terminal (claw-like) setae of different lengths and a shorter subterminal seta; on the third segment all genera have two distal setae (except Texanobathynella, which has only one or no internal seta; fig. $13 \mathrm{~K}$ ), the internal one resembles to a small spine; on the first and second segments, the setation is variable, with different species sharing setal formulas: the formula (1-2-2-3) is shown by some species of the subgenus Asturibathynella (fig. 13A) and by Hexaiberobathynella (fig. $13 \mathrm{~F}$ ); (2-2-2-3), by species of the subgenera Asturibathynella (fig. ${ }_{13} \mathrm{~B}$ ) and Espanobathynella (fig. ${ }_{13} \mathrm{C}$ ) and by Guadalopebathynella (fig. 13I) and Californibathynella (fig. 13J); (2-3-2-3), by Iberobathynella (fig. ${ }_{13} \mathrm{E}$ ) and some species of the subgenera Espanobathynella (fig. ${ }_{13} \mathrm{D}$ ) and Paraiberobathynella (fig. ${ }_{13} \mathrm{G}$ ); in Texanobathynella, there are three different combinations among the five species: (1-2-1-3) (fig. $\left.{ }_{13} \mathrm{~K}\right),(2-2-1-3)$ and (2-1-0-3). Montanabathynella (fig. ${ }_{13} \mathrm{~L}$ ) and Parabathynella (fig. $13 \mathrm{M}$ ) present other combinations with more setae in the first three segments (see table 4 for details). The internal seta of the second endopod segment is always plumose.

Thoracopods ii-vii: All species of the Iberobathynellini tribe have epipod on thoracopods II to VII, and one outer distal smooth seta on the basipod; Montanabathynella lacks an epipod on thoracopods II and III. The exopod, which is always shorter than the four segments of the endopod, consists of two segments in most species of the tribe, except $I$. magna (three segments in thoracopods IV and Downloaded from Brill. come4/28/2023 03:32:19PM 
v) and species of Paraiberobathynella (three or four segments) and Texanobathynella (three segments in some thoracopods) (see table 4); Montanabathynella can have between two and six segments, and in these cases, the exopod is longer than the endopod, and Parabathynella has two segments in all thoracopods, except in P. badenwuerttembergensis, which has two, six or seven segments in thoracopods IV and $\mathrm{v}$; two terminal barbed setae are commonly present on each segment and, on the last one, one of the setae is plumose; ctenidia groups present at the base of the setae and on the posterior side. The endopod consists of four segments of different sizes: the first is about half the length of the second and third, which are similar in length, and the fourth is very small; segment one short and without setae except in the species of the subgenus Iberobathynella that have a terminal inner plumose seta (also found in species of Montanabathynella and $P$. badenwuerttembergensis); segment two with two groups of lateral ctenidia and two setae, one plumose and one smooth (absent on thoracopod VII and sometimes thoracopod VI); segment three with one tiny seta (except in Texanobathynella) and segment four with one seta and two similar strong claws.

Female thoracopod viii (fig. 14): The eighth pair of thoracopods is greatly reduced in species of the Parabathynellidae family. In the tribe Iberobathynellini (except the genus Texanobathynella) it reduced to a simple segment with a relatively triangular appearance, a wrinkled (in six species of the subgenera Asturibathynella and Espanobathynella, fig. 14A, B, E, H, I, O) or smooth cuticle (fig. 14C, D, F, G, J-N, P-Z), one, two or three small teeth and without setae (fig. 14A-Z); in Texanobathynella, it has a scale-like appearance with small terminal denticles (fig. 14AA, BB). Thoracopod VIII in females of Montanabathynella consists of two segments of similar length (basal segment slightly wider than the second one) (fig.
14CC, DD); Parabathynella also has two segments but the basal segment is slightly longer than second one (fig. ${ }_{14} \mathrm{EE}$ ). In both cases, denticles are present on the first segment, and three setae, on the second.

Male thoracopod viii (fig. 15): Its general appearance is almost square in most species of the tribe (fig. $15 \mathrm{~A}-\mathrm{D}, \mathrm{F}-\mathrm{H}, \mathrm{J}$ ), rectangular in I. pedroi (fig. $15 \mathrm{E}$ ) and in species of Texanobathynella (fig. $15 \mathrm{~K}$ ) and trapezoidal in Paraiberobathynella (fig. 15I); very large (twice as long as wide) in Montanabathynella (fig. ${ }_{15} \mathrm{~L}$ ) and elongated in Parabathynella (fig. $15 \mathrm{M}$ ). In species of the Iberobathynellini tribe, the penial region has three lobes: an outer lobe (O.lb), a dentate lobe (D.lb) and an inner lobe (I.lb). Montanabathynella has an additional lobe, the small lobe (S.lb) (fig. ${ }_{15} \mathrm{~L}$ ), and Parabathynella has three lobes, the outer, inner and small lobes, but not a dentate lobe (fig. $15 \mathrm{M}$ ). In all species of the tribe, the outer lobe of the male thoracopod VIII is well developed, in both length and width, the main axis of the lobe can be vertical or inclined on the posterodistal or anterodistal side, partially fused with the basipod at the level of the basal parts of the posterior edge of the lobe and the anterior face of the basipod (Serban, 1977) and is distinctive as a massive element of the lateral face always close to the endopod. The outer lobe differs in the various species: in the subgenera of Iberobathynella, it is rectangular with a sloping main axis in Espanobathynella (fig. 15A, D); orientated towards the posterior part and with a curved main axis in Asturibathynella (fig. ${ }_{15} \mathrm{~B}, \mathrm{C}$ ) and triangular with vertical main axis in Iberobathynella (fig. $15 \mathrm{G}$ ); and in the other genera, it has a posterior part that is longer than the anterior part and a rectangular lateral side in Guadalopebathynella (fig. 15J); a distal part orientated towards the posterior side in Californibathynella (fig. ${ }_{15} \mathrm{~F}$ ); an outer lobe smaller than the dentate lobe, 
with a triangular- or trapezoidal-shaped distal end in Paraiberobathynella (fig. 15I); triangular with setules on the distal end of the inner lobe in Texanobathynella (fig. $15 \mathrm{~K}$ ) and, in Hexaiberobathynella (fig. $15 \mathrm{H}$ ) and anterior part shorter that is shorter than the posterior, a distal part strongly inclined toward the caudal part and a postero-distal inclination on the main axis; the outer lobe in Parabathynella is narrow and slightly longer than the exopod, and is not fused with the basipod (fig. $15 \mathrm{M}$ ). The dentate lobe has between eight and 12 small teeth. The inner lobe, generally larger than the dentate lobe, may have small setules on the distal edge, as in the subgenus Iberobathynella (fig. $15 \mathrm{G}$ ) and in I. asturiensis and I. espaniensis, or small spinules as in Texanobathynella (fig. $15 \mathrm{~K}$ ). The basipod (Bsp) is more or less conical and has a seta on the latero-external face of its distal end. The exopod, which is on the latero-external side of the basipod and covered by the outer lobe, is greatly reduced in all species of the Iberobathynellini tribe, and due to its small size, is the most difficult structure to observe in these species (fig. $15 \mathrm{~A}-\mathrm{K})$; sometimes with small teeth or denticles; Parabathynella has a row of small spines. Endopod always present, with distal end oriented on the latero-external side and with two setae; also present in Parabathynella (fig. 15M) and Montanabathynella (fig. $15 \mathrm{~L}$ ).

Pleopod: The first pair of pleopods, reduced to simple setae, is only present in Californibathynella californica. The other 32 species of the tribe, and those of Montanabathynella and Parabathynella, do not present pleopods nor simple setae.

Pleotelson: Dorsal margin of pleotelson with anal operculum not pronounced in most species of the tribe ( 21 species) and pronounced in the rest (13 species), including eight species of the subgenus Asturibathynella, one of Espanobathynella, I. pedroi, the two species of Hexaiberobathynella and the one of
Californibathynella. Montanabathynella salish and $P$. motasi have a pronounced anal operculum but little protrusion.

Uropod (fig. 16): The sympod is considerably longer than wide in all species of the tribe, and almost always twice as long as the exopod and endopod; it has a row of spines that are equal in size (homonomous), as in the species I. burgalensis (fig. 16B), I. magna, I. cantabriensis and Pi. notenboomi (fig. 16I), or it has a row of spines in which the distal one is greater than the rest (inhomonomous) (fig. 16A, C-F, H, J-K); Montanabathynella (fig. 16L) and Parabathynella (fig. 16M) present an inhomonomous row of spines, similar to most species of the Iberobathynellini tribe; the row of spines can occupy half to two thirds of the sympod or almost its entire length (as in I. pedroi, fig. 16E); the number of spines is highly variable, between nine and 27 in the species of the subgenus Iberobathynella (fig. 16G) and between five and 13 in the subgenera Asturibathynella (fig. 16C, D) and Espanobathynella (fig. 16A, B) and in the rest of the tribe species (fig. 16E, F, H-K); species of Montanabathynella have 15 spines (fig. 16L) and those of Parabathynella, between six and 18 (fig. 16M). The endopod, in lancet form, has approximately the same length as the exopod in almost all species; it may lack setae (only I. cornejoensis and I. burgalensis, fig. 16B, C) or have one [nine species, including all of Paraiberobathynella (fig. 16I) and G. puchi (fig. 16H)], two [nine species (fig. 16D, E) including those of Hexaiberobathynella (fig. 16J)] or three (17 species, fig. 16A, F, G, K) setae that may be smooth, barbed or plumose and of different lengths. Exopod with apical and subapical setae (between two and five) and with (fig. 16A, C, D, E, G-K) or without (fig. 16B, F) a basal seta on the internal side; Montanabathynella (fig. 16L) has between seven and 11 setae, and Parabathynella, between four and eight (fig. 16M). 
Furcal rami (fig. 17): The general shape is triangular or trapezoidal, with a variable number of spines, from five or six (as in I. cornejoensis, I. pedroi, Hi. mateusi, Californibathynella and Texanobathynella, fig. $17 \mathrm{~A}, \mathrm{~F}, \mathrm{H}, \mathrm{J}-\mathrm{L})$ to 12 or 13 (as in I. paragracilipes and Pi. notenboomi, fig. $\left.{ }_{17} \mathrm{E}, \mathrm{I}\right)$, and the two most distal spines are always larger; Montanabathynella has 11 to 14 spines (fig. $17 \mathrm{M}$ ) and Parabathynella has five to 10 (fig. ${ }_{17} \mathrm{~N}$ ). On the dorsal side, the furcal rami have two plumose setae of different lengths.

\section{Discussion}

The results of the morphological and molecular analyses of the Iberobathynellini tribe reveal the need to address the complex group of poorly delimited morphological species using integrative approaches. The morphological, molecular and combined cladograms show the non-monophyletic status of some subgroups and a lack of congruence needed to consider the current taxonomic organization as resolved. The existence of cryptic species and the underestimation of the true diversity of this amphiatlantic group of crustaceans are also highlighted.

\section{Taxonomic status of the Iberobathynellini tribe based on morphology}

Delamare Debouttevile, Serban \& Coineau (1975), in their description of the first species of the Parabathynellidae family found in North America, Texanobathynella bowmani from Texas, highlighted its similarity with species of the genus Iberobathynella, particularly with respect to the structure of ThVIII in the male, the reduction of AII and the morphology of the labrum, uropod and furca. Subsequently, Schminke \& Noodt (1988), who discovered the second North American species, Iberobathynella californica from California, considered Texanobathynella as synonymous with Iberobathynella. Regarding their new species I. californica, they remarked: "The new species shows the diagnostic features of the genus Iberobathynella: antennules 7-segmented; antennae 3-segmented with (4) setae only on distal segment; maxillae 3-segmented, second segment with characteristic seta on inner surface; coxa of thoracopods i-vii with typical conical projection at inner distal border; sympodite of uropods with row of unequal spines; exopod of uropods with basiventral seta". Regarding the differences between I. californica and T. bowmani, they write: "Iberobathynella californica and Iberobathynella bowmani, new combination, can be distinguished by the number of spines on the sympodite of the uropods, by the number of segments of the exopods of thoracopods i-vii, by the number of teeth on the labrum, by the number of segments of the antennules, and by the fact that the first pleopods of I. californica are represented by a pair of setae lacking in I. bowmani".

Camacho and Serban (1998) later reviewed the group in light of new species found in the Iberian Peninsula and offered a new point of view on the systematics of the group by erecting tribe and subtribe categories, in an attempt to better understand the relationships within the group. These authors, for various reasons, considered the species from California distinctive from Iberobathynella and erected the genus Californibathynella. They also considered Texanobathynella as a valid genus (Camacho \& Serban, 1998, 2000). Subsequently Schminke (2011) accepted both of these proposals. At present, the tribe consists of 33 nominal species and three cryptic ones. Here, we have updated information about the character states and their distribution across the morphotypes.

The results of the morphological phylogenetic analysis (fig. 5) does not support the monophyly of the Iberobathynellini tribe with respect to the genera Parabathynella and 
Montanabathynella (i.e., the other two genera of the family present in Europe and North America, respectively). Montanabathynella and Parabathynella appear within the Iberobathynellini tribe. In the combined morpho-molecular dataset the tribe appears monophyletic, however the genera without molecular data are excluded. Also, according to this analysis, at the subtribe level, only Hexaiberobathynellina (with its single genus Hexaiberobathynella) is monophyletic based on the morphological characters used. The internal relationships among subgenera and species are not well resolved either.

Previous phylogenetic reconstructions of Iberobathynellini based on 19 morphological characters (and 14 species) also did not resolve these internal relationships (Camacho et al., 2000; Guil \& Camacho, 2001; Camacho et al., 2006). Those studies used another set of characters that were ordered (polarized) according to criteria that were widely accepted at the time (Schminke, 1974; Schram, 1984, Camacho, 1987; Coineau, 1996; Camacho et al., 2000). They also assumed the reduction of structures (spines, seta, segments, among others) as a common trend $(\mathrm{o}=$ plesiomorphic and 1 or 2 $=$ apomorphic states). These previous studies hypothesized that the phylogenies will gradually become more precise as new species and populations are discovered, allowing for more a robust assessment of kin relationships (Camacho \& Serban, 200o; Camacho et al., 2000; Guil \& Camacho, 2001; Camacho et al., 2006). However, a great deal of uncertainties remains, despite the fact that new species have been described and included in more recent analyses. The set of characters used here defines an almost complete morphospace with all possible states for each of the characters, without any polarization to avoid the subjectivity of previous assumptions. Despite this, the resolution of some relationships remains very low.

\section{Phylogenetic hypothesis for the Iberobathynellini tribe}

The phylogenetic reconstruction of the Iberobathynellini tribe based on morphological data (see fig. 5) does not supports the monophyly of the tribe and it also lacks the necessary resolution to shed light on kinships between and within internal groups, and shows the limited validity of the subtribes and subgenera that were erected by Camacho \& Serban (1998) to help organize the taxonomy of the group. These categories were useful at the time to understand the relationships within the group formed by the four Iberian genera (Iberobathynella, Guadalopebathynella, Hexaiberobathynella and Paraiberobathynella), the two North American genera (Californibathynella and Texanobathynella) and the African species, Pi. maghrebensis (Camacho \& Serban 1998). However, these categories are no longer suitable for the tribe: despite they are more species (10) described, also included in our analyses, the previously considered categories are not monophyletic. The phylogenies obtained from the molecular and combined analyses (see fig. 2 and 6) are largely congruent, and also support the invalidation of the subtribe and subgenera categories, even though the combined analysis did not include some information for the genera Californibathynella, Guadalopebathynella Hexaiberobathynella and the subgenus Iberobathynella (Iberobathynella). Comparisons between the Iberobathynellini tribe and the other two genera of the family present in North America or Europe, and the cosmopolitan genus Hexabathynella, clearly show the monophyly of the tribe and its sister group relationship with the two well-defined genera Montanabathynella and Parabathynella.

Exclusively representatives of the genera of the family that live in the area of the study have been analyzed, excluding other genera of the Parabathynellidae family from all over the world (Australia, India, Asia ...) 
that were already analized globally in previous papers (Camacho et al., 2018b; Camacho et al., 2021a). Our study tries to find the relationships between the genera of the Parabathynellidae family that inhabit Iberian Peninsula and North America using as outgroup Hexabathynella, the only cosmopolitan Bathynellacea genus. We have also used Hexabathynella as outgroup because it is very different from other genera and has only 6 pairs of legs, a character only shared with the Iberian genus Hexaiberobathynella belonging to the Iberobathynellini Tribe. Since the two genera are distantly related, this character is most likely the product of convergent evolution.

We previously found several morphotypes inhabiting some of the same caves in northern Spain (CO2O9 and CO314, among others) that we associated with the nominal species I. parasturiensis, I. imuniensis, I. cantabriensis and I. magna (Camacho et al., 20o6). Despite the morphological differences observed between the specimens from both caves, our analysis of their COI sequences, along with those of specimens of the four species collected from their respective type locality (supplementary table S2), showed that, in Cave co2og, all the specimens belong to only two of the nominal species, namely I. parasturiensis and I. cantabriensis, and that, in Cave CO314, the specimens correspond to these two species plus two new species, $I$. sp. nov. 1 and $I$. sp. nov. 2, which are morphologically identical to I. magna and I. imuniensis, respectively. The genetic divergence between the new species and their respective nominal species is very high (18.5\% and $16.1 \%$, respectively; see supplementary table $\mathrm{S} 2$ ), supporting their designation as cryptic species. After revising the specimens from Fonda and Astui caves, which are morphologically similar to the nominal species I. imuniensis but diverge with it by $14.7 \%$ to $15.6 \%$, we propose that they belong to a new species, $I$. sp. nov. 3 , unrelated to $I$. sp. nov. 2 (genetic distances between $18.1 \%$ and $21.3 \%$ ) (supplementary table $\mathrm{S} 2$ ).

Wide species distribution presented in fig. 1 and supplementary appendix $S_{2}$ for Hexaiberobathynella mateusi (25 populations from Oporto to Castellón, Granada and Jaén passing through Madrid, Guadalajara, Toledo, Soria, Teruel and Huesca), Iberobathynella imuniensis (32 populations from Asturias, Cantabria, Burgos to Alava and Huesca) and Paraiberobathynella fagei (45 populations, from South France to Cadiz, and to Asturias and Mallorca Island) must be taken with caution since these species could represent cryptic species. Unfortunately the absence of molecular data does not allow to verify the presence of cryptic species and related distributional ranges.

Morphological simplification is extreme in Bathynellacea: due to progenetic development, Bathynellacea reach adulthood at a stage corresponding to the ancestral last larval stage (Schminke, 1981). The absence of morphological distinguishability between subterranean species may be related with three mechanisms: niche conservatism, recent divergence or morphological convergence (Trontelj et al., 2012; Meleg et al., 2013; Zagmajster et al., 2018). A homogeneous geographic distribution of cryptic species, with high cor genetic divergences, can occur because these three mechanisms offset each other along spatial or environmental gradients (Eme et al., 2018). Phylogenetic interpretations in cases of convergent evolution can be misleading if they are based only on morphology (Lefébure et al., 2007). To investigate possible morphological convergence, we performed ancestral state reconstructions for five characters representative of morphological differences between groups (see figs. 7 and 8), however, given low support at the nodes, we cannot draw robust conclusions 
from these analyses. Some of the preliminary results of our study, along with those of other studies, such as the phylogenetic study of Australian Parabathynellidae by Abrams et al. (2012), contradict paradigms, including the evolutionary hypothesis that species tend to evolve towards a more simplified body structure with reduction of segments, setae and other structures. However, this hypothesis towards simplification, argued as the basis for many phylogenetic reconstruction analyses (for polarity discussion, see Schminke, 1973, 1974; Schram, 1984; Camacho, 1987, Camacho et al., 200o; Coineau, 1996; Hong \& Cho, 2009; Bandari et al., 2017), is debatable.

The number of segments of antennule, antenna and exopod of thoracopods are characters that have been previously used to define genera and to assess the oligomerization principle (i.e., serial appendage reduction over time), which is commonly invoked in crustacean systematics (Adamowicz et al., 2007) to infer which character state is plesiomorphic or apomorphic. However, given the high occurrence of convergent morphologies in parabathynellids, it is necessary to determine whether the characters used to define genera and species are homoplastic and therefore useless to infer phylogenetic relationships. Previous molecular analyses on Parabathynellidae from different countries (Camacho et al., 2018b; Camacho et al., 2021a) highlighted the paucity of the data available to create a robust phylogeny for the family. Fresh material from type localities (especially from Africa, South America, Asia) should be collected to obtain sequences that could clarify the relationships amongst genera. Also, there are many unexplored areas in all continents that most likely host new species (Bolivia, Argentina, Chile, Brazil, Perú, Mexico, China, Philippines, Malasia, Thailand, Mozambique, Malawi, Zambia, Syria, Turkey ...).
The reality is that there are very few countries/regions that have been heavily/systematically sampled for interstitial/subterranean fauna. Many European countries have a long speleological "tradition" and many cavers sampled several caves throughout the last century. The arid zones of Western Australia are also heavily sampled due to mining developments and environmental legislation. Unfortunately, for the rest of the world subterranean sampling events are just sporadic and opportunistic.

\section{Updated distribution and a palaeobiogeographic scenario}

The Iberobathynellini tribe is distributed across three continents [Europe (Iberian Peninsula), North America (Texas and California) and Africa (the Maghreb, Morocco and Algeria)], with a presumed origin in Laurentia (Camacho, 2003a; Camacho et al., 2018b). In the Iberian Peninsula, the geo-palaeobiological conditions of the Lower Triassic, and an extensive marine domain, favoured the colonization of the continental environment by a common ancestor of the tribe (Camacho et al., 2006). This ancestor may have been present in coastal habitats along the margins of landmasses during the Middle Triassic (238 Mya) (Camacho et al. 200o; Coineau \& Camacho, 2013) when the Iberian Peninsula, North America and North Africa were still linked. This scenario is the most plausible explanation for the existence of these phylogenetically closely related species on these three continents, particularly given that they have no effective intrinsic dispersal mechanism (Coineau \& Camacho, 2013).

The Mesozoic continental split that broke up Pangea (Schram, 1977) may have been the vicariant event responsible for the divergence of the ancestral clade (Coineau \& Camacho, 2013). Continental drift further subdivided the area during the Early Triassic 
(245 to 205 Mya; Golonka, 2007), when the Iberian Peninsula and North America started to separate (Yilmaz et al., 1996) and when parts of present-day Portugal, Galicia and Salamanca, as well as California and Texas, had already emerged (Yilmaz et al., 1996), coinciding with the earliest divergence in iberobathynellids (Coineau \& Camacho, 2013). The break-up of Laurasia has played a major role in shaping the present-day distribution not only in the Bathynellacea but also in other ecologically similar and phylogenetically distant taxa as subterranean amphipod Metacrangonyctidae (BauzaRibot et al., 2012; Pons et al., 2019). The family Metacrangonyctidae lives in caves, wells and other subterranean habitats, as Bathynellacea, in areas covered by the sea in the geological past in several Mediterranean islands (Mallorca, Menorca), and Morocco in North Africa (Pons et al., 2019). The earliest divergences in the Iberobathynellini tribe coincide with the separation of the Iberian Peninsula and Africa, around 100 Mya (Camacho et al., 200o). The ancestor of Paraiberobathynella must have lived on the Tethys seashore and, as suggested by its present distribution, colonized emerged land before the Senonian (88.5 to 65 Mya) when the island of Mallorca, the Iberian Peninsula and the Alboran plate were all still part of the same landmass (Yilmaz et al., 1996; Camacho et al., 200o, Camacho et al., 2018b).

Europe and North America were connected by a land bridge during the late Eocene ( 34 Mya), possible disjunct species between these two areas would have diverged at least at the end of the Eocene (Smith \& Donoghue, 2010), in this case we should find young divergences between taxa. This scenario is consistent with our dating for the separation date between Montanabathynella (North American genus), Parabathynella (European genus) and Texanobathynella. (fig. 7).
The presence of Iberobathynellini in the Cantabric and central Iberian Peninsula can be explained by marine regressions. The ancestor is hypothesized to have colonized these areas of transitional karst-marine facies during the Upper Cretaceous (96-65 Mya) (Yilmaz et al., 1996; Camacho et al., 2006). From our molecular clock analysis, the TMRCA of the Iberobathynella/Paraiberobathynella group and Texanobathynella is dated at $76.8 \mathrm{Mya}$ (see fig. 4), consistent with the Upper Cretaceous colonization hypothesis. Vicariance at local level leading to new biogeographical barriers (faults) or local ecological changes likely influenced speciation and extinction events in the tribe, which were followed by small scale dispersal. The faults and thrusting associated with the Alpine Orogeny during the Cenozoic (63.7 Mya) (Yilmaz et al., 1996) could have been the vicariant processes responsible for the various lineages of Iberobathynella and their present-day distribution. In the Northern Hemisphere there were geological events during the Neogene (23 Mya) (Graham, 1999) that may have played a role in diversification: uplifting of the Rocky Mountains and erosion of the Appalachian Mountains and the formation of the Mountain ranges in Europe, which began in the Paleogene (65-23 Mya) (Thompson, 2005). The lack of molecular information on the Californian species of the Texanobathynella genus prevents us from making assumptions on the divergence on both North American coasts. According to our dating, in the Eocene (4o Mya) Iberobathynella species from Andalusia (I. andalusica and I. celiana) were able to diversify from the rest of species. Also, around 40 Mya, other speciation events within the tribe happened, as the diversification of the species from Burgos ( $I$. burgalensis, I. imuniensis and I. cornejoensis) and País Vasco (I. sp. nov. 3).

This scenario is consistent with the results of the divergence time analysis. The presence of 
species-rich areas associated with low phylogenetic diversity (i.e., areas inhabited by species with short evolutionary histories that group within the same clade) can reflect a process of recent and rapid in situ speciation. Such areas are known as "cradles of diversity" (Jablonski et al., 2006). Infierno Cave represents one such area: it is inhabited by the three closely related species I. espaniensis, I. asturiensis and I. parasturiensis that began to diverge around 41.8 Mya (95\% HPD: 29.3-55.1 Mya) (see fig. 2); the type of diversification that has occurred is an interesting pattern to explore. By contrast, the existence of areas with species displaying higher phylogenetic diversity (i.e., species with long independent evolutionary histories in different clades) suggests decreased extinction rates. These areas are defined as "museums", as diversity is preserved over time (Jablonski et al., 2006). An example is the Ojo Guareña system (Camacho \& Puch, 2021a), were species from different clades occur: I. burgalensis and I. cornejoensis [TMRCA: 39.8 Mya (95\% HPD: 28.9-52.8 Mya)].

The Late Miocene (11.63-5.33 Mya) was characterized by compression along the southeastern margin of Iberia in the Prebetic fold belt and in portions of the Balearic Islands. Westward break out of the Alboran Block opened the North Algerian Basin in its wake. The Alboran Block collided with the southeastern margin of Iberia and the northwestern margin of Africa during the late Oligocene/early Miocene (Yilmaz et al., 1996).

During the Middle Miocene (10.5 Mya) as a consequence of the progressive subduction S-SE of the Iberia ("European lithosphere") towards the "Backarc stretched area", which previously belonged to the "Alpine-Betic belt", new "Alpine-Betic belt" collides, moving towards N-NW. In the North of Africa, the "Apennines-Maghrebides Belt" collides. In this geodynamic framework of the western Mediterranean area, new basins formed (e.g., Algerian Basin and Provençal Basin). In the western area the "Alboran Sea" and "Valencia Trougth" bordered Iberia on the E and $\mathrm{S}$ and separated it from Africa (Andeweg, 2002; Rosenbaum et al., 2002; Carminati et al., 2012,). During Late Miocene, in the Alboran Sea there was the progressive formation of the Gibraltar Arc ("Alboran arc") to the approach of the Baetic Belt ("Alpine-Betic belt") in the South of Iberia and the Rif ("ApenninesMaghrebides Belt") in the North of Africa (Krisjgman et al., 2018). These tectonic movements in Tortonian times (11 Mya) can explain the speciation of Paraiberobathynella the Iberian Peninsula and North Africa (fig. 7), since it is consistent with the divergence time found (about 10 Mya). The lack of molecular data for specimens from Balearic Island populations (Paraiberobathynella cf. fagei) prevented their inclusion in the phylogenetic reconstruction analyses.

As new species and populations are found, and their molecular data analysed, more information can be gathered on the genetic divergence and phylogenetic relationships of the ancient group, Iberobathynellini tribe, to confirm the evolutionary history that extends at early Cretaceous, allowing for more robust species delimitations and divergence time estimations. These data will help to determine the most plausible palaeobiogeographic scenario for this tribe with an amphiatlantic distribution, and provide a better understanding of the current distribution and the true diversity. There is biogeographical congruence with the Holartic subterranean Crangonyctidae amphipod, a group of probably Early Cretaceous origin, that show similar distribution pattern (probably Laurasian origin) of old linages by vicariance (continental level) (Copilas-Ciocianu et al., 2019) as occur also in Metacrangonyctidae subterranean amphipods (Pons et al., 2019). It is interesting to find similar distribution patterns between 
subterranean crustaceans of ancient origin, phylogenetically distant but ecologically similar, which support the plausibility of the proposed biogeographic scenario.

\section{Conclusions}

A modern systematic revision of the Iberobathynellini tribe or "Iberobathynella group" using both molecular and morphological approaches, along with distribution data to delineate species from three continents, is presented here. Despite having information on 33 morphotypes that appear to encompass all the possible morphological variability of the group, and molecular data for 16 nominal and three cryptic species, these data are not sufficient to fully resolve all of the phylogenetic relationships of the group. However, the results of these analyses make it possible to highlight the following conclusions:

1. Subtribe and subgenus are invalid categories so they must be eliminated. However, we keep them in the supplementary material, so that it can be understood why it was necessary to create them when studying the morphological similarities and differences between the species. The systematics proposed in 1998 offered a coherent organization of the morphological variability exhibited by the morphotypes of the tribe at that time.

2. Paraiberobathynella needs to be revisited. At the moment we are going to point out that it may be that Paraiberobathynella has to be synonymous with Iberobathynella, but first we have to obtain DNA from fresh Pi.fagei specimens type locality and include them in the phylogeny to see their relationship with Iberobathynella. It could be that the populations found in Spain are cryptic species, morphologically identical to Pi. fagei, but in reality they are new Iberobathynella species and hence our populations are within a group of Iberobathynella species and the Paraiberobathynella genus could still be valid.

3. The molecular dating results support the early divergence of this group of ancient subterranean crustaceans and the vicariance by plate tectonics as main factor to explain the amphi-Atlantic distribution shown by Iberobathynellini Tribe. Cycles of marine transgressions and regressions, together with vicariance associated with the Alpine Orogeny (faults and thrusting) leading to new biogeographic barriers and local ecological changes may be the processes responsible for the distribution of lineages at local level. The separation of the lineage of the two Andalusian species (I. celiana and I. andalusica) of the rest of genus Iberobathynella is also early.

4. COI p-distances within-between species and genera vary greatly therefore it is not possible to apply a threshold on this group, but assess case by case with multiple evidence (morpho-molecular).

5. There are species morphologically very similar to I. magna and I. imuniensis, but genetically different, we can ensure the existence of at least three cryptic species.

6. Texanobathynella is undoubtedly a valid genus distinct from Iberobathynella.

7. Montanabathynella and Parabathynella are two well-differentiated genera closely related to the tribe Iberobathynellini.

Future taxonomic studies of groundwater animals should be integrative and take advantage of the variety of new techniques for species delimitation. 
Testing biogeographical hypotheses using morphological analyses only is a challenge on Bathynellacea due to the extreme morphological simplification. The lack of useful characters to distinguish species and genera might be due to niche conservatism, recent divergence or morphological convergence (Trontelj et al., 2012; Meleg et al., 2013). In addition, the isolation of different populations in disconnected habitats can lead to high genetic divergences (Finston et al., 2007).

\section{Acknowledgements}

We gratefully acknowledge C. Puch for help with various aspects of the paper. Thanks to A. Brancelj, D. Jaume, B.T. Hutchins and B.F. Schwartz for providing specimens of various species, and to J.A. Noriega who helped in the Infierno cave sampling. We thank Melinda Modrell who helped us with the English translations, and the anonymous reviewers who provided valuable comments. This work was supported by project PID2O19-110243GB-10O by the MICINN/FEDER. PMP is supported by MICIN-FEDER through contract BES2016-077777. EKLE is supported by a doctoral scholarship from CONACyT-Mexico (330519/472100).

\section{Supplementary material}

Supplementary material is available online at: https://doi.org/10.6o84/mg.figshare.16974721

\section{References}

Abrams, K.M., Guzik,M.T., Cooper,S.J.B., Humphreys, W.F., King, R.A., Cho, J.-L. \& Austin, A.D. (2012) What lies beneath: Molecular phylogenetics and ancestral state reconstruction of the ancient subterranean Australian Parabathynellidae (Syncarida, Crustacea). Mol. Phylogenet. Evol., 64,130-164. doi:10.1016/j.ympev.2012.03.o10.

Adamowicz, S.J., Menu-Marque, S., Hebert, P.D.N. \& Purvis, A. (2007) Molecular systematics and patterns of morphological evolution in the Centropagidae (Copepoda: Calanoida) of Argentina. Biol. J. Linn. Soc., 9o, 279-292. doi. org/10.1111/j.1095-8312.2007.00723.X.

Alda, F., Rey, I. \& Doadrio, I. (2007) An improved method of extracting degraded DNA samples from birds and other species. Ardeola, 54, 331-334. Alfaro, M.E., Zoller, S. \& Lutzoni, F. (2003) Bayes or bootstrap? A simulation study comparing the performance of Bayesian Markov chain Monte Carlo sampling a bootstrapping in assessing phylogenetic confidence. Mol. Biol. Evol., 20, 255-266.

Amato, A., Kooistra, W.H., Ghiron, J.H.L., Mann, D.G., Pröschold, T. \& Montresor, M. (2007) Reproductive isolation among sympatric cryptic species in marine diatoms. Protist, 158, 193-207.

Andeweg, B. (2002) Cenozoic Tectonic Evolution of the Iberian Peninsula: effects and causes of changing stress fields. Published PhD thesis, Vrije Universiteit Amsterdam, the Netherlands, $178 \mathrm{pp}$.

Ayres, D.L., Darling A., Zwicki, D.J., Beeril, P. Holder, M.T., Lewis, P.O., Huelsenbeck, J.P., Ronquist, F., Swofford, D.L., Cummings, M.P., Rambaut, A. \& Suchard, M.A. (2012) BEAGLE: An application programming interface and high-performance computing Library for statistical Phylogenetics. Syst. Biol., 61, 170-173. https://doi.org/10.1093/ sysbio/syrioo.

Bandari, E., Shaik, S. \& Ranga Reddy, Y. (2017) A phylogenetic review of the genus Atopobathynella Schminke, 1973 (Crustacea, Malacostraca, Bathynellacea) with three new species from southeastern India. J. Nat. Hist. 51, 2143-2184. doi. org/10.1080/00222933.2017.1360528.

Barroso, R., Klautau, M., Solé-Cava, A.M. \& Paiva, P.C. (2010) Eurythoe complanata (Polychaeta: 
Amphinomidae), the 'cosmopolitan' fireworm, consists of at least three cryptic species. Mar. Biol. 157, 69-8o.

Bauzà-Ribot, M., Juan, C., Nardi, F., Oromi, P., Pons, J, \& Jaume, D. (2012). Mitogenomic Phylogenetic Analysis Supports Continental-Scale Vicariance in Subterranean Thalassoid Crustaceans. Curr. Biol. 22(21), 2069-2074. doi.org/10.1016/ jcub.2012.09.012.

Beheregaray, L.B. \& Caccone, A. (2007) Cryptic biodiversity in a changing world.J. Biol., 6, 9 .

Braga, J.M. (1949) Un Bathynellidae (Crust. Syncarida) du Portugal (Parabathynella lusitanica sp. n. Publ. Inst. Zool. "Dr. A. Nobre", 40, 1-15.

Braga, J.M. (1960) Sur une Parabathynella (Crust. Syncarida) nouvelle du Portugal. Publ. Inst. Zool. "Dr. A. Nobre", 75, 9-22.

Boutin, C. \& Coineau, N. (1987) Iberobathynella sur le continent africain. Implications paléogéographiques. C. R. Acad. Sci. Paris, 304, Série III, 13, 355-358.

Camacho, A.I. (1987) A new subterranean Syncarid (Crustacea) from Spain: Iberobathynella imuniensis n. sp. (Bathynellacea, Parabathynellidae). Arch. Hydrobiol. 111, 137-149.\#8232;

Camacho,A.I.(1988)Historia, clavededeterminación y distribución de género Iberobathynella (Crustacea, Syncarida, Parabathynellidae) en la Península Ibérica. Congreso Ibérico de Entomología, Actas, 3, 43-56.

Camacho, A.I. (2003) Four new species of groundwater crustaceans (Syncarida, Bathynellacea, Parabathynellidae) endemic to the Iberian Peninsula. J. Nat. Hist., 37, 2885-2907.

Camacho, A.I. (2003a) An overview of the distribution of the Parabathynellidae (Crustacea Syncarida Bathynellacea) on the Iberian Peninsula and Balearic Islands. Graellsia, 59, 63-78.

Camacho, A.I. (2003b) Four new species of groundwater crustaceans (Syncarida, Bathynellacea, Parabathynellidae) endemic to the Iberian Peninsula.J. Nat. Hist., 37, 2885-29o7.
Camacho, A.I. (2005) One more piece in the genus puzzle: a new species of Iberobathynella Schminke, 1973 (Syncarida, Bathynellacea, Parabathynellidae) from the Iberian Peninsula. Graellsia, 61, 123-133.

Camacho, A.I. (2007) A new species of Iberobathynella Schminke, 1973 (Syncarida, Bathynellacea, Parabathynellidae) in the South of the Iberian Peninsula. Graellsia, 63(2), 339-347.

Camacho, A.I. (2019) Diversity, morphological homogeneity and genetic divergence in a taxonomically complex group of groundwater crustaceans: the little known Bathynellacea (Malacostraca). Bull. Soc. d'Hist. Nat. Toulouse, 154, 105-16o.

Camacho, A.I. \& Coineau, N. (1989) Les Bathynellacea d'Espagne: Répartition et Biogéographie. Mém. Biospéléol., 16, 111-124.

Camacho, A.I. \& Puch, C. (2021). Ojo Guareña: a hotspot of subterranean Biodiversity in Spain. Diversity, 13, 199. doi.org/10.339o/d13050199.

Camacho, A.I. \& Serban, E. (1998) Tribu des Iberobathynellini nov., diagnoses des taxa nouveaux (Parabathynellidae, Bathynellacea, Podophallocarida). Trav. Inst. Spéléol. «É. Racovitza», 34, 15-75.

Camacho, A.I. \& Serban, E. (2000) Revisión del grupo Iberobathynella (Iberobathynella) Camacho \& Serban, 1998 (Crustacea, Syncarida, Parabathynellidae) endémico de la Península Ibérica. Graellsia, 56, 35-48.

Camacho, A.I., Bello, E. \& Estabrook, G.F. (1997) A statistical approach to the evaluation of characters to estimate evolutionary relationships among the species of the aquatic subterranean genus Iberobathynella (Crustacea, Syncarida). Biol. J. Linn. Soc., 6o, 221-241.

Camacho, A.I.,Serban, E. \& Guil, N. (2000) Phylogenetical review and biogeographic remarks on the interstitial and subterranean freshwater iberobathynells (Crustacea, Syncarida, Parabathynellidae). J. Nat. Hist., 34, $563^{-585}$. 
Camacho, A.I., Torres, T., Ortiz, E., Puch, C. \& Valdecasas, A.G. (2006) Small-scale biogeographical pattern in groundwater Crustacea (Syncarida, Parabathynellidae). Biodivers. Conserv., 15, 3527-3541. doi: 10.1007/ s10531-004-1872-8.

Camacho, A.I., Dorda, B.A. \& Rey, I. (2011) Identifying cryptic speciation across groudwater populations: first cor sequences of Bathynellidae (Crustacea, Syncarida). Graellsia, 67, 7-12.

Camacho, A.I., Dorda, B.A. \& Rey, I. (2012) Undisclosed taxonomic diversity of Bathynellacea (Malacostraca: Syncarida) in the Iberian Peninsula revealed by molecular data. J. Crust. Biol. 32, 816-826. doi: 10.1163/193724012X638473.

Camacho, A.I., Dorda, B.A. \& Rey, I. (2014) Iberian Peninsula and Balearic Island Bathynellacea (Crustacea, Syncarida) database. Zookeys, 386, 1-20.

Camacho, A.I., Stanford, J.A. \& Newell, R.L. (2009) The first record of Syncarida in Montana, USA: a new genus and species of Parabathynellidae (Crustacea, Bathynellacea) in North America. J. Nat. Hist. 43(5-6), 309-321.

Camacho, A.I., Sánchez-Chillón, B., Dorda, B.A. \& Rey, I. (2017) The collection of Bathynellacea specimens of MNCN (CSIC) Madrid: microscope slides and DNA extract. ZooKeys, 678, 31-36. doi: 10.3897/zookeys.678.11543.

Camacho, A.I., Hutchins, B., Schwartz, B.F., Dorda, B.A., Casado, A. \& Rey, I. (2018a). Description of a new genus and species of Bathynellidae (Crustacea: Bathynellacea) from Texas based on morphology and molecular characters. J. Nat. Hist., 52(1-2), 29-51. doi.org/10.1080/oo222933. 2017.140168o.

Camacho, A.I., Mas-Peinado, P., Watiroyram, S., Brancelj, A., Bandari, E., Dorda, B.A., Casado, A. \& Rey, I. (2018b) Molecular phylogeny of Parabathynellidae (Crustacea, Bathynellacea), and three new species from Thai caves. Contrib. Zool., 87, 227-26o.
Camacho A.I., Mas-Peinado, P., Dorda, B.A., Casado, A., Brancelj, A., Knight, L.R.F.D, Hutchins, B., Bou, C., Perina, G. \& Rey, I. (2018c) Molecular tools unveil an underestimated diversity in a stygofauna family: a preliminary world phylogeny and an updated morphology of Bathynellidae (Crustacea, Bathynellacea). Zool.J. Linn. Soc., 183, 70-96.

Camacho A.I., Mas-Peinado, P., Ranga Reddy, Y., Bandari, E., Shaik, S., Perina, G., Dorda, B.A., Casado, A. \& Rey, I. (2021a) An integrated approach to re-evaluate the validity of the family Leptobathynellidae (Crustacea: Bathynellacea). Zool. J. Linn. Soc., 20. 1-43.

Camacho A.I., Mas-Peinado, P., Hutchins, B.T., Schwartz, B.F., Dorda, B.A., Casado, A. \& Rey, I. (2021b). New stygofauna from Texas, USA: three new species of Parabathynellidae (Crustacea, Bathynellacea). J. Nat. Hist., 55(1516), 979-1007. doi.org/10.1080/00222933.2021.1 928316.

Carminati, E., Lustrino, M., \& Doglioni, C. (2012) Geodynamic evolution of the central and western Mediterranean: Tectonics vs. igneous petrology constraints. Tectonophysics, 579, 173-192.

Chappuis, P.A. (1926) Parabathynella stygia n.g. n.sp. nouveau crustacé cavernicole de la Serbie Orientale. Bull. Soc. St. Cluj, II, 7-10.

Cho, J.L. (1996) A new species of the genus Texanobathynella from California (Crustacea, Malacostraca, Bathynellacea). Korean J. Syst. Zool., 12(4), 389-395.

Coineau,N.(1996)Sous-Classe des Eumalacostracés (Eumalacostraca Grobben, 1892). Super-Ordre des Syncarides (Syncarida Packard, 1885). In: J. Forest (Ed.), Traité de Zoologie, Crustacés, 7, 897-954.

Coineau, N. \& Camacho, A.I. (2013) Superorder Syncarida Packard, 1885. Chapter 50, 357-449. In: J.C. von Vaupel Klein, M. CharmantierDaures and F.R. Schram, (Eds), (Founded by P.-P.- Grassé). Treatise on Zoology-Anatomy, Taxonomy, Biology. The Crustacea. Traité de 
Zoologie, Koninklijke Brill NV ISBN 97890 o4 17809 o. Leiden.

Copilas-Ciocianu, D., Sidorov, D. \& Gontcharov, A. (2019) Adrift across tectonic plates: molecular phylogenetics supports the ancient Laurasian origin of old limnic crangonyctid amphipods. Org. Divers. Evol. 19, 191-207. doi.org/10.1007/ s13127-019-00401-7.

Dancau, D. \& Serban, E. (1963) Sur une nouvelle Parabathynella de Roumanie, Parabathynella motasi nov. sp. Crustaceana, 5(4), 241-25o.

Delamare Deboutteville, C. \& Angelier, E. (1950) Sur un type de Crustacé phréaticole nouveau: Parabathynella fagei n.sp. C. R. Hebd. Acad. Sci. Paris, 231, 175-176.

Delamare Debouttevile, C., Serban, E. \& Coineau, N. (1975) Découverte de la famille des Parabathynellidae (Bathynellacea) en Amerique du Nord: Texanobathynella bowmani n.g. n. sp. $C$. R. hebd. Acad. Sci., Paris, Sér, D, 280, 2223-2226.

Drummond, A.J., Suchard, M.A., Xie, D. \& Rambaut, A. (2012) Bayesian phylogenetics with BEAUti and the BEAST 1.7. Mol. Biol. Evol., 29, 1969-1973.

Eme, D., Zagmajster, M., Delić, T., Fišer, C., Flot, J.-F., Konecny-Dupré, L., Pálsson, S., Stoch, F., Zakšek, V., Douady, C.J. \& Malard, F. (2018) Do cryptic species matter in macroecology? Sequencing European groundwater crustaceans yields smaller ranges but does not challenge biodiversity determinants. Ecography, 41(2), 424-436. https://doi.org/10.1111/ecog.02683.

Finston, T.L., Johnson, M.S., Humphreys, W.F., Eberhard, S.M. \& Halse, S.A. (2007) Cryptic speciation in two widespread subterranean amphipod genera reflects historical drainage patterns in an ancient landscape. Mol. Ecol., 16, $355^{-3} 365$.

Folmer, O., Black, M., Hoeh, W., Lutz, R. \& Vrijenoek, R. (1994) DNA primers for amplification of mitochondrial cytochrome c oxidase subunit 1 from diverse metazoan invertebrates. Mol. Mar. Biol. Biotech., 3, 294-299.

Galhano, M.H. (1967) Sur une nouvelles Parabathynella psammique du Portugal. Publ. Inst. Zool. "Dr. A. Nobre", 98, 9-18.
Galhano, M.H. (1970) Contribuçao para o conhecimiento de fauna intersticial em Portugal. Parabathynella lusitanica valbonensis ssp. n. Publ. Inst. Zool. "Dr. A. Nobre", 110, 77-82.

Gilbert, M.T.P., Moore, W., Melchior, L. \& Worobey, M. (2007) DNA extraction from dry museum beetles without conferring external morphological damage. PLoS ONE 2, e272.

Giribert, G., Carranza, S., Baguña, J., Riutort, M. \& Ribera, C. (1996) First molecular evidence for the existence of a Tardigrada + Arthropoda clade. Mol. Biol. Evol. 13, 76-84.

Golonka, J. (2007) Late Triassic and Early Jurassic palaeogeography of the world. Palaeogeogr. Plaeoclimatol. Palaeoecol., 244, 297-307.

González-Miguéns, R., Muñoz-Nozal, E., JiménezRuiz, Y., Mas-Peinado, P., Ghanavi. H.R. \& García-París, M. (2020) Speciation patterns in the Forficula auricularia species complex: cryptic and not so cryptic taxa across the western Paleartic region. Zool. J. Linn. Soc., 190(3), 788-823.

Graham, A. (1999) Late Cretaceous and Cenozoic history of North American vegetation. New York: Oxford University Press.

Guil, N. \& Camacho, A.I. (2001) Historical Biogeography of Iberobathynella (Crustacea, Syncarida, Bathynellacea), an aquatic subterranean genus of Parabathynellids, endemic to the Iberian Peninsula. Glob. Ecol. Biogeog., 10, 487-501.

Guzik, M.T., Abrams, K.M., Cooper, S.J.B., Humphreys, W.F., Cho, J.-L. \& Austin, A. (2008) Phylogeography of the ancient Parabathynellidae (Crustacea: Bathynellacea) from the Yilgarn region of Western Australia. Invert. Syst., 22, 205-216.

Heraty, J.M., Woolley, J.B., Hopper, K.R., Hawks, D.L., Kim, J.W. \& Buffington, M. (2007) Molecular phylogenetics and reproductive incompatibility in a complex of cryptic species of aphid parasitoids. Mol. Phylogenet. Evol., 45, 480-493.

Höhna, S., Landis, M.J, Heath, T.A., Boussau, B., Lartillot, N., Moore, B.R., Huelsenbeck, Downloaded from Brill.com04/26/2023 03:32:19PM 
J.P \& Ronquist, F. (2016) RevBayes: Bayesian phylogenetic inference using graphical models and an interactive model-specification language. Syst. Biol., 65, 726-736.

Hong, S.J. \& Cho, J.-L. (2009) Three new species of Billibathynella from Wertern Australia (Crustacea, Syncarida, Parabathynellidae.J. Nat. Hist., 43, 2365-239o.

Huelsenbeck, J.P., Larget, B. \& Alfaro, M.E. (2004) Bayesian Phylogenetic Model Selection Using Reversible Jump Markov Chain Monte Carlo. Mol. Biol. Evol., 21, 1123-1133. Doi.org/10.1093/ molbev/mshı23.

Jablonski, D., Roy, K. \& Valentine, J.W. (2006) Out of the tropics: evolutionary dynamics of the latitudinal diversity gradient. Science, 314, 102-106.

Jones, R., Culver, D.C. \& Kane, T.C. (1992) Are parallel morphologies of cave organisms the result of similar selection pressures?. Evolution, $46,353-365$.

Kalyaanamoorthy, S., Minh, B.Q., Wong, T.K.F., Haeseler, A. von \& Jermiin, L.S. (2017) ModelFinder: fast model selection for accurate phylogenetic estimates. Nat. Methods, 14, $587-589$

Kane, T.C., Culver, D.C. \& Mathieu, J. (1994) Biotic fluxes and gene flow, pp. 245-259. In, J. Gibert, D.L. Danielopol, \& J. Stanford (eds.), Groundwater Ecology. Academic Press, New York.

Katoh, K. \& Toh, H. (2008) Recent developments in the MAFFT multiple sequence alignment program. Briefings Bioinf., 9, 286-298.

Kearse, M., Moir, R. Wilson, A. Stones-Haves, S., Cheung, M., Sturrock, S., Buxton, S, Cooper, A., Markowitz, S., Duran, C., Thierer, T., Ashton, B., Meintjes, P. \& Drummond, A. (2012) Ganeious Basic: an integrated and extendable desktop software platform for the organization and analysis of sequence data. Bioinformatics, 28, 1647-1649. doi.org/10.1093/bioinformatics/ bts199.

Kendall, D.G. (1948) On the generalized" birth-anddeath" process. Ann. Math. Stat. 19.1, 1-15.
Knowlton, N. (1993) Sibling species in the sea. Ann. Rev. Ecol. Syst., 24, 189-216.

Krisjgman, W., Capella, W., Simon, D., Hilgen, F.J., Kowenhoven, T.J., Meijer, P.T., Sierro, F.J.,Tulbure, M.A., van der Berg, B.C.J., van der Schee, M. \& Flecher, R., (2018) The Gribaltar Corridor: Watergate of the Messinian Salinity Crisis. Mar. Geol., 403, 238-246.

Le Gac, M., Hood, M.E., Fournier, E. \& Giraud, T. (2007) Phylogenetic evidence of host-specific cryptic species in the anther smut fungus. Evolution, 61, 15-26.

Lefebure, T., Douady, C.J., Malard, F. \& Gibert, J. (2007) Testing vicariance and cryptic diversity in a widely distributed groundwater amphipod (Niphargus rhenorhodanensis). Mol. Phylog. Evol., 42, 676-686.

Leigh, J.W. \& Bryant, D. (2015) POPART: fullfeature software for haplotype network construction. Methods Ecol. Evol., 6, 1110-1116. doi.org/10.1111/2041-210X.12410.

Lewis, P.O. (2001) A likelihood approach to estimating phylogeny from discrete morphological character data. Syst. Biol., 50, 913-925.

Little, J., \& Camacho, A. I. (2017) Morphological and molecular characterisation of a new genus and new species of Parabathynellidae (Crustacea: Syncarida) in Queensland, Australia. Invert. Syst., 31, 208-219.

Maddison, W.P. \& Maddison, D.R. (2015) Mesquite: a modular system for evolutionary analysis. Version 3.04 http://mesquiteproject.org.

Meleg, I.N., Zaksek, V., Cene Fiser, C., Kelemen, B.C. \& Moldovan, O.T. (2013) Can environment predict cryptic diversity? The case of Niphargus inhabiting Western Carpathian groundwater. PlosOne, 8, e7676o. doi: 10.1371/journal.pone. oо7676o.

Miller, M.A., Pfeiffer, W. \& Schwartz, T. (2010) Creating the cipres Science Gateway for inference of large phylogenetic trees. In 2010 gateway computing environments workshop $(G C E)$. (p. 1-8). Ieee, 2010.

Minh, B.Q., Scmidt, H.A., Chernomor, O., Schrempf, D., Woodhams, M.D., Haeseler, A. von \& Lanfear, Downloaded from Brill.com04/26/2023 03:32:19PM 
R. (2O2O) IQ-TREE 2: new models and efficient methods for phylogenetic inference in the genomic era. Mol. Biol. Evol., 37, 1530-1534. doi. org $/ 10.1093 / \mathrm{molbev} / \mathrm{msaao15}$.

Noodt, W. \& Galhano, M.H. (1969) Studien an Crustacea Subterranea (Isopoda, Syncarida, Copepoda) aus dem Norden Portugals. Publ. Inst. Zool. "Dr. A. Nobre", 107, 9-75.

Papadopoulou, A., Anastasiou, I. \& Vogler, A.P. (2010) Revisiting the insect mitochondrial molecular clock: the mid-Aegean trench calibration. Mol. Biol. Evol. 27, 1659-1672.

Perina, G., \& Camacho, A.I. (2016) Permanent slides for morphological studies of small crustaceans: Serban's method and its variation applied on Bathynellacea (Malacostraca). Crustaceana, 89, 1161-1173.

Perina, G., Camacho, A.I., Huey, J., Horwitz, P., \& Koenders, A. (2019) The role of allopatric speciation and ancient origins of Bathynellidae (Crustacea) in the Pilbara (Western Australia): two new genera from the De Grey River catchment. Contrib. Zool., 88(4), 452-497.

Pfenninger, M. \& Schwenk, K. (2007) Cryptic animal species are homogeneously distributed among taxa and biogeographical regions. BMC Evol. Biol., 7, 121.

Pons, P., Jurado-Rivera, J.A., Jaume, D., Vonk, R. \& Bauzà-Ribot, M.M. (2019) The age and diversification of metacrangonyctid subterranean amphipod crustaceans revisited. Mol. Phylogenet. Evol. 140, 106599.

Pretus, JL. (1989) Noves dades per a la distribució de l'estigofauna balear. Endins, 14-15, 61-64.

Ronquist, F., Teslenko, M, Van der Mark, P., Ayres, D.L., Darling, A., Höhna, S., Larget, B., Liu, L. \& Huelsenbeck, J.P. (2012) MrBayes 3.2: efficient Bayesian phylogenetic inference and model choice across a large model space. Syst. Biol., 61, 539-542.

Rosenbaum, G., Lister, G.S. \& Duboz, C. (2002) Reconstruction of the tectonic evolution of the western Mediterranean since the Oligocene. Journal of the Virtual Explorer, 8, 107-130.
Schminke, H.K. (1973) Evolution, System und Verbreitungsgeschichte der Familie Parabathynellidae (Bathynellacea, Malacostraca). Akademie der Wissenschaften und der Literatur Mainz, Mathematisch-Naturwissenschaftliche Klasse, Mikrofauna des Meeresbodens 24, 1-192.

Schminke, H.K. (1974) Mesozoic intercontinental relationship as evidenced by Bathynellid Crustacea (Syncarida: Malacostraca). Syst. Zool., $23,157-164$.

Schminke, H.K. (1981) Adaptation of Bathynellacea (Crustacea, Syncarida) to life in the Interstitial ("Zoea Theory"). Internat. Rev. Hydrobiol. Hydrog., 66, 575-637.

Schminke, H.K. (2011) Arthropoda: Crustacea: Malacostraca: Bathynellacea: Parabathynellidae. V 21(1), pp 244. In: Flora and Fauna de Korea. Invertebrate Fauna of the World. National Institute of Biological Resources, Ministry of Environment, Republic of Korea.

Schminke, H.K. \& Noodt, W. (1988) Groundwater Crustacea of the Order Bathynellacea (Malacostraca) from North Amerika. J. Crust. Biol., 8, 290-299.

Schram, F.R. (1977) Paleozoogeography of late Paleozoic and Triassic Malacostraca. Syst. Zool., 26, 367-379.

Schram, F.R. (1984) Fossil Syncarida. Transact. San Diego Soc. Nat. Hist., 20, 189-246.

Serban, E. (1977) Sur les péréiopodes viı males de Iberobathynella cf. fagei de Majorque (Bathynellacea, Parabathynellidae). Crustaceana, 33(1), 1-16.

Serban, E. \& Comas, J. (1978) Contribution à la connaissance du genre Iberobathynella Schminke: I. asturiensis n. sp. et I. espaniensis n. sp., nouvelles espèces d'Espagne (Bathynellacea, Parabathynellidae). Trav. Inst. Spéol. "É. Racovitza", 17, 13-37.

Serban, E. (1977) Sur les péréiopodes VIII males de Iberobathynella cf. fagei de Majorque (Bathynellacea, Parabathynellidae). Crustaceana, 33(1), 1-16. 
Simon, C.L., Frati, F., Beckenbach, A., Crespi, B., Liu, H. \& Flook, P. (1994) Evolution, weighting, and phylogenetic utility of mitochondrial gene sequences and a compilation of conserved PCR primers. Ann. Entomol. Soc. America, 87, 51-701.

Smith, S.A. \& Donoghue, M.J. (2010) Combining historical biogeography with niche modelling in the Caprifolium clade of Lonicera (Caprifoliaceae, Dipsacales). Syst. Biol., 59, 322-341.

Stadler, T. (2009) On incomplete sampling under birth-death models and connections to the sampling-based coalescent. J. Theoret. Biol., 261, $58-66$.

Swofford, D.L. (2002) PAUP*: Phylogeny Analysis Using Parsimony ( *and other methods), version 4.obio. Sunderland, MA: Sinauer Associates Inc. Thompson, J.D. (2005) Plant evolution in the Mediterranean. Oxford University Press.
Trontelj, P., Blejec, A. \& Fiser, C. (2012) Ecomorphological convergence of cave communities. Evolution, 66, 3852-3865.

Yilmaz, P.O., Norton, I.O., Leary, D. \& Chuchla, R.J. (1996) Tectonic evolution and paleogeography of Europe. In P. A. Zieglers, \& F. Howath (Eds), Peri-Tethys Memoirs 2: Structure and Prospects of Alpine Bassins and Forelands (pp. 47-6o). Paris, Mém. Mus. Nat. Hist. Nat.

Zagmajster, M., Malard, F., Eme, D. \& Culver, D.C. (2018) Subterranean Biodiversity Patterns from Global to Regional Scales. Chapter, 9, 195-227. Moldovan et al., (eds). In "Cave Ecology", Ecological Studies 235. https://doi. org/10.1007/978-3-319-98852-8_9.

RECEIVED: 16 JULY 2021 | 2 NOVEMBER 2021 | ACCEPTED: 4 NOVEMBER 2021

EDITOR: R. VONK 